\title{
SOME NOVEL PLUTONIUM FUELING METHODS FOR THERMAL. REACTORS
}

DEVELOPMENT

REPORT
NOVEMBER, 1965

FUEL CYCLE ANALYSIS STAFF MEMBERS

OF PHYSICS AND INSTRUMENT DEPARTMENT 


\section{LEGAL NOTICE}

This report was prepared as an account of Government sponsored work. Neither the. Unifed States, nor the Commission, nor any person acting on behalf of the Commission:

A. Makes any warranty or representation, expressed or implied, with respect to the accuracy, com. pleteness, or usefulness of the information contained in this report, or that the use of any informotion, apparatus, method, or process disclosed in this report may not infringe ptivately owned rights; or

B. Assumes any liabilities with respect to the use of, or for damages resulting from the use of any information, apparatus, method, or process disclosed in this report.

As used in the above, "person acting on behalf of the Commission" includes ony employee or contractor of the Commission, or amployes of such contractor. to the extent that such employee or controctor of the Commission, or employee of such contractor prepares, disseminates, or provides access to, any information pursuant to his employment or contract with the Commission, or his employment with such contractor.

\section{PACIFIC NORTHWEST LABORATORY \\ RICHLAND, WASHINGTON \\ operated by}

BATTELLE MEMORIAL INSTITUTE

for the

UNITED STATES ATOMIC ENERGY COMMISSION UNDER CONTRACT AT(45-1)-1830 


\section{5}

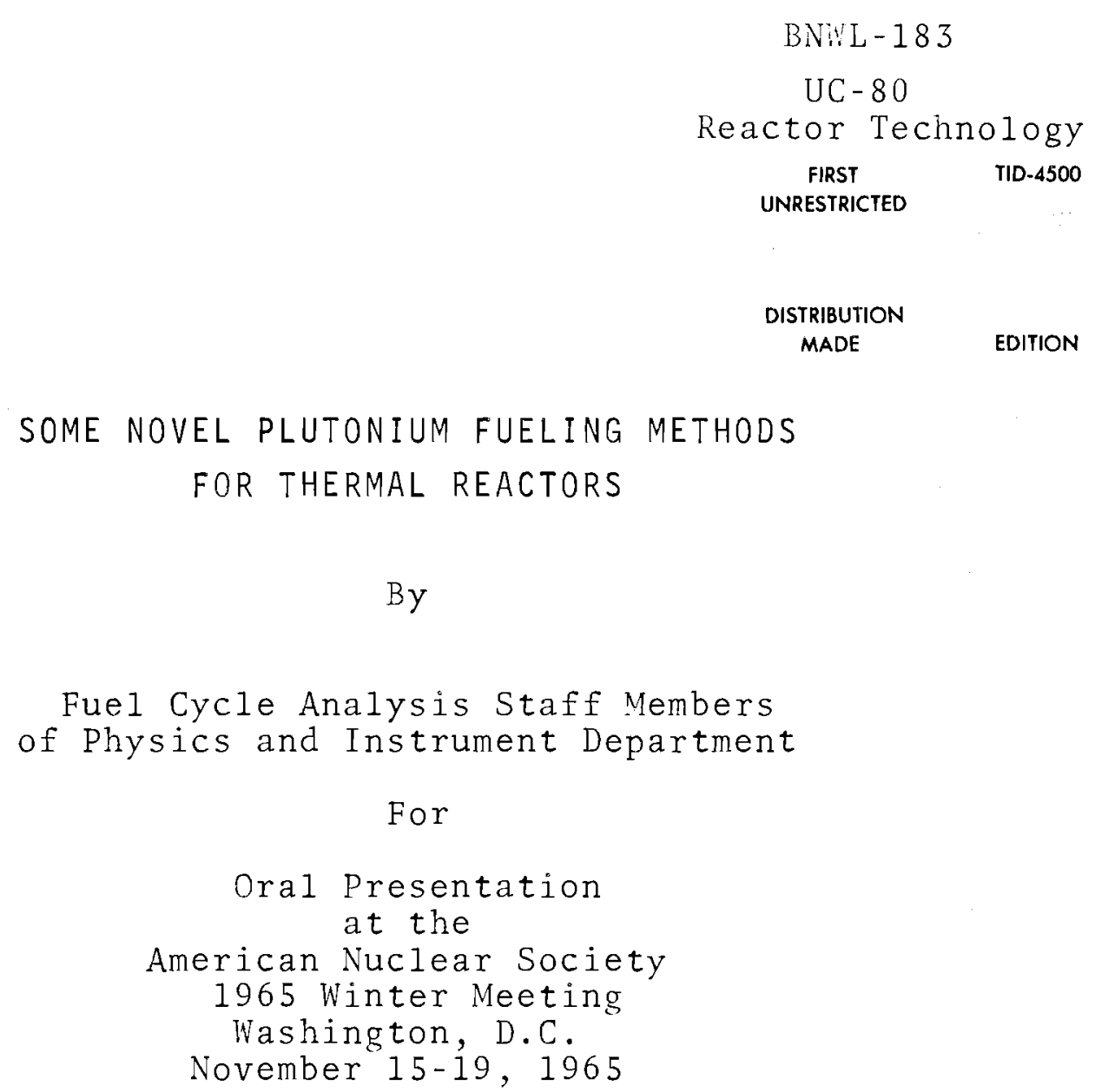

November, 1965

PACIFIC NORTHWEST LABORATORY

RICHLAND, WASHINGTON 
Printed in USA. Price \$4.00. Available from the Clearinghouse for Federal Scientific and Technical Information, National Bureau of Standards

U.S. Department of Commerce, Springfield, Virginia 


\section{TABLE OF CONTENTS}

\begin{tabular}{|c|c|c|c|}
\hline INTRODU & TION & . & \\
\hline SECT ION & I . & $\begin{array}{l}\text { MONTE CARLO CALCULATIONS OF OPT IMUM LOAI } \\
\text { OF PLUTONIUM IN THERMAL REACTOR FUELS }\end{array}$ & I - 1 \\
\hline SECTION & II. & $\begin{array}{l}\text { A NEW FUEL CONFIGURATION TO INCREASE } \\
\text { PLUTONIUM VALUE . } . . \\
.\end{array}$ & I I - 1 \\
\hline SECT ION & I I . & 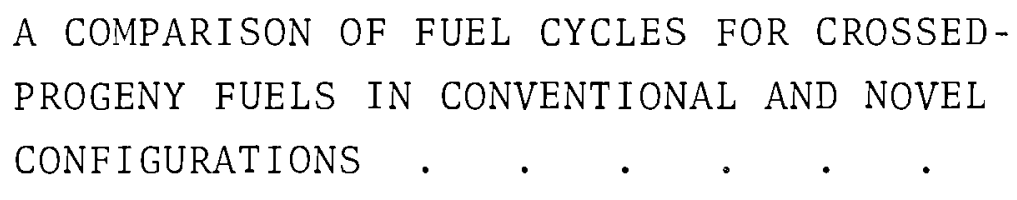 & I I I - 1 \\
\hline SECTION & IV. & $\begin{array}{l}\text { THE CALIBRATION OF A HIGH SPEED BURNUP } \\
\text { CODE FOR NUCLEAR FUEL SURVEYS }\end{array}$ & IV -1 \\
\hline SECT ION & V. & 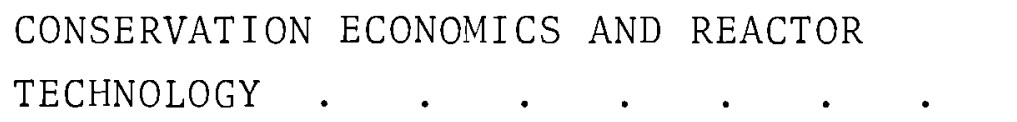 & $V-1$ \\
\hline
\end{tabular}





\title{
INTRODUCTION
}

\author{
E. A. Eschbach*
}

The following five papers, which were presented orally at the winter Meeting of the American Nuclear Society in washington D.C. during the week of November 19, 1965, are concerned with thermal reactor fueling systems that may lead to a basic improvement in the utilization of plutonium.

The novel fueling systems to be described in these papers were first out lined during the period 1956-1960,just after the Plutonium Recycle Program began at Hanford. However, analys is and demonstration of these potentially better fueling systems awaited the demonstration of a more straightforward system--namely, uniform enrichment of $\mathrm{UO}_{2}$ with $\mathrm{PuO}_{2} \cdot{ }^{* *}$ Preliminary work carried on in behalf of these novel plutonium enrichment schemes was reported from time to time in the plutonium Pecycle Quarterly Reports. In September 1962, these fueling systems were reviewed in a Hanford presentation at the Plutonium Topical Meeting held in Richland, Washington. Although the following five papers represent considerable work during the past year, they do not claim to be exhaustive.

*Manager, Fuel Cycle Analysis Section **one of the better summaries describing uniform $\mathrm{PuO}_{2}$ enrichment of $\mathrm{UO}_{2}$ can be found in $\mathrm{HW}-82400$, entitled "Proceedings - Commercial Fabrication of Plutonium Fuels - Hanford Laboratories, Invitational Meeting, Richland, Washington, April 2-3,1965."
Like so many papers, they answer some questions, but raise many more. Some aspects of plutonium and uranium fueling have not even been touched upon. For example, no mention is made either of ternary fuels $\left(\mathrm{Pu}^{240}, \mathrm{U}^{238}\right.$, and $\mathrm{Th}^{232}$ used as fertile material in the same fuel element) or of Phoenix fuels. Moreover, the reactor burnups have purposely been limited to the zero dimension. While greater dimensionality would complicate analysis, it would also clarify the versatility of the novel plutonium fueling schemes taken singly or in combination. Nor do any of the papers assess the worth (to reactor control) of the relatively flat reactivity characteristics possible with these fuel configurations.

The first paper deals with Monte Carlo calculations of plutonium performance characteristics when plutonium is ( 1 ) distributed throughout the fue 1 as described in $\mathrm{HW}-82400$, (2) distributed on the surface of the fuel, (3) placed in the center of the fuel, and (4) diffused outward after being placed in the center of the fuel. Systems with fuel configurations (1) and (2), which maximize the plutonium reaction rates, are important if inventory costs are high or the reactor contains parasitic absorbers. Systems with fuel configurations (3) and (4), which reduce reaction rates and the alpha $\left(\frac{{ }^{\sigma} c}{\sigma_{f}}\right)$ ratios, are important both 
because they allow matching of the plutonium reaction rate to those of $U^{235}$ and $U^{233}$ and because they allow an increase in eta (neutron yield). However these two advantages must be balanced against the increased inventory charges associated with the reduced reaction rates.

The second paper deals with measuring the relative value of plutonium recycled in $U^{238}$ fuel configurations (1), (2), (3), and (4) evaluated in the first paper. Since several factors are involved--cross sections, neutron yields, and inventory charges-the paper necessarily deals in part with describing an equitable measurement of monetary value. (The utilization of uranium as a natural resource is discussed in the fifth paper.) The second paper concludes that, as a straight substitute for uniformly enriched uranium, plutonium fuel configurations (1), (2), (3), and (4) have values that are very sensitive to inventory charges. With high interest rates applied, plutonium placed on the surface of the fuel seems to be the most economical configuration, despite the fact that plutonium placed in the center of the fuel rod has a better eta. However, further Monte Carlo computations may show that lower concentrations of plutonium may be used in the center of the fuel rod without increasing alpha and without preventing a substantial increase in the effective cross section. Even if such improvements are not possible in centrally located plutonium, its flatter reactivity characteristics and its matching of the plutonium reaction rate with those of $U^{233}$ and $U^{235}$ may override the importance of inventory cost. In addition, centrally located plutonium makes possible the burning of $\mathrm{Pu}^{242}$ in thermal reactors. In the past, for purposes of estimating the minimum value of plutonium in thermal reactors, $\mathrm{Pu}^{242}$ was regarded as a parasite leading to higher isotopes $\left(\mathrm{Cm}^{244}\right.$, for example) which were of no economic value. Moreover, $\mathrm{Pu}^{242}$, which fissions in a fast spectrum--especially in a hard fast spectrum--could contribute as a moderately valuable fuel in fast reactors. However, computations described in the first paper indicate that the center of a thermal reactor fuel element can also have a spectrum fast enough for the $\mathrm{Pu}^{242}$ contained therein to have a low alpha of 5. Although this does not represent an eta* of 1.0 , the resulting reduction in neutron losses and the contribution of heat would substantially improve the value of plutonium in thermal reactors. Even with an alpha of $5, \mathrm{Pu}^{242}$ would substantially contribute to a high isotope production, which is proportional to $1-\frac{1}{1+\alpha}$, or $\frac{\alpha}{1+\alpha}$.

The third paper considers a broader application of plutonium fuel configurations (1), (2), (3), and (4). It addresses itself to the crossed-progeny concept--namely, the use of $\mathrm{U}^{233}$ as an enrichment for $u^{238}$ fuel whose plutonium output is used as an enrichment for thorium fuel that

$$
\text { *eta }=\frac{v}{1+a} \text {. }
$$


produces $\mathrm{U}^{233}$. With plutonium in the center of the thorium fuel and with $\mathrm{U}^{233}-\mathrm{U}^{238}$ in a high-fast-effect 1 at tice, this two-reactor type system is a near breeder than can be sustained by natural uranium.

The second and third papers indicate that the appropriate use of the new fue 1 configurations and fueling sequences requires, because of inventory costs, an adjustment in performance characteristics. Thus the burnup and economic codes used for this work must be reasonably accurate, and must use a minimum of computer time; otherwise the many operating points to be sifted cannot be examined within a reasonable interval of calendar time. The fourth paper describes the calibration of the computer code used in the burnup analyses presented in the second and third papers. The fourth paper shows that cross shielding of the epithermal resonances of $\mathrm{Pu}^{239}$, $\mathrm{Pu}^{241}, \mathrm{Am}^{241}$, and $\mathrm{Np}^{237}$ was necessary in addition both to the shadow shielding from $\mathrm{Pu}^{240}$ and to the flux depression from $\mathrm{U}^{238}, \mathrm{U}^{234}$, and $\mathrm{Th}^{232}$ resonance absorption. The source data for calibration of the burnup code were obtained from analyses of spent Yankee and VBWR fuel rods having exposures up to $31,000 \mathrm{MWd} / \mathrm{T}$. Satisfactory checks were obtained for all isotopes measured. These included $\mathrm{Cm}^{244}$, which is produced by 5 sequential neutron absorptions after the initial absorption in $\mathrm{U}^{238}$. Only the zero-dimensional mode of the burnup code was used in the fuel configuration comparisons. The next step in evaluating these fuels will necessarily use the one-dimensional mode of the burnup code.

Since there is much concern today about uranium utilization, it is worthwhile to see if the economic decisions assumed in the second and third pances are inconsistent with uranium utilization. The fifth paper concludes that they are not. Considering economic factors as well as uranium utilization, the fifth paper indicates that our known uranium resources will be sufficient if a fast-breeder development and demonstration plan can produce good performance breeders by 1990. This remains true even if additional lower priced resources are not discovered and if no ore upgrading processes are developed. 


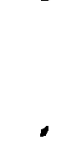




\title{
SECTION I
}

MONTE CARLO CALCULATIONS OF OPTIMUM LOADING OF PLUTONIUM

IN THERMAL REACTOR FUELS

\author{
E. T. Merrill
}

Battelle Memorial Institute

Pacific Northwest Laboratory

Richland, Washington

November, 1965

Paper for oral presentation at the American Nuclear Society 1965 Winter Meeting

Washington, D.C. November 15-19, 1965 


\section{MONTE CARLO CALCULATION OF OPTIMUM LOADING OF PLUTONIUM IN FUELS*}

\section{E. T. Merri11**}

A we11-known complication in computing plutonium fuel performance in thermal reactors hangs on the fact that as the plutonium isotope concentrations change so do the relevant cross sections. This makes it particularly difficult to compute the number of neutrons reproduced by $\mathrm{pu}^{239}$ in thermal reactors. For example, if the estimates of reduced neutron yield from $\mathrm{pu}^{239}$ in certain therma 1 reactors are derived from a table of basic physics data prepared for the infinitely dilute case, significant errors can creep in due to the overemphasis on the low-lying pu 239 resonances. In physical fact, however, as additional amounts of plutonium are added to the fuel, the resonances "self-shield" and plutonium neutron yields are greater, although the gain is sometimes offset due to spectral hardening caused by the high plutonium cross sections in the thermal regions.

The present paper discusses how the theoretical benefits of self-

\footnotetext{
* This paper is based on work performed under united States Atomic Eneray Commission Contract $A T(45-1)-1830$. Permission to phblish is gratefully acknowledaed.

* Senior Research Engineer, Physics and Instruments Department, Pacific Northuest Laboratory, operated b: Battelle Memorial Institute for the Uniter States atomic Energy Commission, Fichland, washington.
}

shielding can be maximized by placing plutonium in the center of the fuel rods. The theoretical benefits, however, may be compromised by the increased inventory costs associated with the resultant thermal flux depression, by increased fabrication costs, or by poorer heat transfer characteristics. The calculations to be described were designed to cover a wide range of loading so as to identify the point of diminishing returns. The results indicate a surprisingly broad range of productive loadings. The economic and uranium conservation gains implied in this paper, as well as the complicated computations involved, suggest the desirability of some good critical experiments on the fuel rod geometries to be described.

The RBU Monte Car10 code ${ }^{(1)}$ has been used to estimate the interrelationship of fissile content, fissile placement, and the ratio of water-tofuel volume to the a of fissile isotopes. This discussion is based upon 80 calculations representing four enrichments of plutonia in natural urania $(0.5 \%, 1 \%, 2 \%, 4 \%)$, four configurations of these enrichments, and five water volume to fuel volume ratios $(0.625,0.94,1.18$, $1.44,1.72$ ) of these enrichments and configurations. Slide 1 shows crosssectional views of the four configurations to be considered. In the 
Placement of Enrichment for $4 \sigma_{0}$ Cases

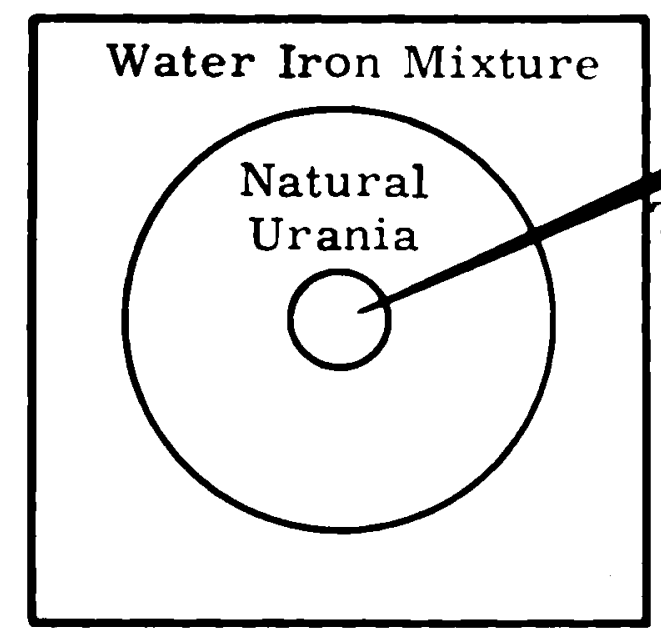

Tight Pencil

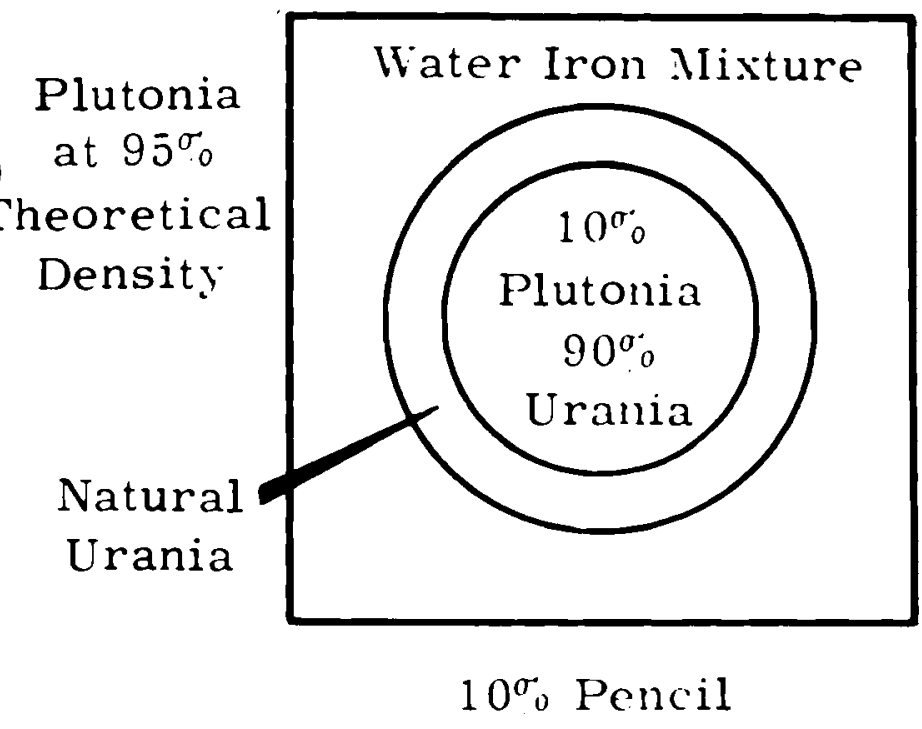

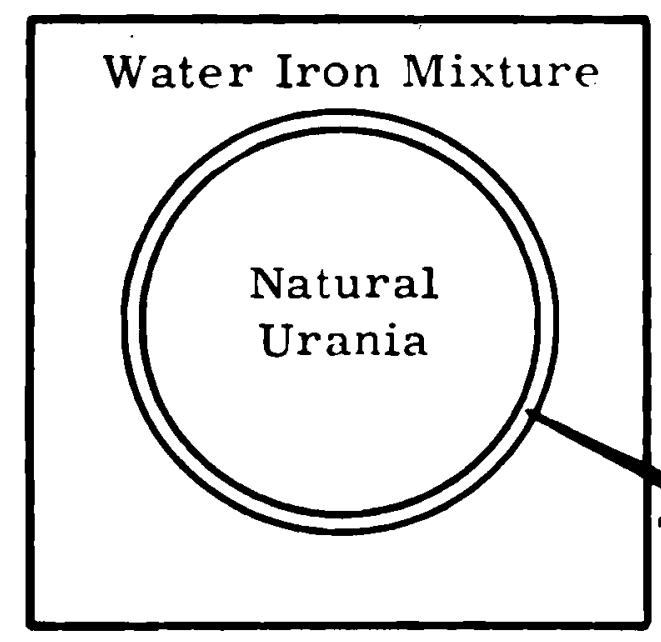

Annulus
Plutonia at $95^{\sigma_{0}}$ Theoretical Density

Isotopic Plutonium Composition:

$\mathrm{Pu}^{239} 60^{\sigma_{0}}, \mathrm{Pu}^{240} 18^{\sigma_{0}}, \mathrm{Pu}^{241} 1 \sigma^{\sigma_{0}}, \mathrm{Pu}^{242} 5^{\sigma_{0}}$ 
uniform configuration, each of the cour desired enrichments was obtained by varying the mixture of plutonia and urania. In the special configurations, the desired enrichment was obtained by varying the relative volumes of the two fuel regions. It should also he noted that the same rod size was used for a 11 configurations and that the water-to-fue 1 ratios were determined by five different moderator region sizes. The uniform configuration was included as a standard or reference case. The tight pencil configuration was expected to provide the hest characteristics for plutonium fuel. The $10 \%$ mixed oxide pencil configuration was chosen, first, to represent a possible situation if plutonia from a tight pencil diffused into the urania, and second, to determine how dense the plutonium had to be to obtain the desired result. The annular configuration was designed to study the efrect on in situ burning of plutonium; for in this case, the plutonium being formed will he shielded by the plutonium in the annulus. This is in contrast to the tight pencil configuration wherein the plutonium being formed will not he shielded by the plutonium enrichment. It should be emphasized that plutonia may diffuse into the adjacent urania unless special nrecautions are taken, and it may be easier to take these precautions with pellets, ba11s, or lumps than with rods. Such a change in shape would not negate this study of rods since the principle we are investigating is common to all of the lumped plutonium systems to some degree.
The RBU Monte Carlo code is designed to compute microscopic fluxes, in this case for 190 energy groups, for cach of the regions in the system considered. Regions are defined by enclosing a volume with a plane or other surfaces that can be second order in $x, y$, or $z$. The contents of each region are specified by isotope name and atomic density. "Particles" representing neutron groupings are "followed" from collision to collision to obtain source coordinates and directions for neutron "beams" at discrete energies. The integrated track lengths of the attenuated heams are "tallied" by region and microenergy group since they are the flux volume integrals. Resonance parameters may be entered for any of the isotopes, in addition to the microgroup cross sections, to permit a more accurate cstimatc of the attenuation in each region for the specific neutron energy produced in the slowing down process. Cross sections are calculated for each isotope, hased on the sum of the two nearest resonances, and using single lcvel formulas and Doppler hroadening functions. Resonance reaction rates are tallied by isotope, region, and macroscopic energy group. These reaction rates, plus microgroup reaction rates derived from microgroun fluxes and cross sections, may be summed to ohtain macrogroup cross sections. In this case 20 macrogroup cross sections were obtained for each isotope. These cross sections may be used in difrusion and burnup codes if desired. In this study, however, 
the reactions rates were summed to provide comparisons of interest.

Each of the 80 calculations represents 40 minutes of IBM 7094 computer time in the Monte Carlo section of the code. There is a finite error possible in any single Monte Carlo calculation, but each set of the 20 cases was designed such that all of the variables of interest may be assumed to be smoothly varying functions of both enrichment and waterto-fuel ratio. The Monte Car1o calculated results may thus be treated as imperfect measurements and fitted to smooth functions. The fitting was done by program MISFIT ${ }^{(2)}$ which provides the coefficients to the terms in the functions. It also produces a plot of the function and the data on the same page. These functions provide reliable trends within the range of the calculations since for each of the four configurations studied they correlate 20 separate calculations representing more than 12 hours of IBM 7094 computer time in Monte Carlo. The fitted functions were used to identify three calculations that appeared to be in error (i.e., 3 out of 80 ). Two new calculations were made for each of these cases, using different input particles and, therefore, obtaining different and independent solutions. These values are now included in a second correlation of the calculations. An alternative approach would have been to continue the questionable calculations for an additional 40 or 80 minutes but this idea was rejected for three reasons: (1) inspection of the results obtained at the 10 - and 20-minute stage of the calculations indicated that the values were not changing rapidly; (2) four other "pilot" cases showed no major changes after 40,60 , or 80 minutes; (3) earlier test calculations of the code indicated that wide fluctuations in calculated values for cell cases damped out in 40 or 50 minutes, as shown in Slide 2 , but no unique solution was obtained even though the calculation was continued for 3 hours. Since a value obtained after 2 hours seems to be no more precise than the value after 40 minutes, the most reli. able result from a 2 -hour investment of computer time is obtained from the average of three separate 40-minute values. Incidentally this is a calculation of one of the experiments reported by kouts and sher in BNL-486. Their reported value of $p$, excluding the $1 / v$ absorptions in $U^{238}$, was 0.72 . The value of 0.62 shown here includes the $1 / v$ absorptions. Excluding the $1 / v$ absorptions, this value corrects to 0.74 ; therefore RBU Monte Carlo was deemed to be operating satisfactorily. Also, the computed values of $\varepsilon$ and thermal utilization were less than $1 \%$ different from the reported values. The code has also been compared to plutonium critical experiments, and agreement within tho accuracy of the concentration and cross-section data was obtained.

In order to compare the relative merits of the three special configura* tions to the standard, or uniform case, it seemed convenient to calculate the terms of the familiar four-factor formula: $\varepsilon, f, p$, and $\eta$. I hope that 
MONTE CARLO CALCULATION OF RESONANCE ESCAPE PROBABILITY

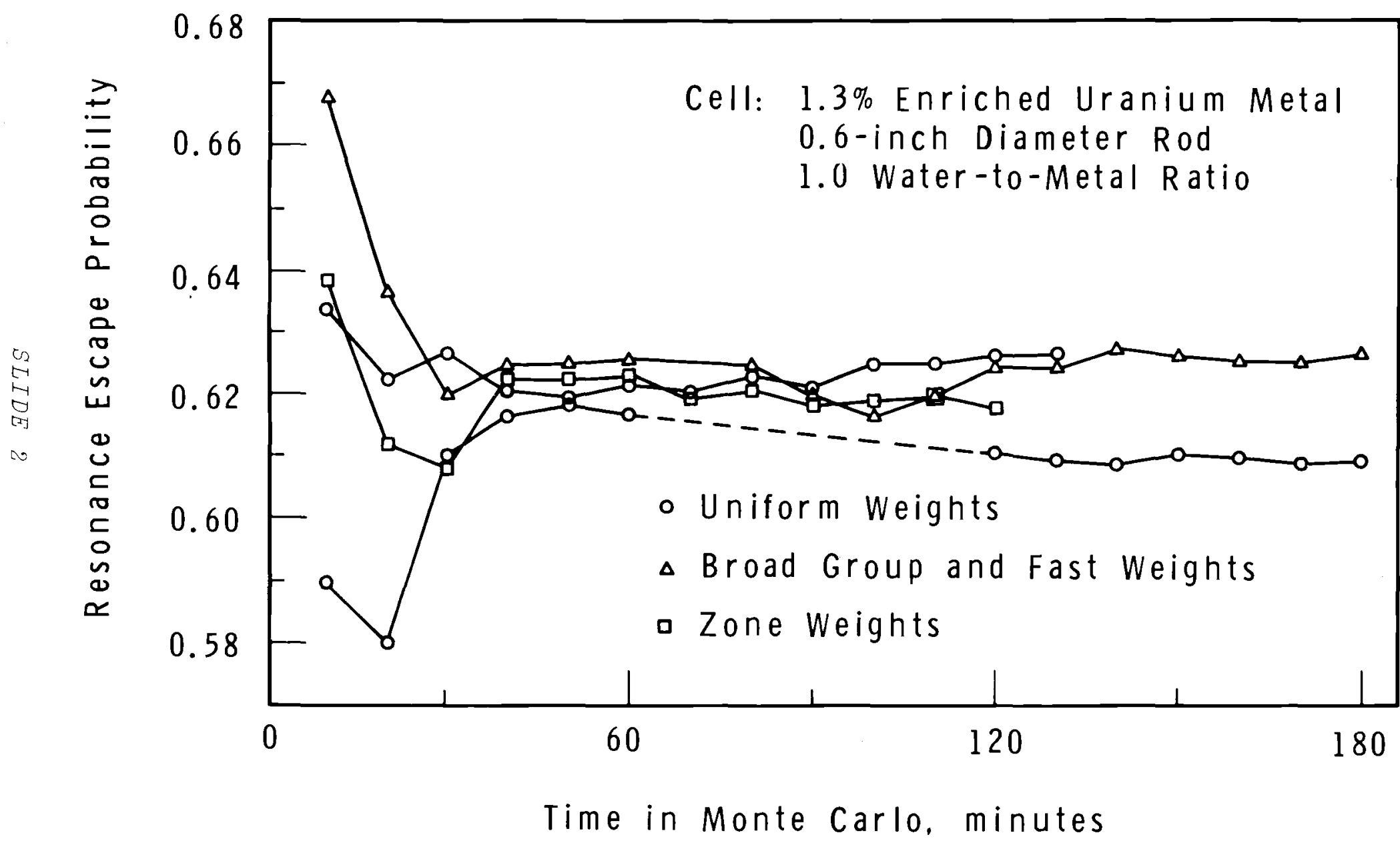


comparison in this simplified manner is not misleading, but direct comparison using the large amount of very detailed data computed by the code becomes very involved. Only part of the data computed has been examined so far and only part of that is presented here.

For this comparison, $\varepsilon$ was defined as the ratio of the neutrons produced by all six fuel isotopes to those produced by the three fissile isotopes. That is to say, it is the gain in neutrons due to fast neutron reactions with $\mathrm{U}^{238}, \mathrm{Pu}^{240}$, and $\mathrm{Pu}^{242}$. Slide 3 is a photograph of a machine-produced plot of all the data and the resulting correlation. The four curves represent the variation of $\varepsilon$ versus waterto-fuel ratio at each enrichment. The increase in $\varepsilon$ shown from curve to curve as the plutonium content of the fuel increases is due to the higher fission cross section of the plutonium isotopes. Slide 4 is a photograph of the machine-produced plot of the data and correlation for the uniform configurations. Note that this figure is nearly identical in appearance with Slide 3. The correlations indicate that the placement of the plutonium has no influence upon $\varepsilon$. Slides for the other configurations were not prepared since they are essentially the same as this one.

The neutron utilization, or $f$, was computed as the ratio of two reaction rates. The numerator included the neutron absorption in all fuel isotopes at thermal energy and in fissile isotopes at epithermal energies. The denominator was the numerator plus the reaction rate in nonfuel isotopes. Slide 5 indicates, as expected, lower neutron utilization in the pencil configurations than in the uniform case, because of the flux depressions. However, contrary to expectation, no improvement of neutron utilization is indicated for the annular case wherein the plutonium reaction rates are maximized.

Resonance neutron capture in $\mathrm{u}^{238}$ is greatest in the tight pencil configuration and decreases as the plutonium is distributed away from the center. This decrease is due to the increased competition of the plutonium resonances which deplete the slowing-down spectrum. There is an additional decrease in the annular configuration because the diameter of its urania is slightly smaller than in the other configurations. Both decreases become more pronounced as the plutonium enrichment increases and the water-to-fuel ratio decreases. However, resonance neutron capture in $\mathrm{Pu}^{240}$ and $\mathrm{Pu}^{242}$ is more difficult to explain. It tends to be least in the tight pencil configuration, increas ing as the plutonium is distributed away from the center; but this increase is partially offset by the increase in competition from the resonances of $\mathrm{Pu}^{239}$ and $\mathrm{Pu}^{241}$ at higher energy. The net result of captures in $\mathrm{U}^{238}, \mathrm{Pu}^{240}$, and $\mathrm{Pu}^{242}$ may be expressed as a resonance escape probability. Variation in resonance escape probability is shown in Slide 6 for the various configurations at $1 \%$ and $2 \%$ enrichment. Note that at both enrichments the reduced capture by $\mathrm{pu}^{240}$ and $\mathrm{Pu}^{242}$ in the tight pencil configuration permits the highest resonance 


\section{EPSILON VALUES FOR ALL CONFIGURATIONS}

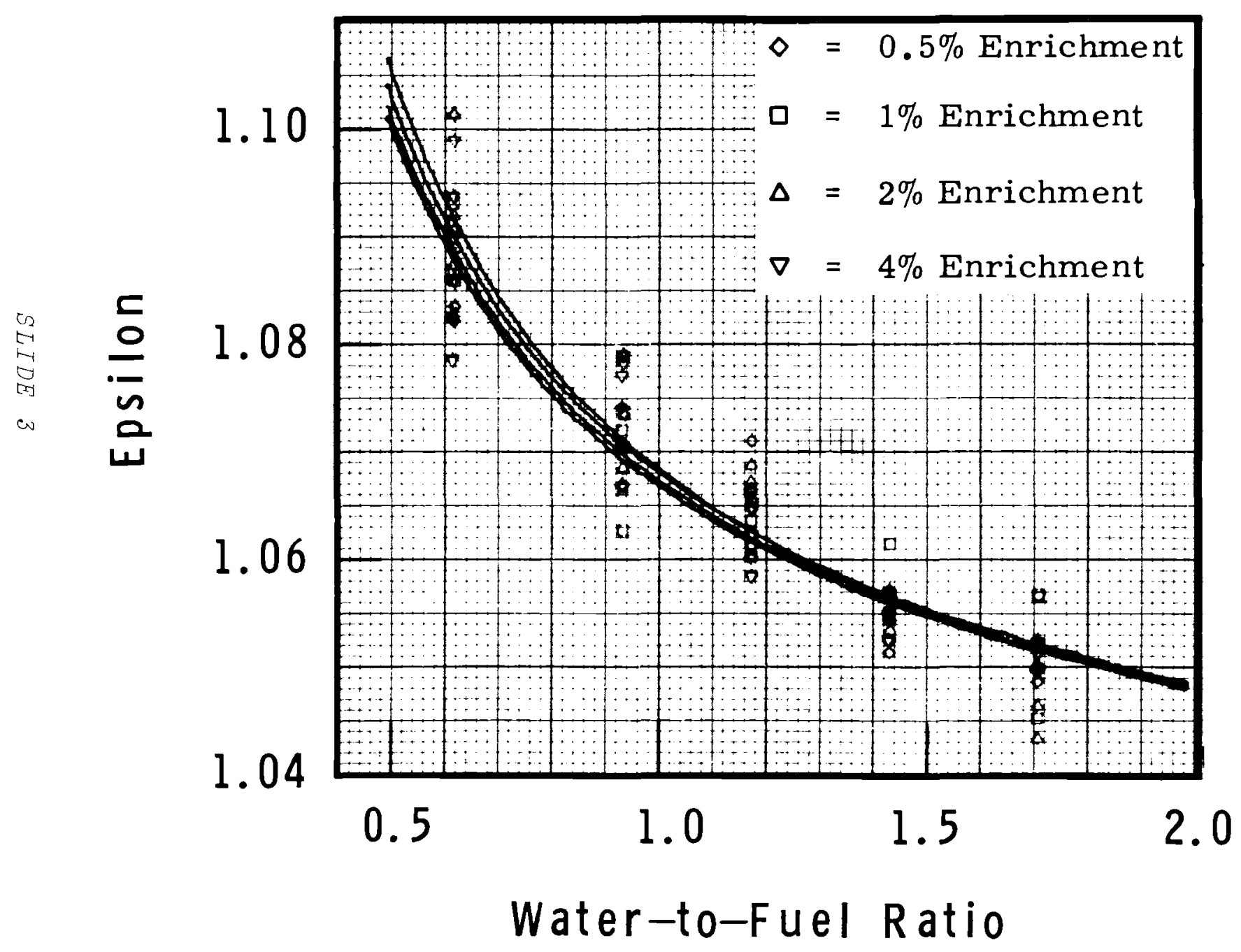




\section{EPSILON VALUES FOR UNIFORM}

ENR ICHMENT CONFIGURATION

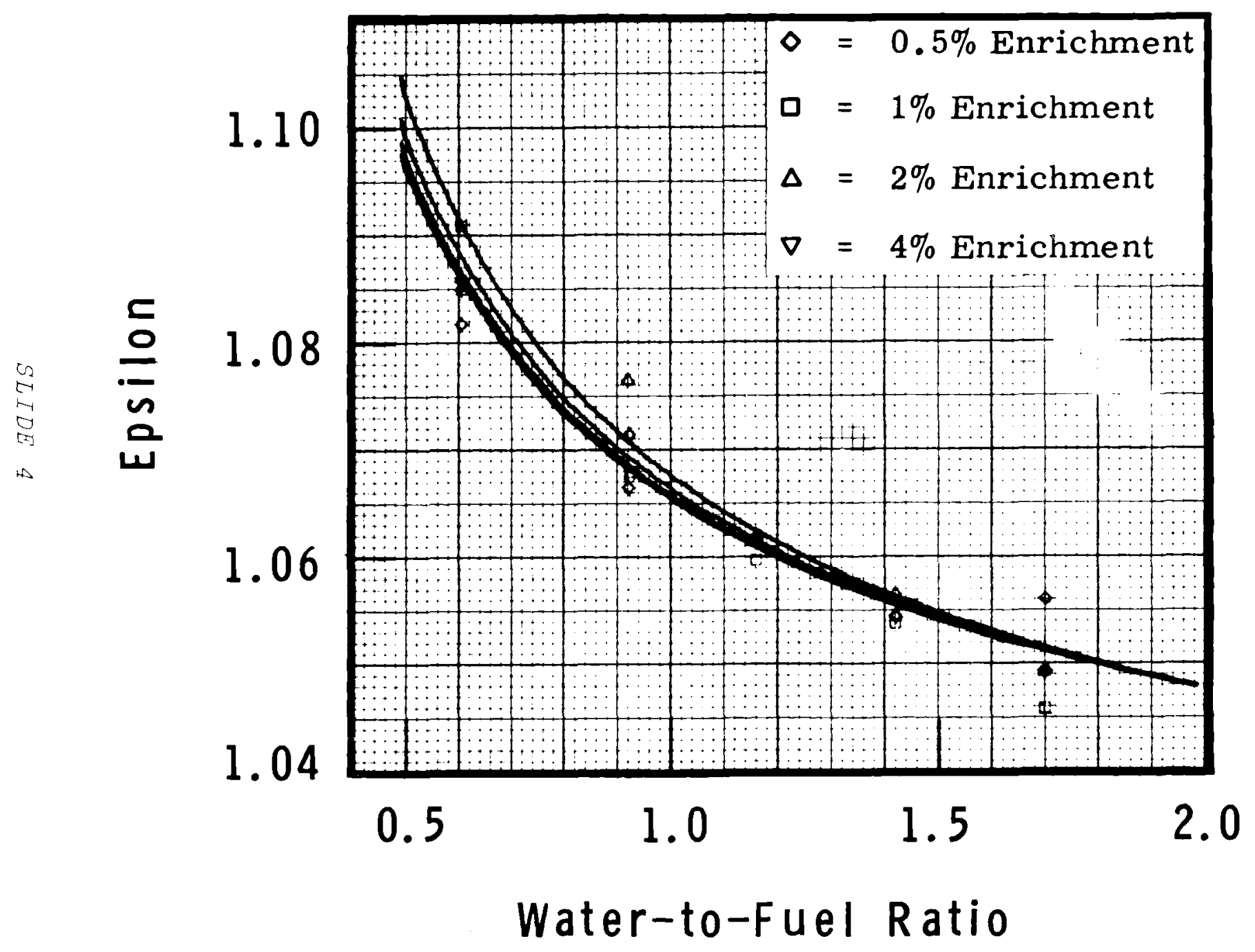


NEUTRON UTILIZATION FOR VARIOUS FUEL CONFIGURATIONS AND ENRICHMENTS

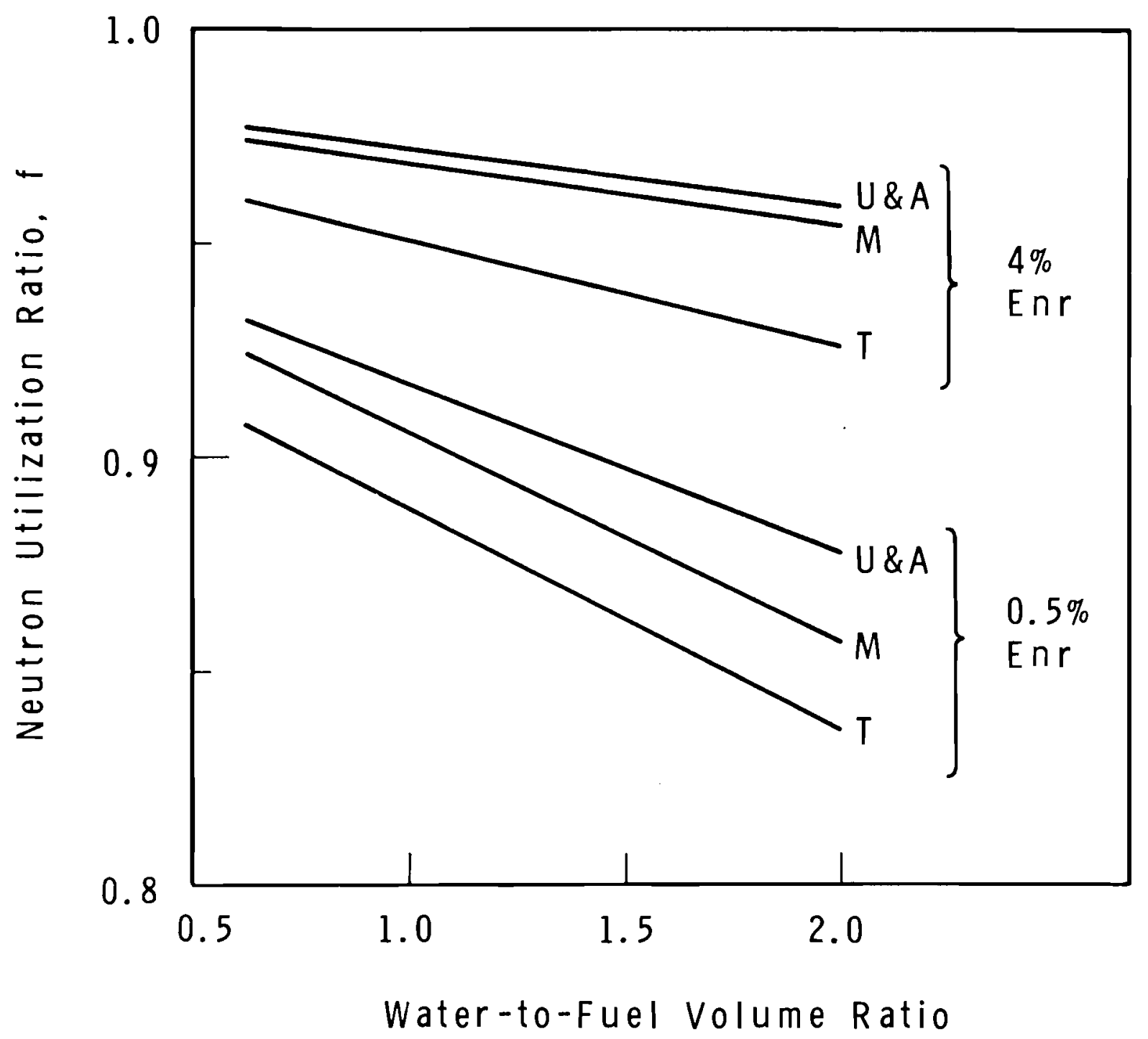

$U \& A$ Uniform and Annular Configurations

$M \quad 10 \% \mathrm{PuO}_{2}-\mathrm{UO}_{2}$ Mixed Oxide Pencil Configuration

$T$ Tight Pencil Configuration 
CUMULATIVE RESONANCE ESCAPE PROBABILITY VALUES OF PU240. PU242 AND U238 FOR VARIOUS FUEL CONFIGURATIONS AND ENRICHMENTS

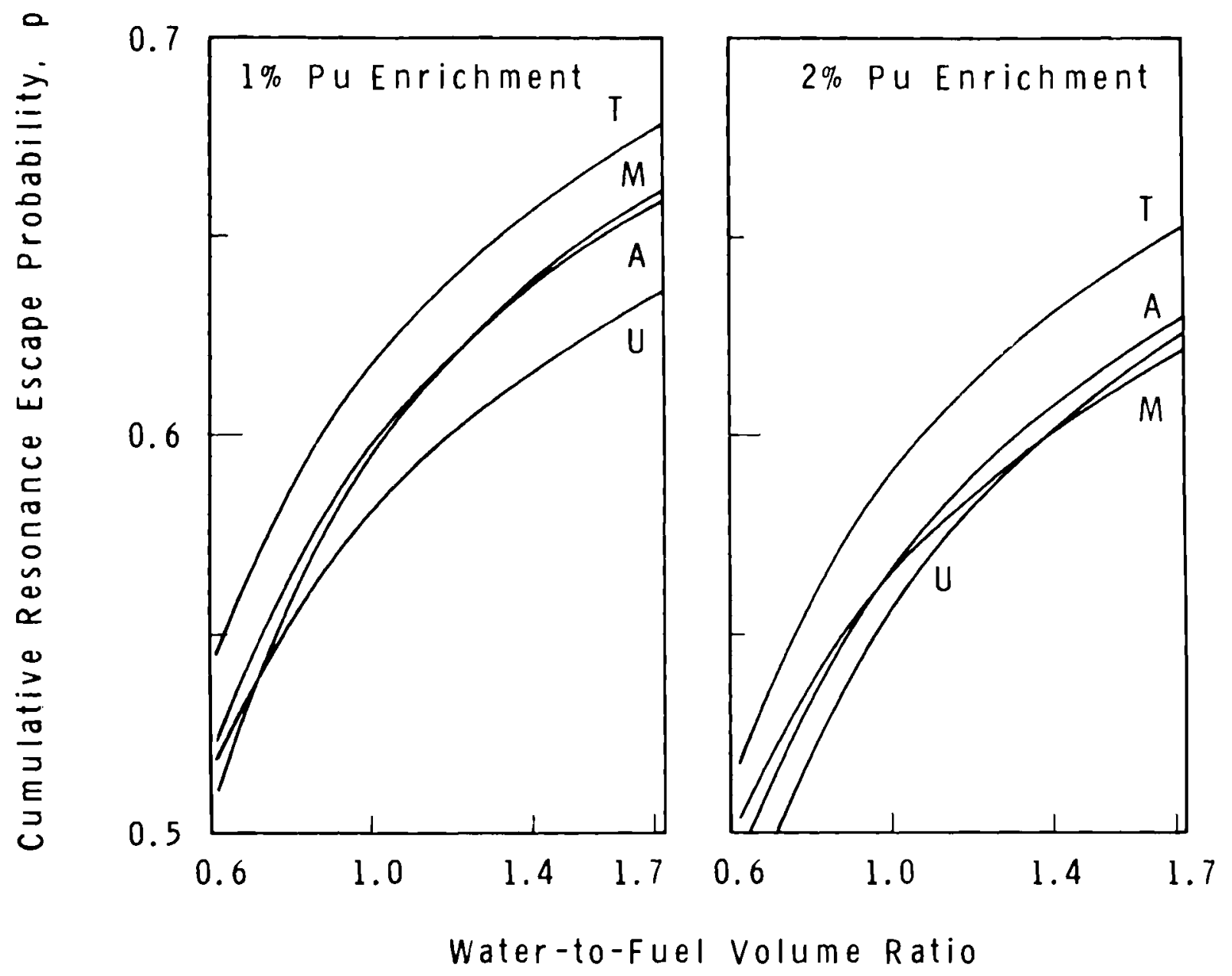

U Uniform Configuration

A Annular Configuration

$\mathrm{M} \quad 10 \% \mathrm{PuO}_{2}-\mathrm{UO}_{2}$ Mixed 0xide Pencil Configuration

$T$ Tight Pencil Configuration 
escape. At $1 \%$ enrichment both the mixed oxide pencil and the annular configurations tend to have higher resonance escape probabilities than the uniform case. This is due to the reduced plutonium captures in the mixed oxide pencil and the reduced uranium captures in the annular case. At $2 \%$ enrichment the resonance escape probability is substantially the same for the mixed oxide pencil, the annular, and the uniform configurations, since the variations in capture by uranium and plutonium roughly compensate each other.

The only clear trend that is shown at these enrichments and also at $0.5 \%$ and $4 \%$ is that the resonance escape probability is highest in the tight pencil configuration. This means that diffusion of plutonia from an original tight pencil configuration into the surrounding urania during reactor operation may not create a hazardous reactivity transient. The exact response would be strongly dependent on the isotopic composition of the plutonium, but these calculations indicate that, with $18 \% \mathrm{Pu}^{240}$ and $5 \% \mathrm{Pu}^{242}$ (the balance being $\mathrm{Pu}^{239}$ and $\mathrm{Pu}^{241}$ ), reactivity will decrease if diffusion of plutonia causes a change from the tight pencil to the mixed oxide pencil configuration.

The remaining factor of interest is that of the reproduction of neutrons by plutonium being strongly influenced by the a of $\mathrm{Pu}^{239^{\circ}}$. The effective $\alpha$ of $\mathrm{Pu} 239$, in turn, is strongly influenced by the relative reaction rates at thermal energies versus the rates at neutron energies throughout the $0.3 \mathrm{eV}$ resonance. Slide 7 is a linear plot of the cross section of $\mathrm{Pu}^{239}$ from $0.01 \mathrm{eV}$ to 0.5 eV. Note that the cross section in the range of thermal energy is on the order of 700 to 1000 barns, and $\alpha$ in this range is about 0.4 . The resonance cross section rises to 5200 barns, and a in this range is about 0.7 . This large cross section is much more effective in causing flux depression or shielding in fuel assemb 1 ies.

When the flux at the $0.3 \mathrm{eV}$ resonance is depressed the thermal reactions become more important. of course, if a high density fuel region is large enough, the thermal flux is also severely depressed. The plutonium reaction rates may then be too smal1 for normal fuel applications.

Inspection of S1ide 8 suggests that the lowest a is obtained in the tight pencil configuration, as predicted, especially at the larger water-to-fuel ratios. This improvement is due to the drastically increased shielding of the resonances. Since the resonance data used in the Monte Carlo code have essentially constant, partial, capture widths and variable, partial, fission widths, the resonances with lower a must be broader and not as strongly shielded as the resonances with a higher $\alpha$. Note that the alpha value at water-to-fuel ratios of about 1.0 for $2 \%$ plutonium enrichment is about 0.51 for the tight pencil configuration, compared to about 0.55 for the uniform, or reference, configuration. This difference in a corresponds to an increase in $n$ from 1.87 (uniform configuration) to 1.92 (tight pencil configuration).

I should mention at this point that $n$ should be computed as the 


\section{ABSORPTION CROSS SECTION VS NEUTRON ENERGY FOR PU239}

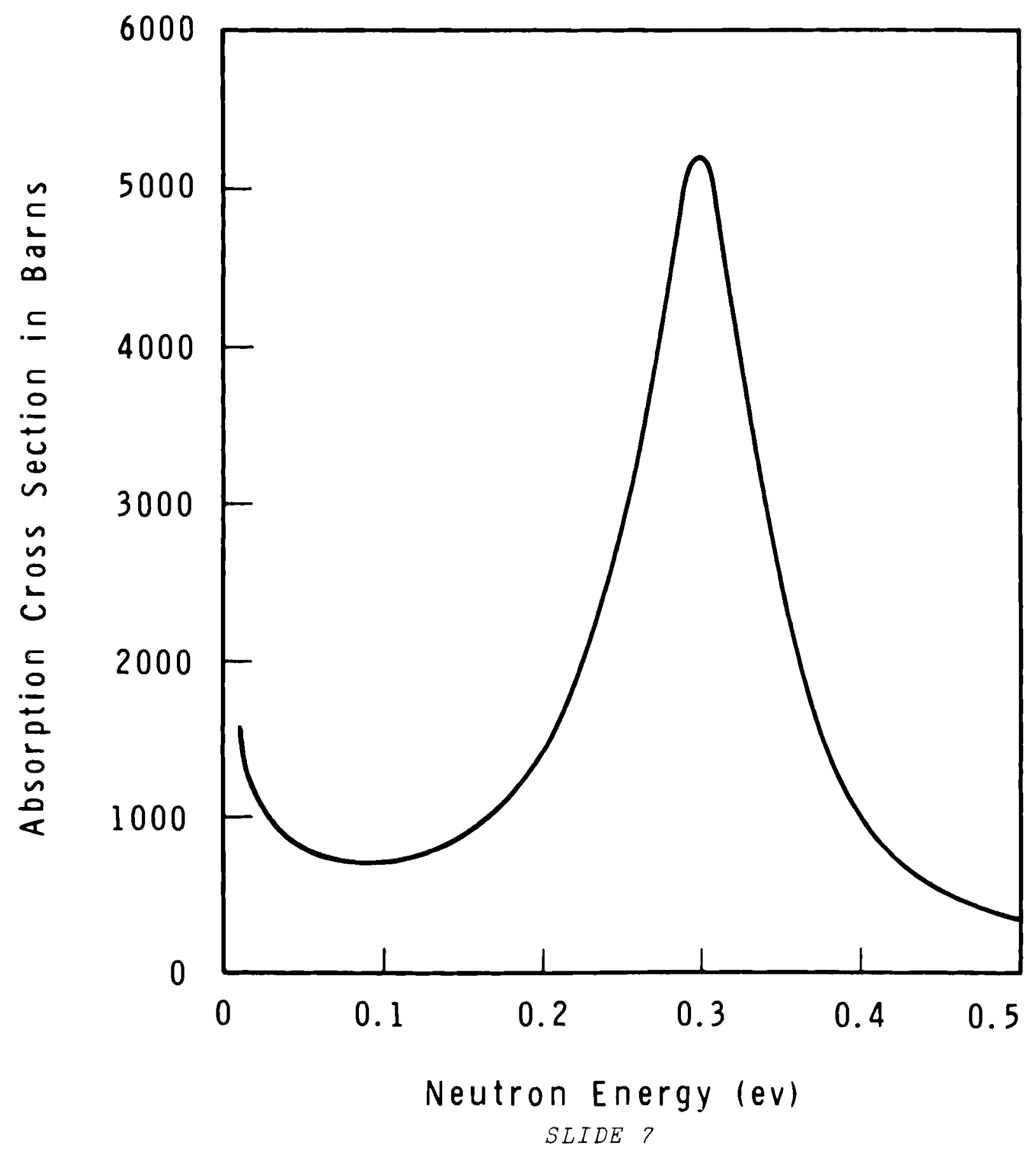


PLUTONIUM 239 ALPHA VALUES FOR VARIOUS FUEL CONFIGURATIONS AND ENRICHMENTS
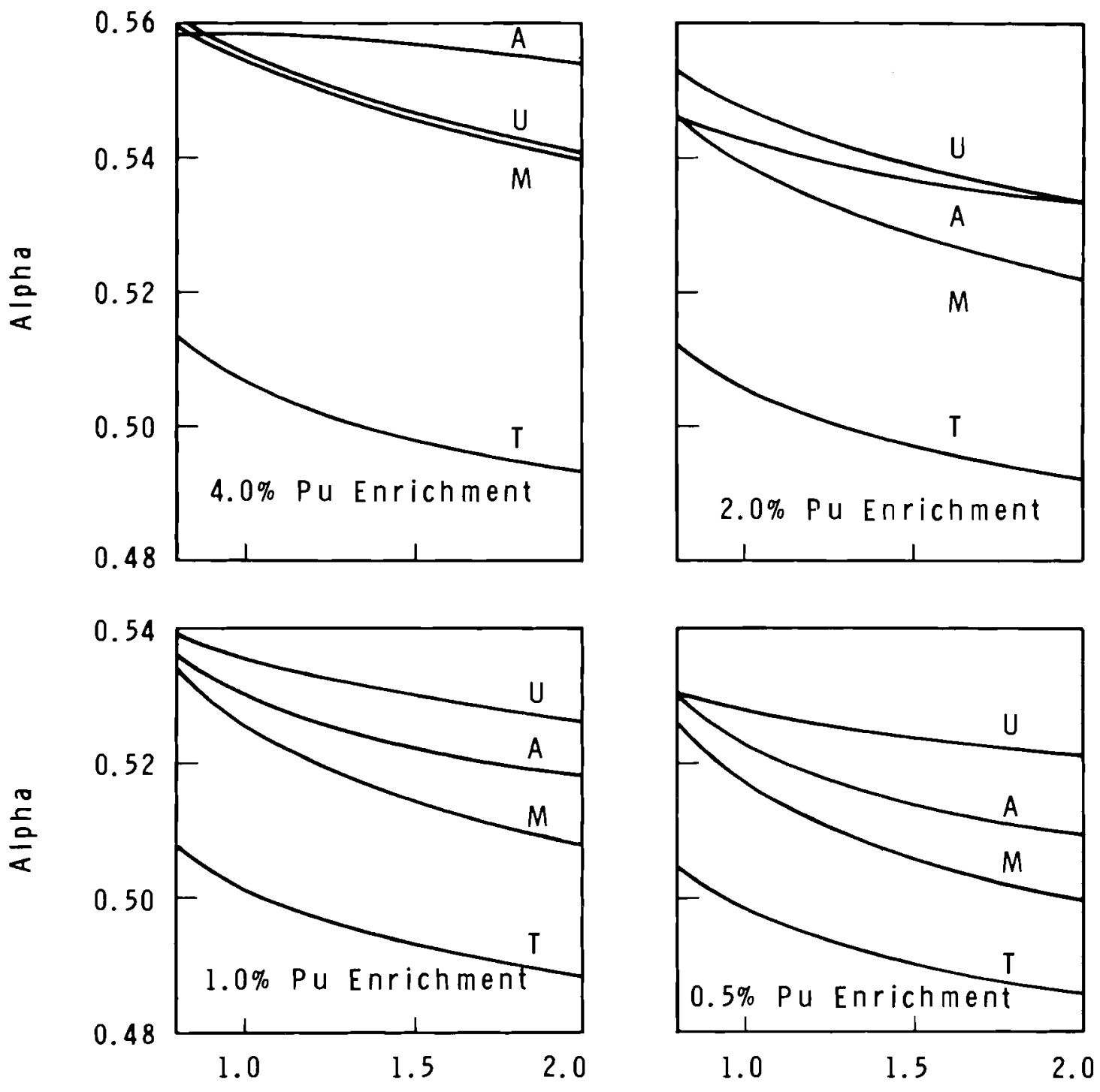

Water-to-Fuel Volume Ratio

U Uniform Configuration

A Annular Configuration

$M \quad 10 \% \mathrm{PuO}_{2}-\mathrm{UO}_{2}$ Mixed oxide Pencil Configuration

$T$ Tight Pencil Configuration 
ratio of emitted neutrons to neutrons absorbed rather than as an average $\nu$ divided by one plus an average $\alpha$. Two values for $v$, such as are used in the Battelle Northwest Laboratory survey code ALTHAEA, are probably the minimum acceptable, while the 190 values used in this RBU study usually exceed the need.

It should be noted that $\alpha$ in the tight pencil configuration, even at an enrichment level of $4 \%$, is less than in any other configuration over the entire range of enrichments from $0.5 \%$ to $4 \%$. Furthermore, the lowest $\alpha$ obtained for the uniform configuration was 0.52 at $0.5 \%$ enrichment and a water-to-fuel ratio of 2.0 .

For the tight pencil configuration $\alpha$ is well below 0.52 except at the lowest water-to-fue 1 ratios considered. From this standpoint a reactor designer may now be permitted to recycle plutonium in water moderated reactors in concentrations and in lattices previously believed to be uneconomic.

This shielding principle may be applied to reactors with moderators other than water, of course; but the results are also influenced by other reactor design conditions. For example, part of the shielding is already achieved in the multirod cluster designs of heavy water reactors. Furthermore, the moderator temperature strongly influences a because of the up-scatter of thermal neutrons to energies near the $0.3 \mathrm{eV}$ resonance. Therefore, this shielding technique may be expected to be especially productive if the moderator tempera ture is low, and rather marginal if the moderator temperature approaches the equivalent temperature of the $0.3 \mathrm{eV}$ resonance.

For the circumstances which permit strong shielding of the $0.3 \mathrm{eV}$ resonance by depressing the flux, other benefits also accrue. Alpha for $\mathrm{Pu}^{241}$ is improved since its thermal alpha is also less than alpha in its resonance at $0.25 \mathrm{eV}$. In addition, the poisoning effect of $\mathrm{Am}^{241}$ is reduced because of the drastic reduc-

tion of the reaction rate in the $0.3 \mathrm{cV}$ resonance of $\mathrm{Am}^{241}$.

An interesting extension of this reasoning is to place high concentrations of plutonium in the core of a fue 1 rod to burn $\mathrm{Pu}^{242}$. In thermal fluxes, about $1 \%$ of the neutron reactions with $\mathrm{Pu}^{242}$ result in fission, so, as $\mathrm{Pu}^{242}$ accumulates, the reactivity contributions of plutonium are reduced. other studies at Pacific Northwest Laboratory have shown that the value of a plutonium batch as a thermal reactor fuel may be computed as $\$ 11 / \mathrm{g}$ of contained $\mathrm{Pu}^{239}$ plus $\mathrm{Pu}^{241}$ minus $\$ 15 / \mathrm{g}$ of contained $\mathrm{Pu}^{242}$. It has been suggested by Pacific Northwest Laboratory investigators and others that batches of plutonium high in $\mathrm{Pu}^{242}$ be used as fast reactor fuel since it has a fission cross section of 1.5 barns or so, which compares favorably with other plutonium isotopes. This study shows that in a pencil configuration the high concentrations of $\mathrm{Pu}^{242}$ cause a large thermal flux depression and effectively shield the resonances, but the fast fission cross section is not decreased. 
Slide 9 presents the effective $\alpha$ of $\mathrm{Pu}^{242}$ under these extreme conditions.

Plutonium of this composition (61\% $\mathrm{Pu}^{242}$ ) may be obtained from a plutonium enriched fuel element if the plutonium used for enricnment is kept separate from the plutonium produced during the irradiation. Although this specific configuration and composition may not be economic, it does indicate that the contribution of $\mathrm{Pu}^{242}$ to the value of plutonium as a reactor fue 1 can be less negative than previous $1 y$ believed. These a values of 5 to 7 should be compared to values of 20 to 25 for tight pencils containing $5 \%$ $\mathrm{Pu}^{242}$ and to values of 80 to 100 for uniformly enriched fuel containing less than $0.5 \% \mathrm{Pu}^{242}$.

Other ramifications of this flux depression principle involve tailoring the reaction rates of high cross section materials to match reaction rates of other materials of lower cross section. For example, plutonium enrichment of thorium could be matched to the reaction rate of $\mathrm{U}^{233}$ being produced. This tends to keep the heat production and the reactivity more nearly constant over a longer period of time. In fact, the pencil configurations will tend to produce a more constant reactivity in a plutonium burner since the reaction rate is high on the surface and the surface area is constant.

As $\mathrm{Mr}$. Neef will discuss later, the overall conservation of uranium is more sensitive to the a of $U^{235}$ than to the $\alpha$ of $\mathrm{Pu}^{239}$. The pencil configuration should also improve the behavior of $\mathrm{U}^{235}$. For this reason, future work will include calculations using $U^{235}$ and $U^{233}$ in the pencil configuration for $\mathrm{D}_{2} \mathrm{O}$, graphite, and $\mathrm{H}_{2} \mathrm{O}$ moderators.

Most of the 80 RBU calculations have been checked by the combination of the Hanford Revised GAM(3) code for reaction rates above $0.68 \mathrm{eV}$ and THERMOS (4) below $0.68 \mathrm{eV}$. The use of Dancoff and Bel1 prescriptions for calculation of input to HRG implies an ability to express the heterogeneous cell as a homogeneous medium. This concept is subject to some question, especially in the annular fuel configuration. The THERMOS calculations are based on the assumption that a cylindrical water region having the same volume as a rectangular region produces the same result. This assumption becomes more questionable as the water volume becomes smaller, especially at the higher enrichments. Comparisons between codes are desirable but identical agreement with Monte Carlo as used by RBU is not expected. GAM-THERMOS calculations in general confirm the trends predicted by Monte Carlo for variations in placement and water-to-fuel ratio, but indicate that a for plutonium does not vary with enrichment level as much as Monte Carlo indicated. The a values calculated by GAMTHERMOS at the $2 \%$ enrichment leve 1 agree with Monte Carlo, but are greater at lower enrichments, and less at higher enrichments. Resonance escape probabilities calculated by HRG are, in general, higher than the values from Monte Carlo, and show less variation with enrichment. The 
FISSIONING OF PLUTONIUM 242 IN A TIGHT PENCIL CONFIGURATION(1)

Additional

Enrichment, \%(2)

1.7

4.7

\begin{tabular}{lcc}
\multicolumn{3}{c}{ Alpha of $\mathrm{Pu}^{242}$} \\
$\frac{(3)}{7.2}$ & $\frac{(4)}{6.7}$ & $\frac{(5)}{6.5}$ \\
5.0 & &
\end{tabular}

(1) The Core of the Tight Pencil Configuration Constitutes $13 \%$ of the Fuel Rod and Consists of Plutonia at $95 \%$ Theoretical Density. Isotopic Composition (2\% Pu239, 25\% Pu240, $12 \%$ $\mathrm{Pu} 241,61 \% \mathrm{Pu}^{242}$ ).

(2) The $87 \%$ of the Fuel Outside the Core of the Tight Pencil Configuration is a Mixture of Natural Urania plus Plutonia at $95 \%$ Theoretical Density. The Isotopic Content of this Plutonium is $\left(60 \% \mathrm{Pu}^{239}, 18 \% \mathrm{Pu} 240,17 \% \mathrm{Pu}^{241}, 5 \% \mathrm{Pu}^{242}\right)$.

(3) Water-to-Fuel Volume Ratio 0.625

(4) Water-to-Fuel Volume Ratio 0.94

(5) Water-to-Fuel Volume Ratio 1.44 
variation with placement seems to be confirmed, in that the resonance escape probability is greater for the mixed oxide pencil configuration than for the uniform case, and even greater in the tight pencil configuration.

It would be possible either to try several other codes and sets of cross section data or to adjust parameters to obtain confirmation or correction of these calculations, but the results would still be suspect.

However, the calculations with both coding systems do permit us to draw several conclusions. To summarize briefly: we find that the tight pencil placement of plutonium can improve the $\alpha$ of $\mathrm{Pu}^{239}$ by 0.04 , and permits the design of plutonium enriched reactors to have lower waterto-fuel ratios and higher enrichments than previously expected. This should lead to more complete burning of the plutonium, longer economic life of the fuel, more heat genera- ted in fast fission of $U^{238}$, and smaller reactor vessels for a given amount of power. This technique can also be used to tailor the effective cross section of all plutonium isotopes and to enhance the fast fissioning of $\mathrm{Pu}^{242}$. I believe that these improvements are of sufficient magnitude and of sufficient importance to justify a series of critical experiments.

\section{REFERENCES}

1. J.R. Triplett, E. T. Merrizl, and $J$. R. Burr. The RBU ReactorBurnup Code: Formulation and Operating Procedure, HW-70049. General Electric Company, Richland, Washington.

2. B. H. Duane. Unpublished Data.

3. G. D. Joanou and J.S. Dudek. GAM-I: A Consistent $P_{1}$ Multigroup Code for the Calculation of Fast Neutron spectra and Multigroup Constants, GA-2850. General Atomic Division, General Dynamics Corporation. June 28, 1961.

4. H. C. Honeck. THERMOS: A Thermalization Transport Theory Code for Reactor Latice Calculatione, BNL-5826. Brookhaven National Laboratory. 1960. 
.

\section{•}

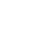




\section{SECTION II}

A NEW FUEL CONFIgURATION TO INCREASE PLUTONIUM VALUE

D。 E. Deonigi

J. H. Nail

Battelle Memorial Institute

Pacific Northwest Laboratory

Richland, Washington

November, 1965

Paper for oral presentation at the American Nuclear Society 1965 Winter Meeting Washington, D.C., November 15-19, 1965 


\title{
A new fuel CONFiguration to InCREASE PLUTONiUm VAlue*
}

\author{
D. E. Deonigi**
}

J. H. $\mathrm{Nail}{ }^{\text {H. }}$

The present paper considers the burnup characteristics and the value effects of concentrating plutonium in the core of fuel rods of water moderated reactors. Such a concentrated fuel configuration makes possible (1) an adjustable cross section of plutonium, (2) an improvement in the alnha of $\mathrm{Pu}^{239}$, and (3) the use of $\mathrm{Pu}^{242}$ as a fuel.

In the early days of nlutonium recycle, PRTR operation with plutonium spikes and natural uranium core was considered. But in that system the fission cross section of plutonium was two to three times that of $\mathrm{U}^{235}$, and hence, for a given control allowance, the permissible loading of plutonium was so slight that the induced short fuel exposures greatly increased the associated fabrication and processing costs. However, the plutonium tight pencil configuration described earlier by Mr. Merrill offers the possibility of both adjusting the effective cross section of

* This paper is based on work performed under United States Atomic Energy Commission Contract AT (45-1) -1830. Permission to publish is gratefully acknowledged.

* Senior Research Engineer

$\because \quad$ Engineer, Physics and Instruments Department, Pacific Northwest Laboratory, operated by Battelle Memorial Institute for the United States Atomic Fnergy Commission, Richland, Washington. plutonium to that of a $U^{235}$ load and of reducing the alpha of $\mathrm{Pu}^{239}$. More specifically, calculations for plutonium pencils of usable size indicate that flux depressions sufficient to reduce reaction rates by a factor of 3 can be achieved. However, adjust ing the fission cross section of plutonium to that of $\mathrm{U}^{235}$ is not necessarily desirable, because in slightly enriched uranium fuel there is a combination of $\mathrm{U}^{235}$ and plutonium fissioning. Consequently, the cross section that must be matched by spiked fuel is more than that of $\mathrm{U}^{235}$ but less than that of $\mathrm{Pu}^{239}$.

In this study a zero-dimensional version of the ALTHAEA burnup code was used to assess the effect that reduced cross sections and alphas would have both on the value of plutonium in thermal reactors and on the burnup characteristics of tight pencil fuel. More specifically, the reactivity and the power distribution of tight pencil fuel are compared with normal uniformly mixed, or homogeneous, fue 1 .

In the first slide, we see a comnarison of ALTHAEA zero-dimensional cross sections with those of the RBU data presented earlier by Mr. Merrill. Upon inspection we find a satisfactory agreement between the RBU cross sections and those calculated by the 


\section{COMPARISON OF RBU AND ALTHAEA CROSS SECTIONS}

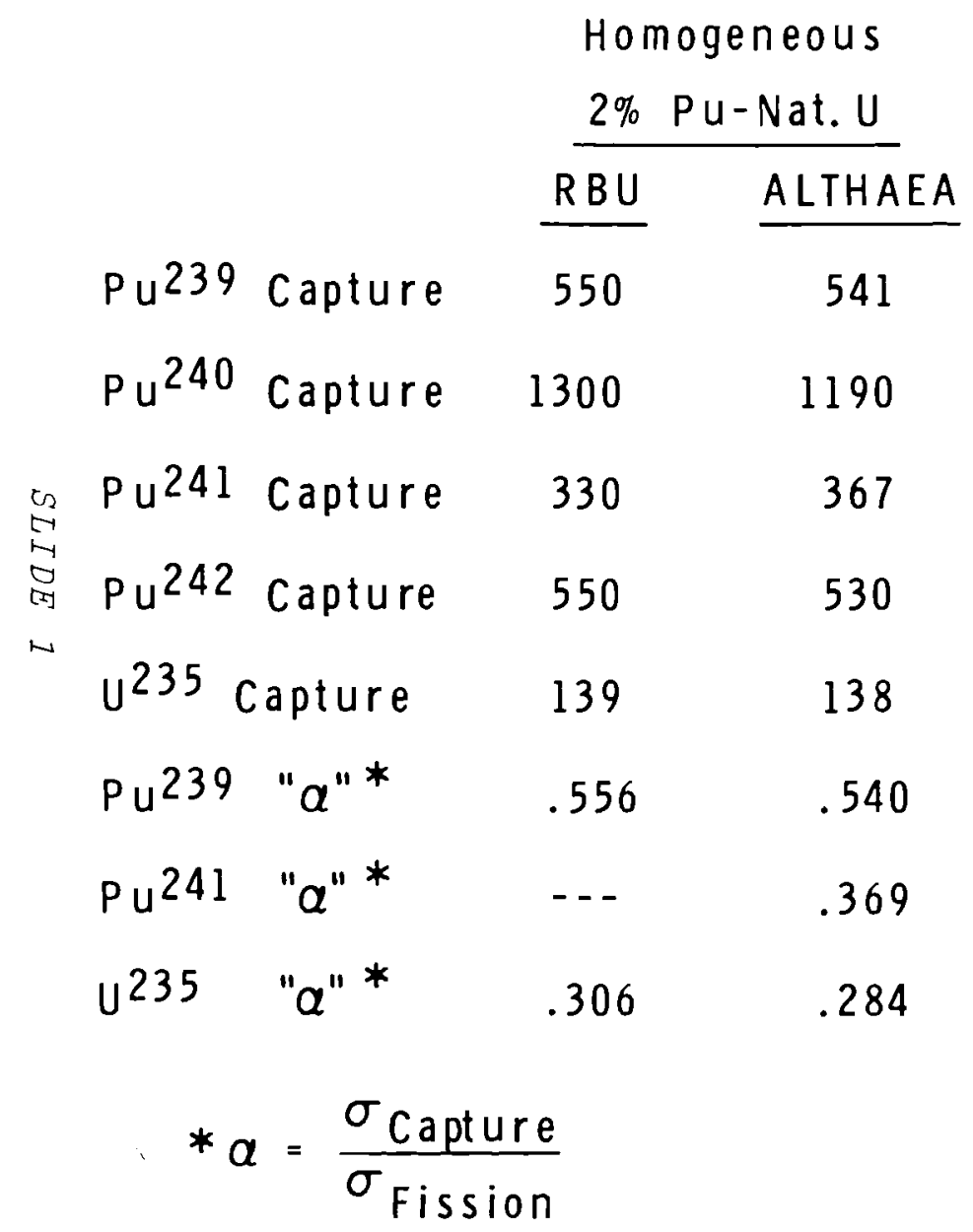

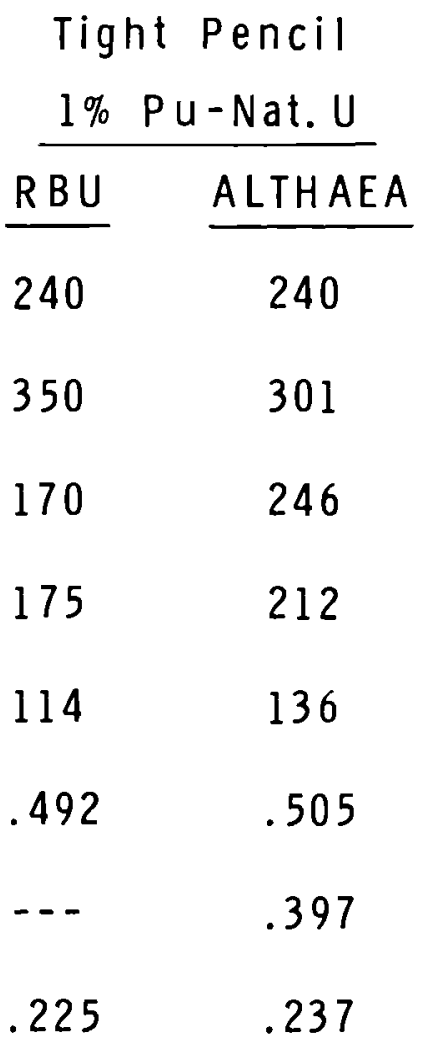

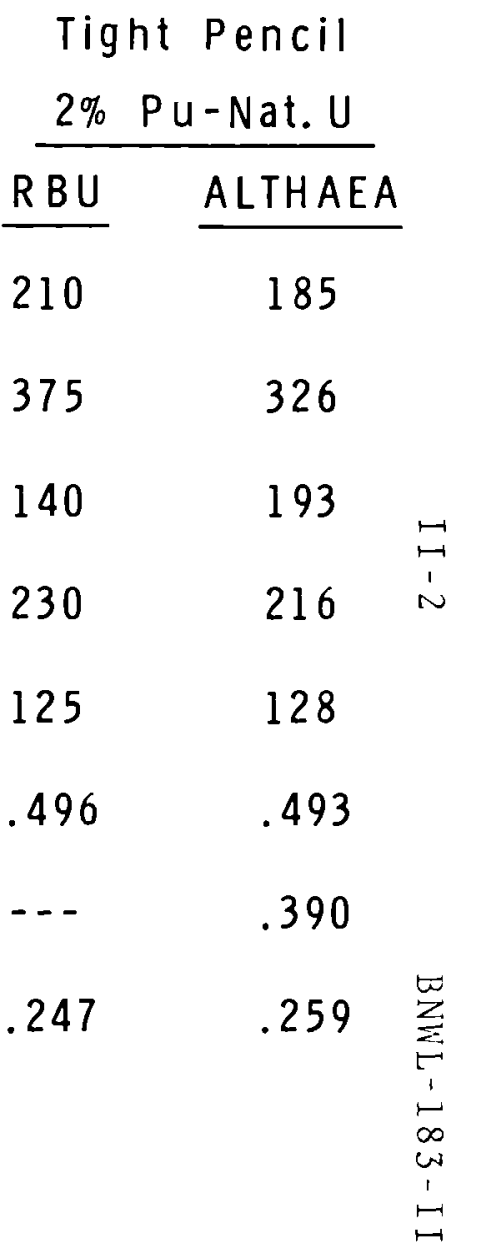


ALTHAEA code after calibration of the resonance shielding parameters.

Notice that in the tight pencil fuels the changes in cross section and alpha as a function of the percent of plutonium enrichment in natural uranium are proportional to those predicted by the RBU calculations described by Merrill. With the homogeneous, or uniformly mixed, fuel the agreement is very good. The ALTHAEA computer code simulated the burnup by using two different sets of plutonium isotopes, one representing the plutonium in the inner region of the tight pencil fuel, which has the calibrated resonance shielding parameters, the other representing the outer region plutonium, which has the homogeneous, or normal, shielding parameters.

Calibration for the inner region of the tight pencil fuel was obtained by increasing both the self-shielding and the cross-shielding parameters. It is interesting to note that when calibrating the inner region shielding parameters of $\mathrm{Pu}^{239}$ in ALTHAEA we had to use factors almost 100 times those normally associated with homogeneous fuel. It was also observed that the plutonium formed in the outer fuel region shielded the plutonium of the inner.region with the same effectiveness as a plutonium atom in the inner region. Thus the self-shielding of the plutonium in the inner region was effectively dependent on the concentration of plutonium in both regions of the tight pencil fuel configuration. However, the plutonium in the inner region provided very little shielding for the plutonium formed in the outer region during burnup. The thermal flux depressions used in these calculations were derived from an interpretation of the RBU results for various enrichments; the flux depression for a $2 \%$ enriched tight pencil fue 1 is approximately 2.5 .

In S1ide 2 we see the cumulative percent of heat produced by isotopes in the inner and outer fuel regions of low exposure plutonium. The plutonium composition represented here is similar to that discharged from a slightly enriched water reactor. The burnup data in the slide apply to a pressur ized water reactor with a moderatorto-fuel ratio of 1.4 . As you can see from the solid lines, about $70 \%$ of the initial heat produced comes from the plutonium in the inner fuel region. But as soon as plutonium begins to accumulate in the outer fuel region, the heat produced in this region rapidly approaches that of the inner region. The reason for this is that plutonium accumulated in the outer fuel region has a cross section two or three times greater than that of plutonium in the inner region. By the end of the burnup, both fuel regions have produced about equal amounts of heat. Consequently, we can conclude that the effective alpha and cross section adjustments necessary to simulate tight pencil fuel configurations 1 ie between the parameters required to match the cross sections given earlier by $\mathrm{Mr}$. Merrill for the tight pencil and for homogeneous fuel configurations.

S1ide 3 shows the heat production from the same isotopes, but instead of using low exposure plutonium we are using high exposure plutonium 
PERCENT OF HEAT (CUMULATIVE) PRODUCED BY ISOTOPES IN TIGHT PENCIL CONFIGURATION FUEL

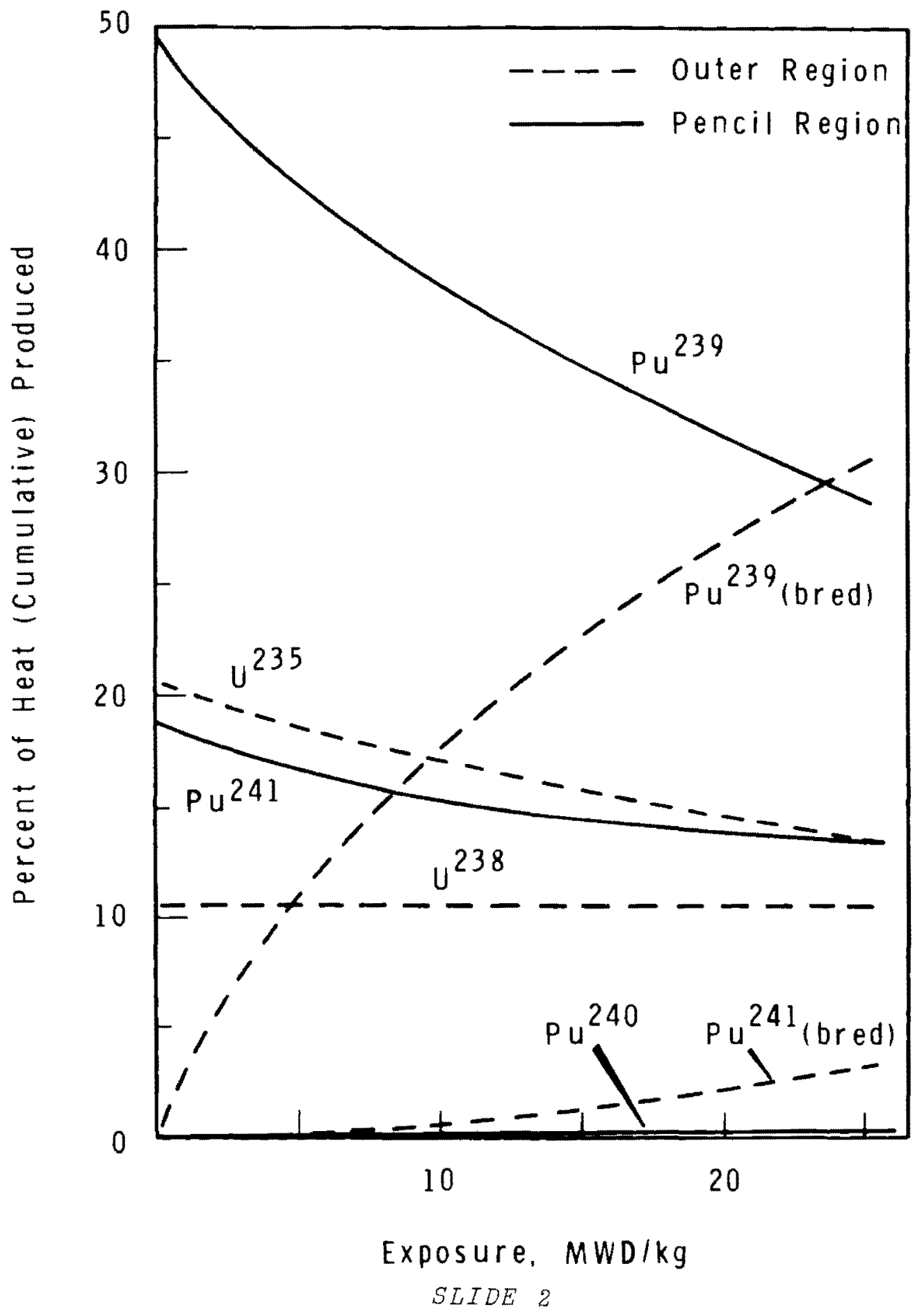


PERCENT OF HEAT (CUMULATIVE) PRODUCED BY ISOTOPES IN TIGHT PENCIL CONFIGURATION FUEL USING HIGH EXPOSURE PLUTONIUM

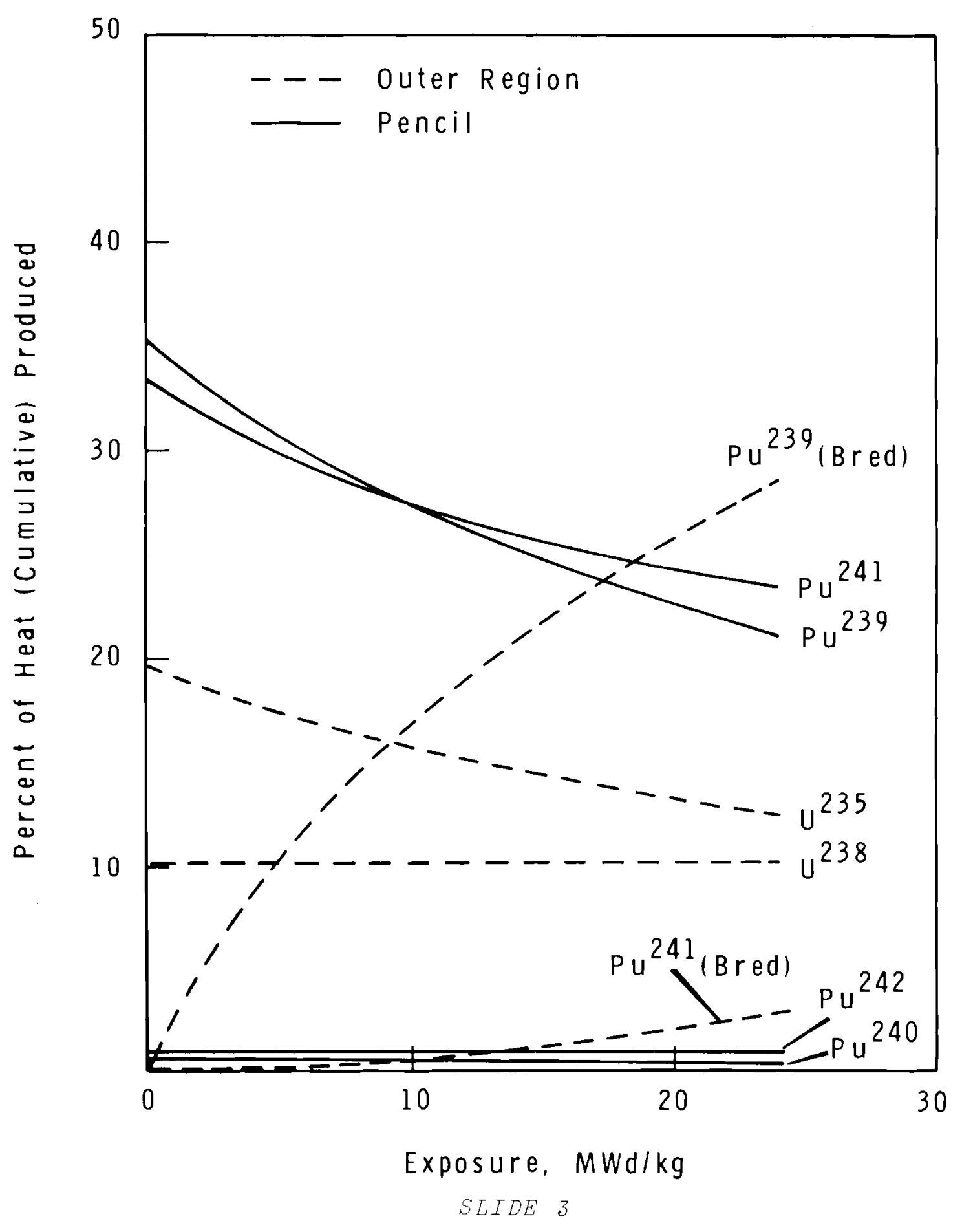


that is rich in $\mathrm{Pu}^{242}$. In this fue 1 the alpha of $\mathrm{Pu}^{242}$ is about 15 , whereas the alpha of the $\mathrm{pu}^{242}$ in low exposure plutonium is about 30 , and about 50 in the homogeneous mixture of plutonium-uranium fuels. The heat produced by pul2 in this high exposure plutonium is about $1 \%$ of the total; in the low exposure plutonium the heat produced by $\mathrm{Pu}^{242}$ is less than $0.1 \%$ of the total. (Because this amount is still small, it could not be shown in the previous slide.) In the homogeneous plutonium-uranium fuel, the heat produced by $\mathrm{Pu}^{242}$ is even lower-about $0.01 \%$ of the total fuel heat produced. The use of high exposure plutonium instead of low exposure plutonium has the effect of reducing the heat output of $\mathrm{Pu}^{239}$ by about $15 \%$ and of increasing the heat output of pu 241 by about $14 \%$. The reason for this is that the high exposure plutonium has a lower Pu ${ }^{239}$ content than the low exposure fuel. It should be noted, however, that the heat output from the plutonium formed during the burnup is about the same for both the high and low exposure fuel. Again, it should be pointed out that the fast fission cross section for the $\mathrm{Pu}^{242}$ in the inner fuel region was calibrated to match the results of the RBI data presented earlier by Mr. Merrill.

In Slide 4 we have plotted the effective alpha of two plutonium isotopes during the burnup of low exposure fuel. Each curve represents the average alpha of the entire fuel, with the alpha of the inner and outer regions being weighted by the heat produced in their respective regions. The starting point of the $\mathrm{Pu}^{239}$ curve represents the alpha of $\mathrm{Pu}^{239}$ in the inner fuel region. The average alpha of pu 239 rises quickly at the beginning of the burnup because the plutonium being formed in the outer region is unshielded, resulting in an alpha of about 0.57 for that region. However, the curve levels off because, as the burnup proceeds, the $\mathrm{Pu}^{239}$ in the outer region becomes shielded, causing the alpha in the outer region to drop to nearly 0.51 . During this entire time the alpha in the inner region remains almost constant.

The starting point of the pull curve represents the alpha of $\mathrm{Pu}^{241}$ in the inner fuel region. This entire curve represents the effect that cross shielding of outer region $\mathrm{Pu}^{239}$ and $\mathrm{Pu}^{241}$ has on inner region $\mathrm{Pu}^{241}$. The contribution to this curve from the outer region is small because of the small buildup of $\mathrm{Pu}^{241}$ in that region.

S1ide 5 shows a comparison of the integrated reactivity limited 1 ifetimes of homogeneous and $t$ ight pencil fuels. Notice that in these curves we are comparing three different tight pencil fuel situations. The tight pencil plutonium and the homogeneous plutonium represent low exposure fuels, and the tight pencil plutonium rich in pu 242 represents high exposure fuel. These situations are calculated for a moderator-to-fuel ratio of about 1.4. The third tight pencil fuel represents low exposure plutonium in a harder spectrum with a moderator-to-fuel ratio of about 0.94. Notice that the reactivity swing of the low exposure homogeneous plutonium fuel is slight 1 y more than that of enriched uranium. we notice next that the tight pencil 
INSTANTANEOUS AVERAGE OF PLUTONIUM ALPHAS IN BOTH

REGIONS OF TIGHT PENCIL FUEL

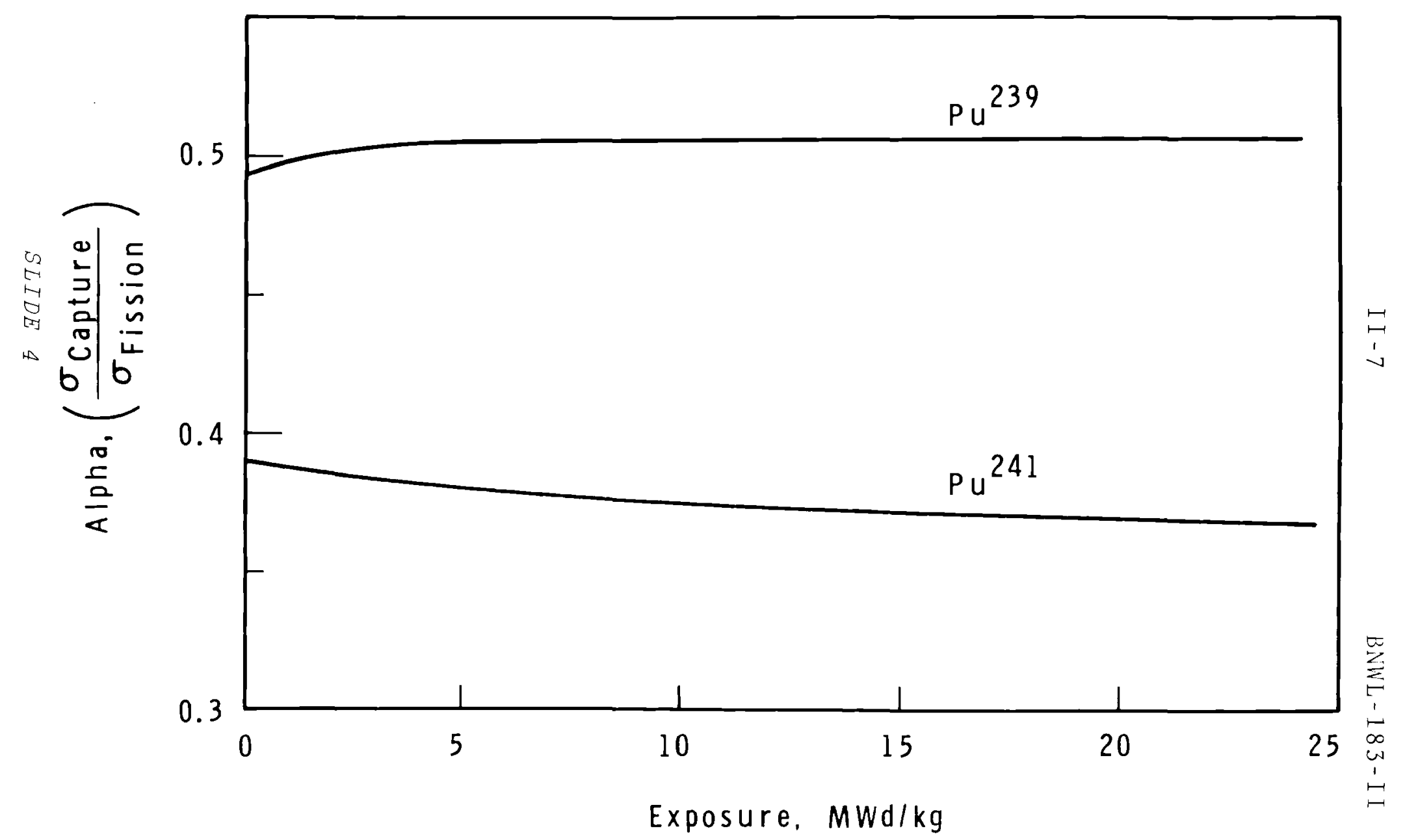


COMPARISON OF THE REACTIVITY LIMITED

LIFETIMES OF HOMOGENEOUS AND TIGHT PENCIL FUELS

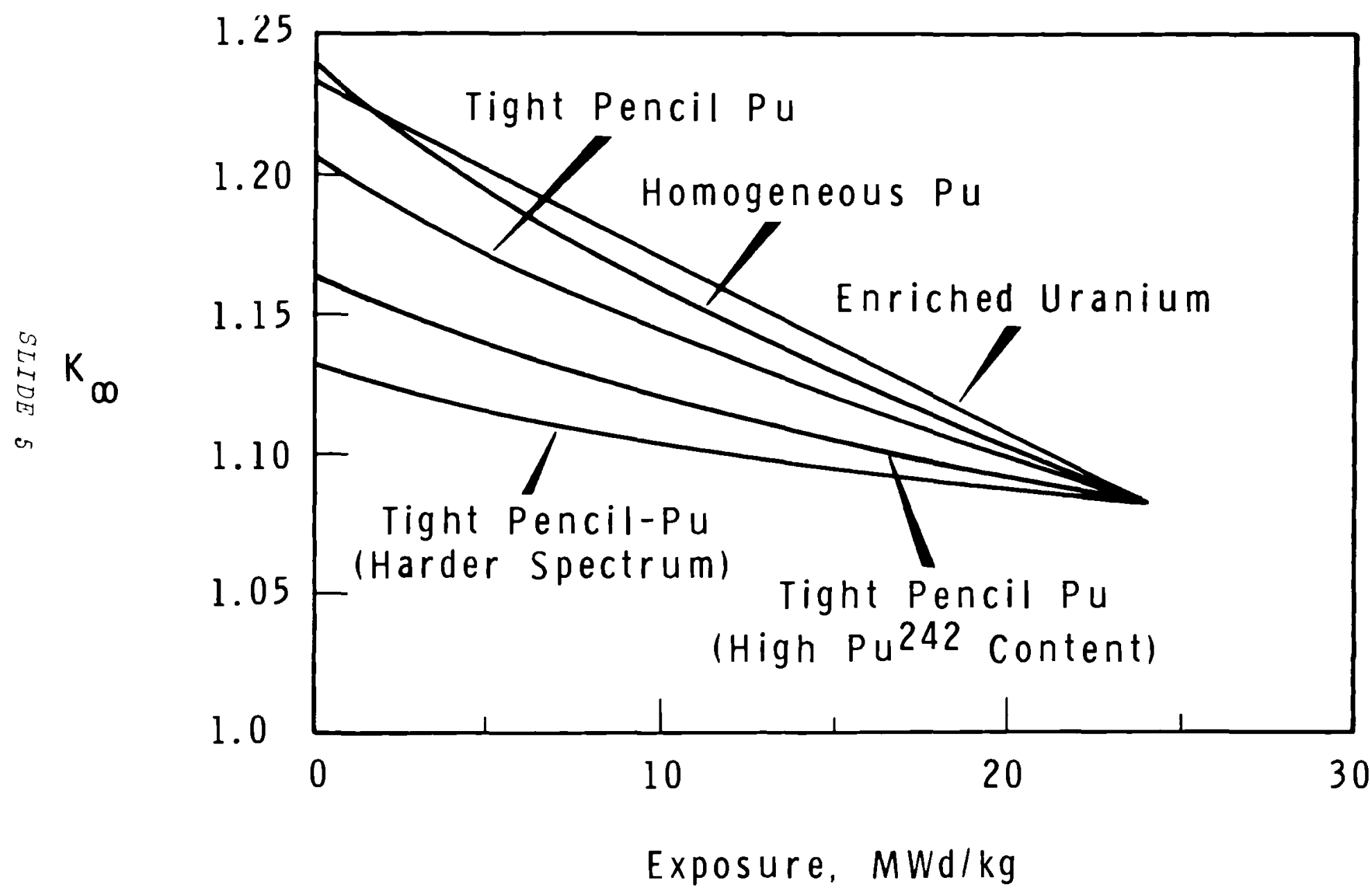

尸
$\vdots$
$\infty$ 
low exposure plutonium fuel has significantly lower, or better, reactivity swing than either of the two homogeneous fuels. There are two main reasons for the improved reactivity swing of the tight pencil low exposure plutonium fuel. One reason is that concentrating plutonium in the inner region of the fuel rod great $1 y$ decreases the cross section of plutonium in that region so that the initial reactivity is lower. The other reason is that plutonium formed in the outer region during the burnup is not as greatly depressed as that in the inner region. Because of this, the plutonium in the outer region helps to prevent the reactivity from decreasing during the burnup.

The tight pencil fuel high in $\mathrm{Pu}^{242}$ has a still better reactivity swing because the initial fissile content is lower and because there are gains both from the plutonium formed in the outer region and from the conversion of $\mathrm{pu}^{240}$ in the inner region. The curve with lowest reactivity swing represents low exposure plutonium pencil fuel in a tighter lattice. The reactivity swing is particularly low for the tight pencil plutonium fuel with a hard neutron spectrum because the cross section of the plutonium being formed in the outer region in the harder spectrum is larger than the cross section of plutonium in a soft neutron spectrum. The plutonium in the outer region therefore maintains the reactivity of the entire fuel at a nearly constant level. The plutonium in the inner region, with its resonances fully shielded even in soft spectrum, shows very little increase in cross section with the hardening of the spectrum.
Slide 6 shows the isotopic compositions of plutonium in the tight pencil configuration and in homogeneous fuels. At zero exposure the plutonium composition in the inner fuel region is $60 \%$ $\mathrm{Pu}^{239}, 18 \% \mathrm{Pu}^{240}, 17 \% \mathrm{Pu}^{241}$, and $5 \%$ $\mathrm{pu}^{242}$. Notice that in the inner region the percentage of $\mathrm{Pu}^{239}$ is decreasing because there is no $U^{238}$ as a source for new $\mathrm{Pu}^{239}$. Notice also that the plutonium composition in the outer region is predominately $\mathrm{pu}^{239}$. The composition of the combined regions after $24 \mathrm{MWd} / \mathrm{kg}$ exposure is $51 \% \mathrm{Pu}^{239}$, $27 \% \mathrm{Pu}^{240}, 15 \% \mathrm{Pu}^{241}$, and $7 \% \mathrm{Pu}^{242}$. Now comparing this plutonium composition with that from a $24 \mathrm{MWd} / \mathrm{kg}$ burnup of plutonium homogeneously mixed with natural uranium, we find that the pencil fuel has less $\mathrm{Pu}^{242}$ and more fissile content. The rather obvious point that should be made here is that the improvement in alpha of both $\mathrm{Pu}^{239}$ and $\mathrm{pu}^{241}$ tends to prevent the formation of $\mathrm{Pu}^{242}$.

We will now consider the effect of plutonium pencil fuel configurations on plutonium value. But before doing this, let us briefly review the technique for calculating plutonium value. Slide 7 demonstrates the calculation of a plutonium indifference value. Observe that we first calculate the fuel cost of a slightly enriched uranium cycle as a function of the plutonium credit. Of course, as the credit goes up, the fuel cost comes down. Then we take the plutonium that we discharged from such a uranium cycle, make it available to a plutonium cycle, and vary the credit in the same manner over the same range. When this is done we will observe an intersection of the two curves. At the plutonium 


\section{ISOTOPIC COMPOSITIONS FOR PLUTONIUM IN TIGHT PENCIL CONFIGURATION}

AND HOMOGENEOUS FUELS

Exposure MWd/kg

0

(Tight Pencil)

is 3.4 (Tight Pencil)

学 10.2 (Tight Pencil)

क 17.0 (Tight Pencil)

24.0 (Tight Pencil)

24.0 (Tight Pencil Core and outer Region Combined

24.0 (Homogeneous) $\frac{\text { Tight Pencil Composition }}{60-18-17-5}$

$57-20-17-6$

$53-24-16-7$

$49-27-16-8$

$44-31-16-9$ $\frac{\text { Outer Region Composition }}{0}$

$95-4-1-0$

$87-8-4-1$

$8 l-11-7-1$

$76-13-9-2$

$51-27-15-7$

$44-27-18-11$ 
FUEL COST AND ASSIGNED PU PRICE FOR A HYPOTHETICAL NON BREEDING REACTOR

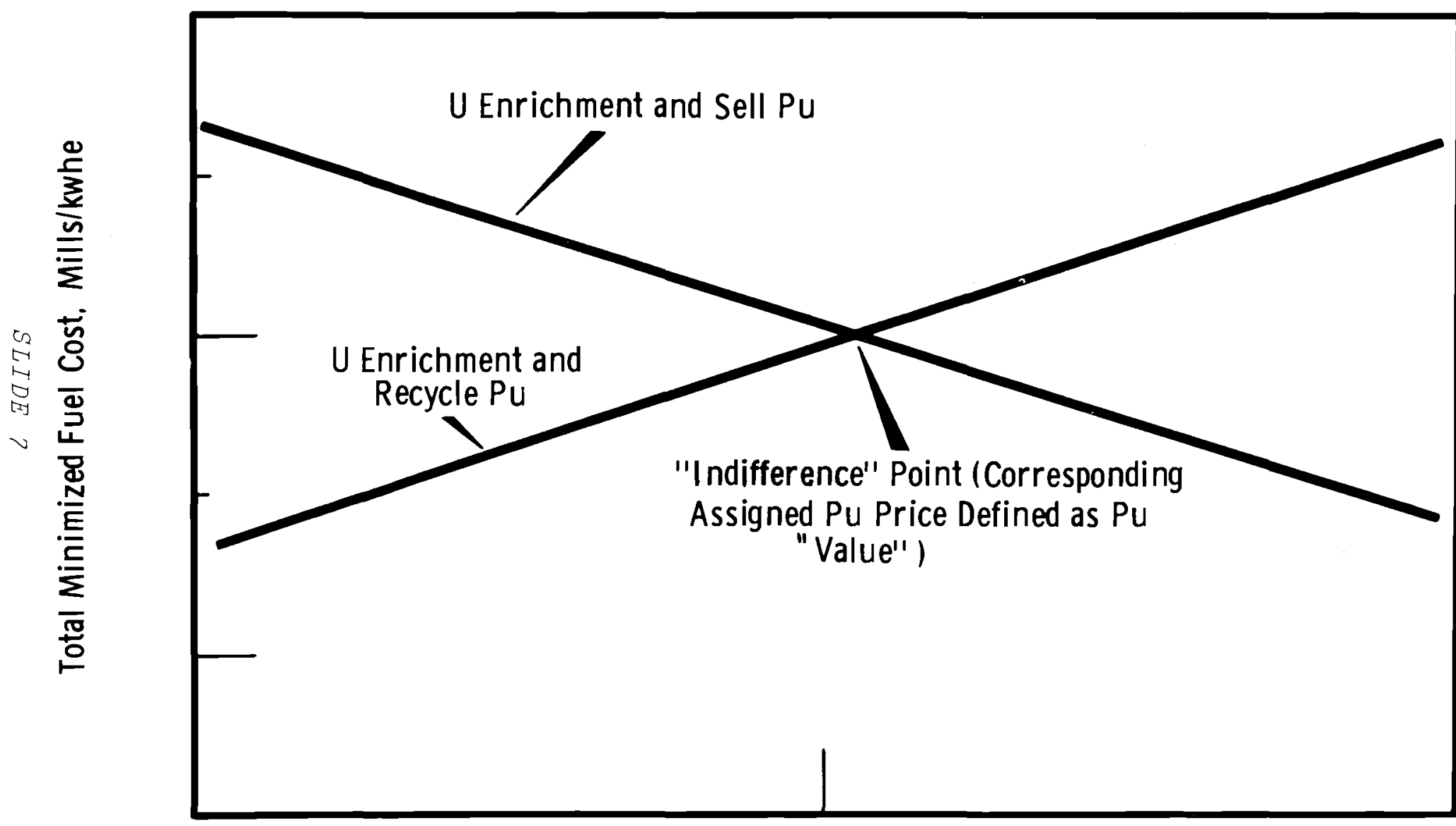

Assigned Pu Price, \$/gm Fissile 
credit corresponding to this intersection, a fuel cycle operator would be indifferent to whether he used a slightly enriched uranium cycle or a plutonium enriched cycle. His costs would be essentially the same. Of course, other problems may be involved if the fueling system is changed; and additional costs may be incurred which can injure the eventual market price for plutonium. To perform this calculation it is necessary to assume that the value of plutonium which enters the reactor is equal to the value of the plutonium that is discharged. Because the plutonium composition is changing radically as burnup proceeds, this is not a good assumption unt 1 equilibrium is reached. So to solve this problem a series of recycles are performed.

Let us now look at the diagram in Slide 8 , where the plutonium is represented as being taken out of the reactor and successively recycled, with slightly enriched uranium being used to make up the required enrichment deficit. In another technique (not shown in the slide) plutonium can be cycled by using fixed amounts of uranium enrichment and by using larger sources of plutonium than that discharged from a single reactor to make up the enrichment deficit necessary to continue the cycle. In either technique the composition of the recycled plutonium is continually changing. However, this change is regular and the first three plutonium isotopes $\left(\mathrm{Pu}^{239}, \mathrm{Pu}^{240}\right.$, and $\mathrm{Pu}^{241}$ ) having large cross sections come into equilibrium very rapidly. Pu ${ }^{242}$ does not come into equilibrium as quickly because it has a smaller cross section. When al1 four plutonium isotopes are in equilibrium, the value of plutonium discharged from one cycle can be set to that of the previous cycle, thus validating the original assumption of equilibrium. The next thing to be done is to solve a set of simultaneous equations which express the cost of each cycle as a function of a constant and two other coefficients, one being a function of the input plutonium value, the other a function of the discharged plutonium value. This set of equations is given in the bottom portion of the slide. By assuming that the fuel cost of all cycles must he equal, as in the indifference solution, and by solving the set of equations that have the appropriate end conditions, such as equilibrium, * the true plutonium values as functions of composition during the series of burnups are derived. The results of such calculations show a very positive correlation between the value of plutonium and the percent of $\mathrm{Pu}^{242}$ formed during the burnup. If we plot the value of plutonium as a function of the percent of $\mathrm{Pu}^{2+2}$ formed in four reactor types, we see the results shown in side 9 .

The slopes in this plot vary because the neutron spectrum in each of the reactor types has a different effect on the amount of $\mathrm{Pu}^{242}$ that is formed during the burnup. In the harder spectrum reactors, such as the PWR, the Pu ${ }^{242}$ has a larger micro-

* Ironically, at true equilibrium the straightforward solution of these equations must be altered. 
SCHEMATIC REPRESENTATION OF OPTIMIZED PLUTONIUM RECYCLE WITH

URANIUM ENRICHMENT

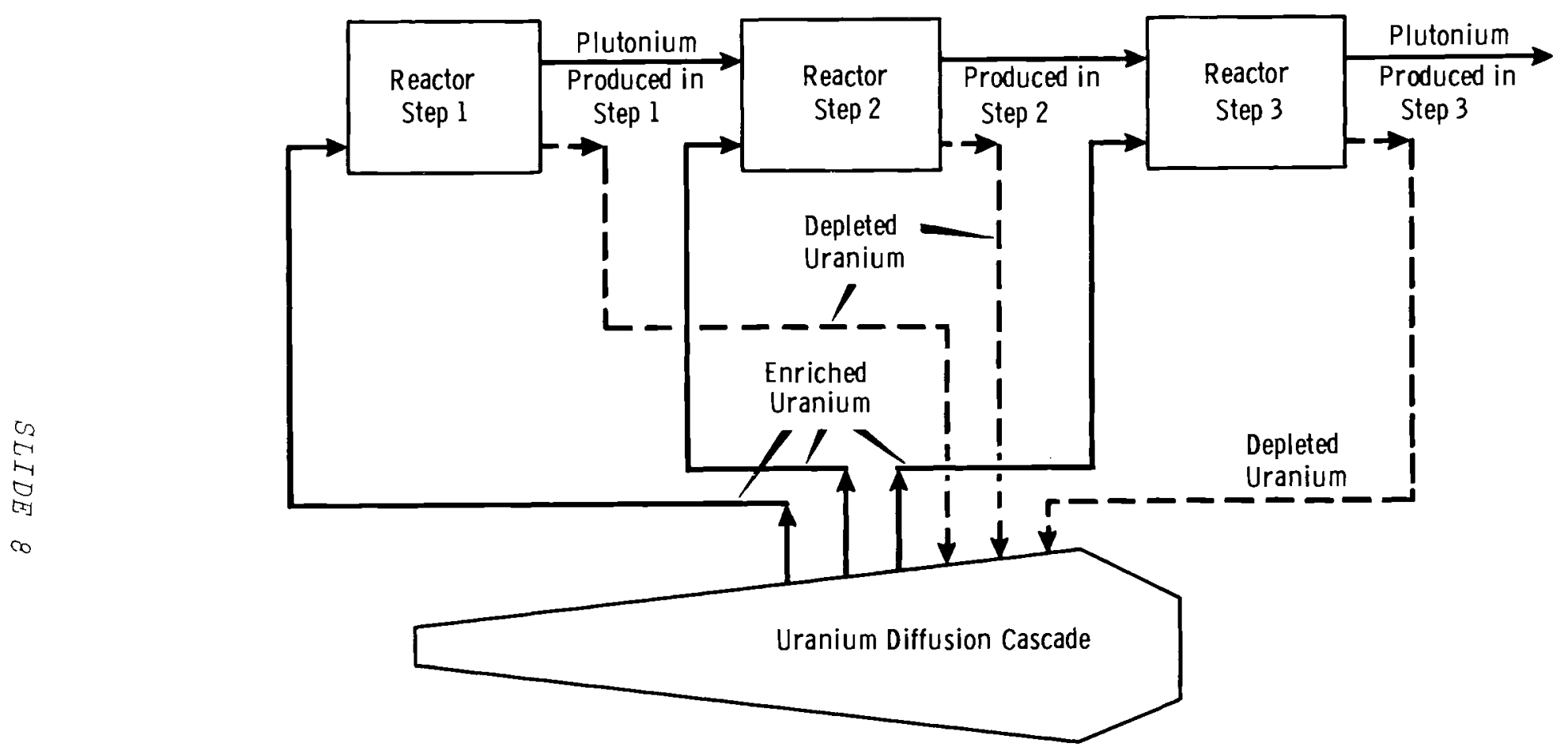

The enrichment of the Uranium supplied to each step is such that for a given Plutonium value the fuel cost is a minimum. The fuel cost for the ith step is:

$$
F_{i}=A_{i}+B_{i} x_{i-1}-C_{i} x_{i}
$$

Where $F_{i}$ is the fuel cost and $A_{j}, B_{i}$, and $C_{i}$ are constants. $X_{i-1}$ and $X_{i}$ are the values of the Plutonium supplied and discharged respectively.

Note that the value of the Plutonium supplied to a step is equal to the value of the Plutonium discharged from the previous step but is not, in general, equal to the value discharged from the step. 
PLUTONIUM VALUES VS PU242 CONTENT

(Recycle of Self-Produced Plutonium in Slightly Enriched Uranium)

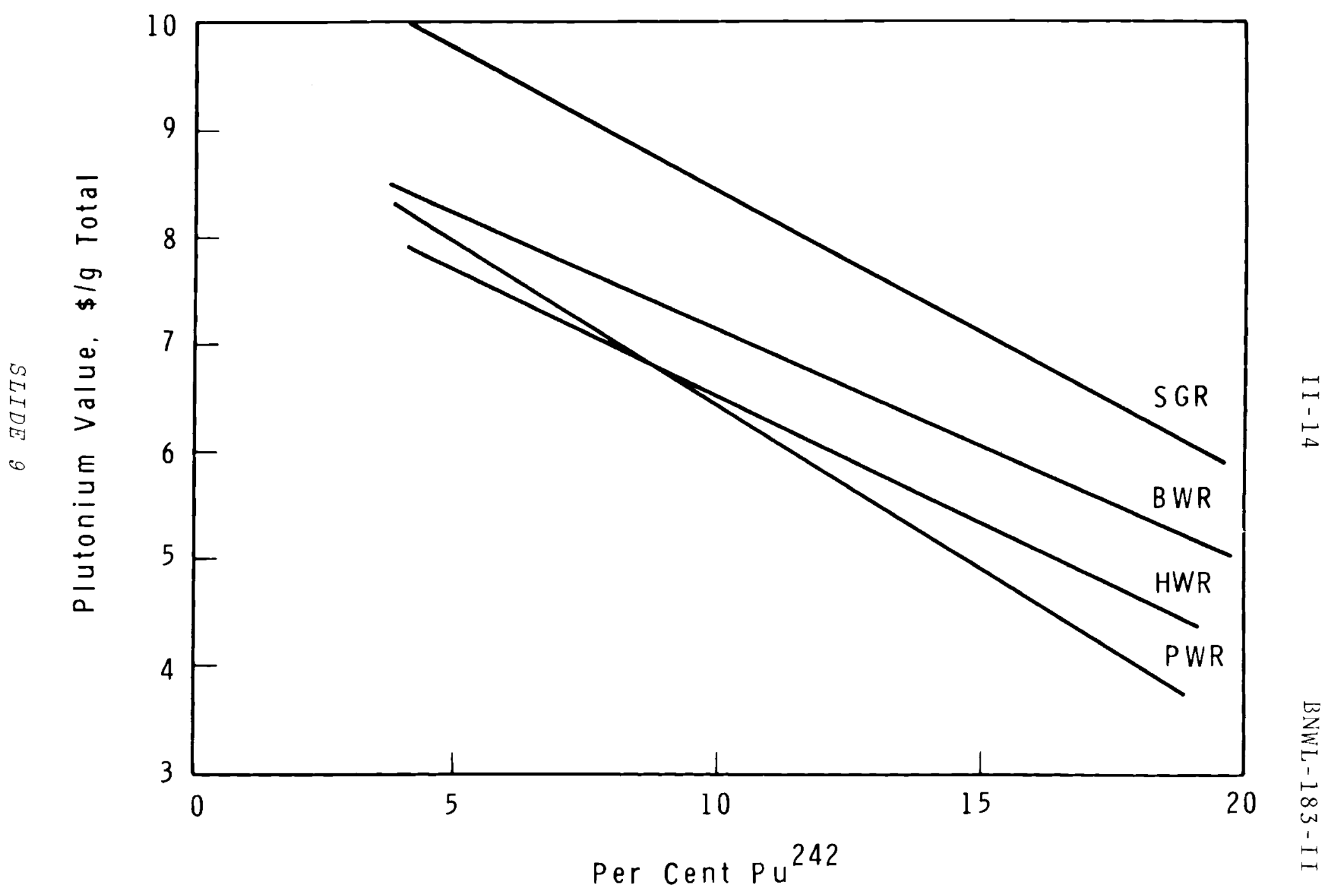


scopic cross section and is burned during the irradiation. Thus, the percent of $\mathrm{Pu}^{242}$ content in the fuel discharge is lower. In the soft spectrum reactor, such as the HWR, where the microscopic cross section is lower, the eventual equilibrium concentration is higher. The different heights of the 1 ines in the graph are due to the fact that the reactors have different neutron spectrums and nonfuel cross sections. In reactors such as the SGR, which has stainless steel cladding and therefore a high nonfuel cross section, the plutonium with a larger cross section than that of $\mathrm{U}^{235}$ will result in improved thermal utilization. Also, as the spectrum becomes harder, the cross section ratio of plutonium to $U^{235}$ becomes even greater. The higher thermal utilization is reflected as a higher plutonium value. However, this does not necessarily imply a lower fuel cost.

We will now consider how plutonium value is functionally related to thermal utilization, neutron spectrum, and $\mathrm{Pu}^{242}$ content in the reactors previously described. As shown in Slide 10, we have the constant A plus $B$ times a nonfuel absorption index (SNF), which is inversely proportional to thermal utilization. In the formula on Slide 10 , the nonfuel absorption index is divided by the slowing down power per unit volume of fuel, which is effectively the moderator-to-fuel ratio in a water reactor. The $A$ plus $B$ times SNF over SDPV portion of the equation represents the value of all isotopes in the fuel except $\mathrm{Pu}^{242}$. Thus, the plutonium value increases with SNF, as we have already seen in the case of the SGR, which has stainless steel cladding. The plutonium value decreases with an increase in SDPV. In that portion of the equation in brackets, C plus D over SDPV is multiplied by the fraction of Pu 242 in the fuel. This last half of the equation represents the $\mathrm{Pu}^{242}$ contribution to the plutonium value. Note that this contribution is negative. Thus, as the fraction of $\mathrm{Pu}^{242}$ increases, the plutonium value declines. This decline is partly due to the poisoning effect of $\mathrm{Pu}^{242}$ cross section. Also, as the SDPV decreases, the spectrum becomes harder, and the effect of $p u^{242}$ is magnified by an increase in the $\mathrm{Pu}^{242}$ cross section.

In Slide 11 we show the effect of alpha improvement on plutonium values for self-produced recycle of two fuel configurations in a pressurized water reactor having a moderator-to-fuel ratio of 1.4. That the plutonium values shown in the side are higher for tight pencil fuel $(\$ 12.40$ and $\$ 10.85$ per gram fissile) than for homogeneous fuel $\$ 10.00$ and $\$ 9.21$ per gram fissile) is due only to an improvement in the alpina of $\mathrm{Pu}^{239}$. From these numbers we conclude that the improvement in plutonium value will be near $20 \%$. llowever, this calculation does not include the effect of an inventory increase due to a decrease in plutonium cross section. On the other hand, neither does this calculation include any credit for the improvement in reactivity swing in terms of neutron economy or reduced control requirements. We are pres. 


$$
\begin{aligned}
P u \text { Value }=A+B & \frac{S N F}{S D P V}-\left[C+\frac{D}{S D P V}\right] \times 242 \text { Fraction } \\
S N F= & \text { Non-Fuel Absorption Index } \\
S D P V= & \begin{array}{l}
\text { Moderator Index } \\
\quad \text { Low Value }=\text { Hard Neutron Spectrum) }
\end{array}
\end{aligned}
$$

Fits Within 30 to $40 \%$ 
PLUTONIUM VALUES FOR SELF-PRODUCED RECYCLE (TWO FUEL CONFIGURATIONS IN A PRESSURIZED WATER REACTOR)

\begin{tabular}{|c|c|c|c|c|c|}
\hline & u Compo & tion, $\%$ & & Homogeneous & Tight Pencil \\
\hline$P u-239$ & $P u-240$ & $P u-24 l$ & $P u-242$ & $a_{49}=0.55$ & $\alpha_{49}=0.50$ \\
\hline 63 & 22 & 12 & 3 & 10.60 & 12.40 \\
\hline 49 & 24 & 16 & 11 & 9.21 & 10.85 \\
\hline
\end{tabular}


ent $1 y$ developing techniques to assess the effects that reactivity swing has on the fuel cost. For this reason, no fuel cost comparisons are made at this time. The effect of reduced reactivity swing would be of particular interest to reactor operators who are presently using sightly enriched uranium and who in the future would be considering plutonium recycle fueling.

Slide 12 shows the effect of $\mathrm{Pu}^{242}$ alpha on the $\mathrm{Pu}^{242}$ coefficient in the plutonium value equation explained earlier. Plutonium pencil fuel configurations make possible the burning of some $\mathrm{Pu}^{242}$. In the past, for purposes of estimating the minimum value of plutonium in thermal reactors, $\mathrm{Pu}^{242}$ was regarded as a parasite leading to higher isotopes $\left(\mathrm{Cm}^{244}\right.$, for example) of no economic value. The burning of $\mathrm{Pu}^{242}$ is a result of an improvement in its alpha in the pencil configuration fue $1 \mathrm{~s}$. If $\mathrm{Pu}^{242}$ is to contribute as a fuel, one would expect that the variation in plutonium value with $\mathrm{Pu}^{242}$ content would decrease. Thus, we note in the slide that as the alpha of $\mathrm{Pu}^{242}$ decreases, the slope a1so decreases. In particular, note that the slope for an alpha of 5 is nearly one-half that of an alpha of 50. This indicates the gains that may be possible.

By way of summary, it should be noted that the gains of a tight pencil configuartion cannot be secured unless the gain in eta (by reducing alpha), the flattening of the reactivity swing, and the decrease in cross section are combined into an optimum. The study just described has by no means treated the best configuration of each fuel. However, it appears that the lumping of plutonium within fuels does add a valuable versatility to plutonium fueling of thermal reactors. For in pencil fuels the cross section of plutonium can be adjusted both for a better match of plutonium fission rate with the $f$ ission rates of $U^{235}$ and $U^{233}$ and for a reduction in the alpha of $\mathrm{Pu}^{239}$. But it should be noted that this reduction in cross section increases the plutonium inventories required. Pencil fuels also offer the possibility of fissioning a significant amount of $\mathrm{Pu}^{242}$ in thermal reactors. Final1y, it appears that the reactivity swings of pencil fuels are substantially less than those of homogeneous plutonium fue $1 \mathrm{~s}$. 


\section{EFFECT OF PU ${ }^{242}$ ALPHA ON THE Pu 242 COEFFICIENT IN THE PLUTONIUM VALUE* EQUATION}

$\begin{array}{cc}\frac{\text { Alpha Pu242 }}{50} & \frac{\text { E, Slope }}{0.274} \\ 25 & 0.249 \\ 10 & 0.214 \\ 5 & 0.164 \\ \text { * Pu Value }=A+B & \frac{\text { SNF }}{\text { SDPV }}-E(\% P u 242)\end{array}$


.

. 
SECTION III

\section{A COMPARISON OF FUEL CYCLES FOR CROSSED-PROGENY FUELS IN CONVENTIONAL AND NOVEL CONFIGURATIONS}

D. E. Deonigi

Battelle Memorial Institute Pacific Northwest Laboratory Richland, Washington

November, 1965

Paper for oral presentation at the American Nuclear Society 1965 Winter Meeting

Washington, D.C., November 15-19, 1965 


\section{A COMPARISON OF FUEL CYCLES FOR CROSS-PROGENY FUELS * IN CONVENTIONAL AND NOVEL CONFIGURATIONS}

\section{E. Deonigi ${ }^{* *}$}

Water reactors are usually thought of as producing low cost powe $r$ and as having high fuel cycle costs with low conversion ratios. However, recent studies with optimized lattices indicate that a pressurized water reactor may reduce its fuel cycle cost and increase its fue 1 conversion ratio by burning $U^{233}$ mixed with natural uranium instead of burning slightly enriched uranium. Our studies indicate further that plutonium-thorium may be attractive fue 1 in a $\mathrm{D}_{2} \mathrm{O}$ moderated reactor. Plutonium-thorium in a $D_{2} \mathrm{O}$ reactor has been found to have a fuel cycle cost equal to that of slightly enriched uranium fuel but with a better conversion ratio. These two improved fueling methods could even complement each other, since the discharge from one could be made to serve as fuel for the other, the $D_{2} O$ reactor supplying $\mathrm{U}^{233}$ and the PWR that burns $\mathrm{U}^{233}$ supplying plutonium. We refer to

* This paper is based on work performed under United States Atomic Energy Commission Contract AT(45-l)-2830. Permission to publish is gratefully acknowledged.

* Senior Research Engineer, Physics and Instruments Department, Pacific Northwest Laboratory, operated by Battelle Memorial Institute for the United States Atomic Energy Commission, Richland, Washington. these plutonium-thorium and $U^{233}$. natural uranium fueling systems as crossed progeny systems; they have also been referred to as cross-over sys tems.

Now, before comparing different crossed progeny fueling methods, let us first consider the technique used to determine the optimum moderatorto-fuel ratio of a reactor. In the examples that follow we will use a wate $r$ reactor fueled with slightly enriched uranium. The first slide shows the total fue 1 cost and its components as a function of fue 1 exposure. Upon inspecting the total fuel cost curve, we see two minimum points, one labeled the mathematical, the other the "backed-up" minimum point, both of which have been determined by a computer searching technique. The position of the backed-up minimum point shows that for a large reduction in fuel exposure from the mathematical minimum, only a small fue 1 cost penalty $\left(0.1 \mathrm{mill} / \mathrm{kWh}_{\mathrm{e}}\right)$ is incurred. This is because the curve around the mathematical minimum is quite flat. Currently, fuel technology is such that reduced fuel exposures are attractive. With fue 1 durability improvements, one could expect the mathematical minimum operating point to reduce fuel hand1 ing and reactor shut downs. Now, since each moderator-to-fuel ratio 

TYPICAL FUEL COST DATA AS A FUNCTION OF FUEL
EXPOSURE

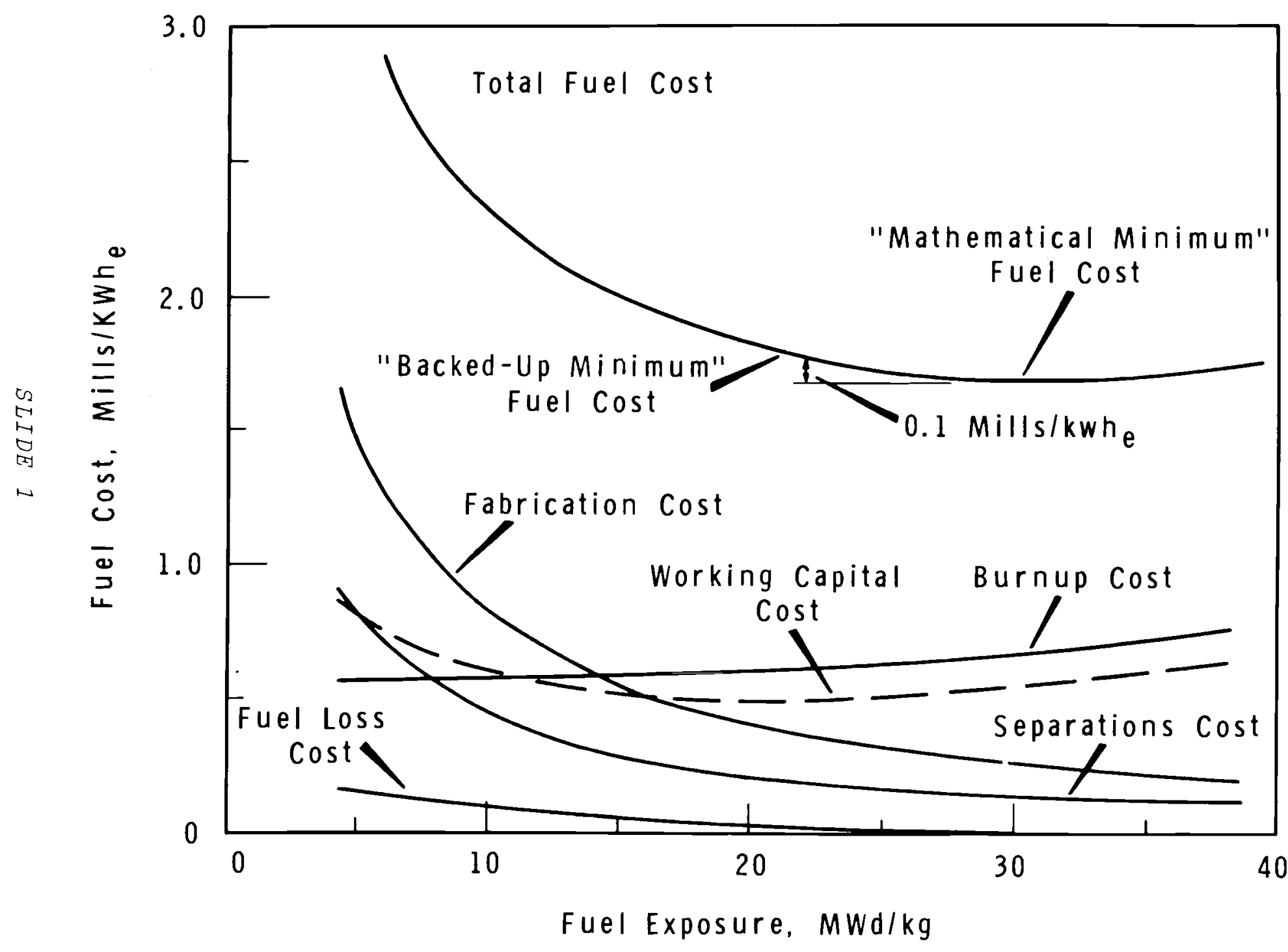


will have a backed-up minimum point, we can determine the optimum moderator-to-fuel ratio by plotting these backed-up minimum points on a line as shown in slide 2 , which is a three-dimensional plot. Notice that the optimum moderator to fuel ratio for this water reactor using slightly enriched uranium is 1.7 ; at this point, both the fuel cost and the fuel exposure are optimized. It should be noted, however, that the slide does not include a correction for differences in the neutron leakage rate as the reactor size changes with the moderator-to-fuel ratio. Also, there is no correction for the significant cost differences due to the pressure vessel size changing with the moderator-to-fuel ratio. For our purpose, however, it suffices to say that the end cost effects of these differences move in opposite directions and, to some extent at least, they cancel each other.

The third slide shows that a change in plutonium credit has more effect on the optimum moderator-tofue 1 ratio than a change in processing costs. For example, if the plutonium credit is doubled--say from 8 to 16--the optimum moderator-to-fuc 1 ratio may be reduced as much as $10 \%$. llowever, doubling the processing costs (which include fabrication and shipping costs) causes on 1 y a small change in the optimum moderator-tofuel ratio. It is in the fuel cycle costs where doubling the processing costs would be primarily felt, not in the optimum moderator-to-fuel ratio.

So far we have briefly described the technique used for determining the optimum cost situation, describing at the same time how changes in processing costs and plutonium credit would affect the optimum moderatorto-fuel ratio, or what is the same thing, the optimum lattice spacing. Now let us compare $U^{233}$ crossed progeny fuel with some other fueling schemes in a pressurized water reactor.

In Slide 4, the curve representing slightly enriched uranium fuel is used as our reference. This curve is based on a plutonium credit of $\$ 10 / \mathrm{g}$ fissile and on processing costs of $\$ 116 / \mathrm{kg}$. To allow for special processing difficultics, we have based all other curves on processing costs that are $10 \%$ more than the reference curve. The plutonium credit, however, is the same for all curves, namely, $\$ 10 / g$ fissile. Among these curves one notices at once that the $u^{233}$-natural uranium fuel has the lowest fuel cost (this curve published in the Transactions of this meeting is mislabeled) and that the plutonium-thorium fuel has a much higher cost. This is due to the high enrichment reyuirement. Notice, too, that the $U^{23.3}$-thorium fuel has a higher fuel cost than plutoniumthorium fuel, even though the former has a higher conversion ratio. The reas on is twofold: $U^{233}$ is more expensive than plutonium, and more $\mathrm{U}^{233}$ is required as enrichment because $U^{233}$ has a smaller cross section than plutonium. Both of these curves, by the way, are based on a $\mathrm{U}^{233}$ price of $\$ 14 / \mathrm{g}$ fissile.

Now let us look at the plutoniumnatural uranium and the slightly 


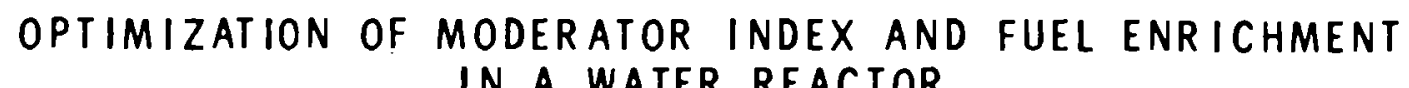

IN A WATER REACTOR

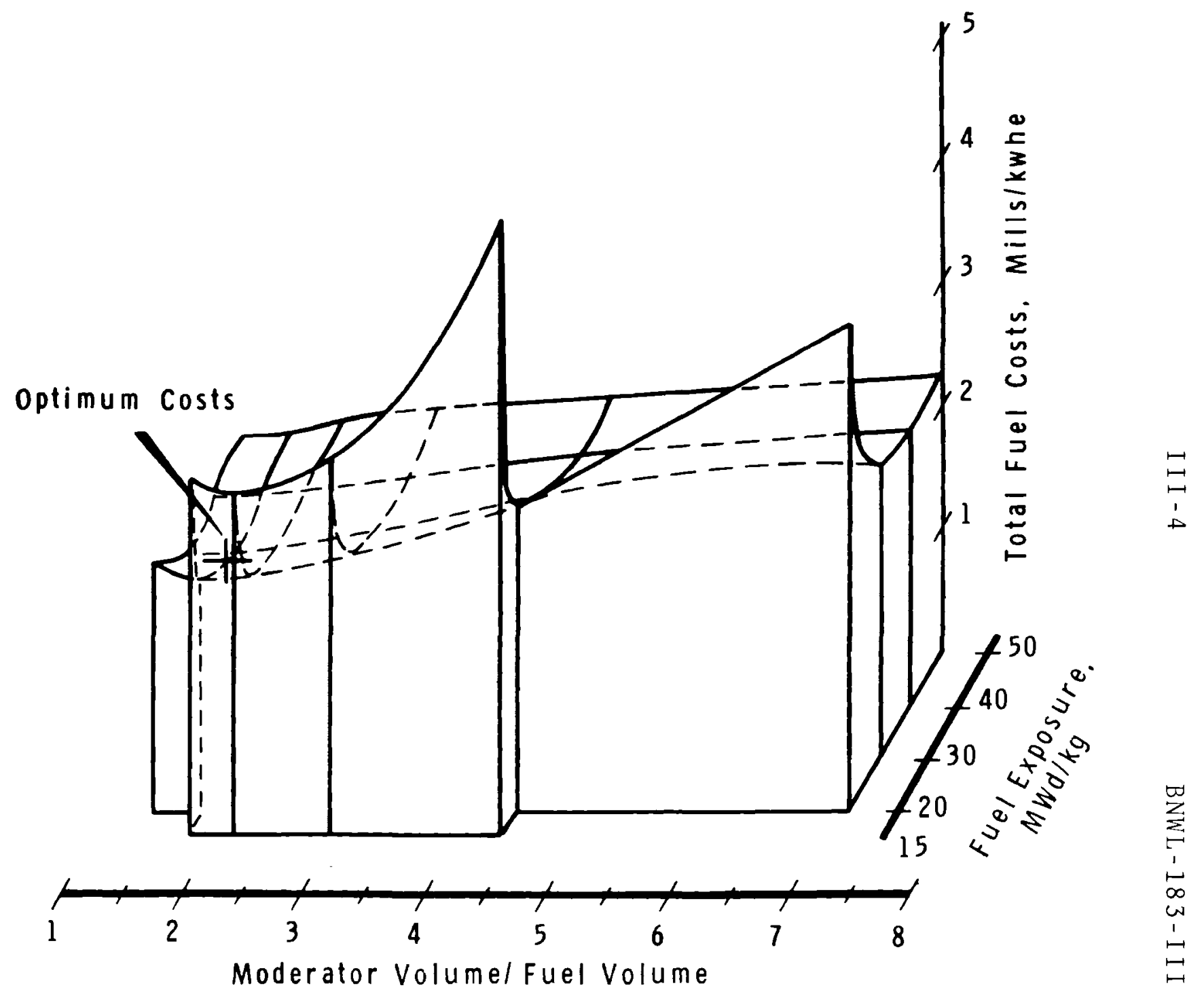


THE EFFECT OF PROCESSING COSTS AND PLUTONIUM PRICE ON THE OPTIMUM MODERATOR VOLUME/FUEL VOLUME RATIO

\begin{tabular}{|c|c|c|c|}
\hline $\begin{array}{l}\text { Processing } \\
\text { Costs, } \$ 1 \mathrm{~kg} \\
\end{array}$ & $\begin{array}{c}\text { Plutonium } \\
\text { Price } \$ / g m \text { Fissile } \\
\end{array}$ & $\begin{array}{l}\text { Optimum } \\
\text { M/F Ratio }\end{array}$ & $\begin{array}{c}\text { Fuel Cycle } \\
\text { Costs } \\
\end{array}$ \\
\hline 129 & 16 & 1.593 & 1.660 \\
\hline 129 & 14 & 1.638 & 1.689 \\
\hline 129 & 10 & 1.705 & 1.744 \\
\hline 129 & 8 & 1.728 & 1.769 \\
\hline 71 & 16 & 1.594 & 1.412 \\
\hline 71 & 14 & 1.661 & 1.452 \\
\hline 71 & 10 & 1.750 & 1.522 \\
\hline 71 & 8 & 1.772 & 1.554 \\
\hline
\end{tabular}




\section{MINIMUM FUEL COST AS A FUNCTION OF MODERATOR-TO-FUEL RATIO FOR VARIOUS PWR FUELING SYSTEMS}

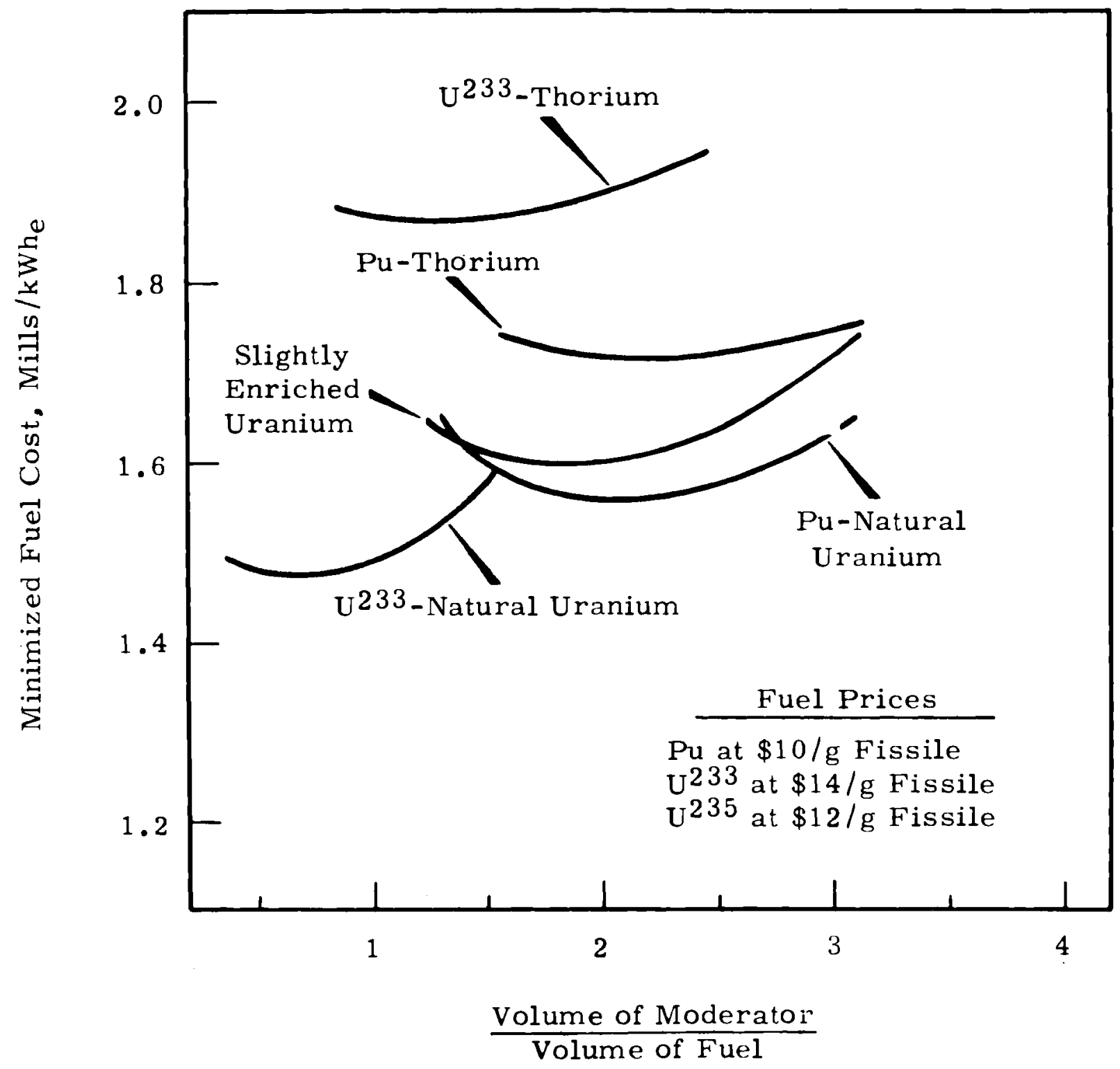


enriched curves. As mentioned before, the plutonium price is assumed to be $\$ 10 / \mathrm{g}$ fissile. But since this price is based on the use of slightly enriched uranium as a reference, it appears that, at the point where each fuel has the optimum moderator-to-fue 1 ratio, the price of plutonium would have to be higher than $\$ 10 / \mathrm{g}$ fissile before the two fuels would have the same fuel $\cos t$.

In the case of the $U^{233}$-natural uranium fue1, the optimum moderatorto-fue 1 ratio is 0.6 , whereas that of slightly enriched uranium is 1.7 . The reason the $U^{233}$-natural uranium fue 1 finds such a low optimum moderator-to-fuel ratio is that the $\alpha$ of $\mathrm{U}^{233}$ is unaffected by the hard spectrum, while the gains from $\mathrm{U}^{238}$ fast fissions and, to some extent, from $U^{233}$ fast fissions are appreciable. On the other hand, the high a of $\mathrm{Pu}^{239}$ in both the plutonium-natural uranium and slightly enriched uranium cases tends to drive the minimum fuel cost to a higher moderator-to-fuel ratio where the $\alpha$ of $\mathrm{Pu}^{239}$ would be lower. The fast effect in the $\mathrm{U}^{233}$-natural uranium fue 1 at a $M / F$ ratio of 0.6 is about 1.11. A calculation that agrees with experimental data indicates that the $\mathrm{U}^{238}$ fast effect is 1.10 in a water reactor lattice where the $M / F$ ratio is 0.6 , with the remaining fast effects of about 0.01 being due to. $U^{233}$ and plutonium fast cross sections.

Slide 5 shows the average conversion ratio and the initial enrichment of $U^{233}$-natural uranium fue 1 in a water reactor lattice. The top curve points out that the average conversion ratio decreases as a longer fue 1 exposure causes more plutonium to be formed during the burnup. The average conversion ratio is initia11y more than 1.0 because of the high $\eta$ of $\mathrm{U}^{233}$. The curve shows that by the time the exposure reaches $15 \mathrm{MWd} / \mathrm{kg}$, the average conversion ratio is 0.94 . The bottom curve indicates that at this same exposure of $15 \mathrm{MWd} / \mathrm{kg}$ the enrichment is only about $2 \%$ because of the high fast effect.

In S1ide 6 the average neutron balance is given for a $15 \mathrm{MWd} / \mathrm{kg}$ exposure for natural uranium enriched with $U^{233}$, which has an initial $n$ equal to 2.2. After the start of the burnup, the average $n$ is reduced, giving an average $n$ of 2.0 for the entire $15 \mathrm{MWd} / \mathrm{kg}$ exposure. This $\mathrm{n}$ of 2.0 and the fast effect, which is slight 1 y above 1.1 , yield a total fission neutron availability of about 224 neutrons, assuming a total of 100 neutrons being absorbed in the fis sile materials. During the burnup on $1 y 33 \%$ of the fissile absorptions take place in $\mathrm{Pu}^{239}$ atoms. The 124 neutrons available for nonfissile absorption are mostly absorbed in $\mathrm{U}^{238}$. The fact that $\mathrm{U}^{238}$ has a very large cross section in this spectrum where the $M / F$ ratio is 0.6 tends to increase the conversion ratio. It also reduces the loss of neutrons to water and cladding, a loss already low because of the very low $M / F$ ratio. The control and leakage losses are based on an average reactivity loss of about $65 \mathrm{mil1i-k}$. It may be noted here that the reactivity change in 
AVERAGE CONVERSION RATIO OF U 233 ENR ICHED NATURAL URANIUM FUEL IN PWR WITH MODERATOR VOLUME/FUEL

VOLUME $=0.6$

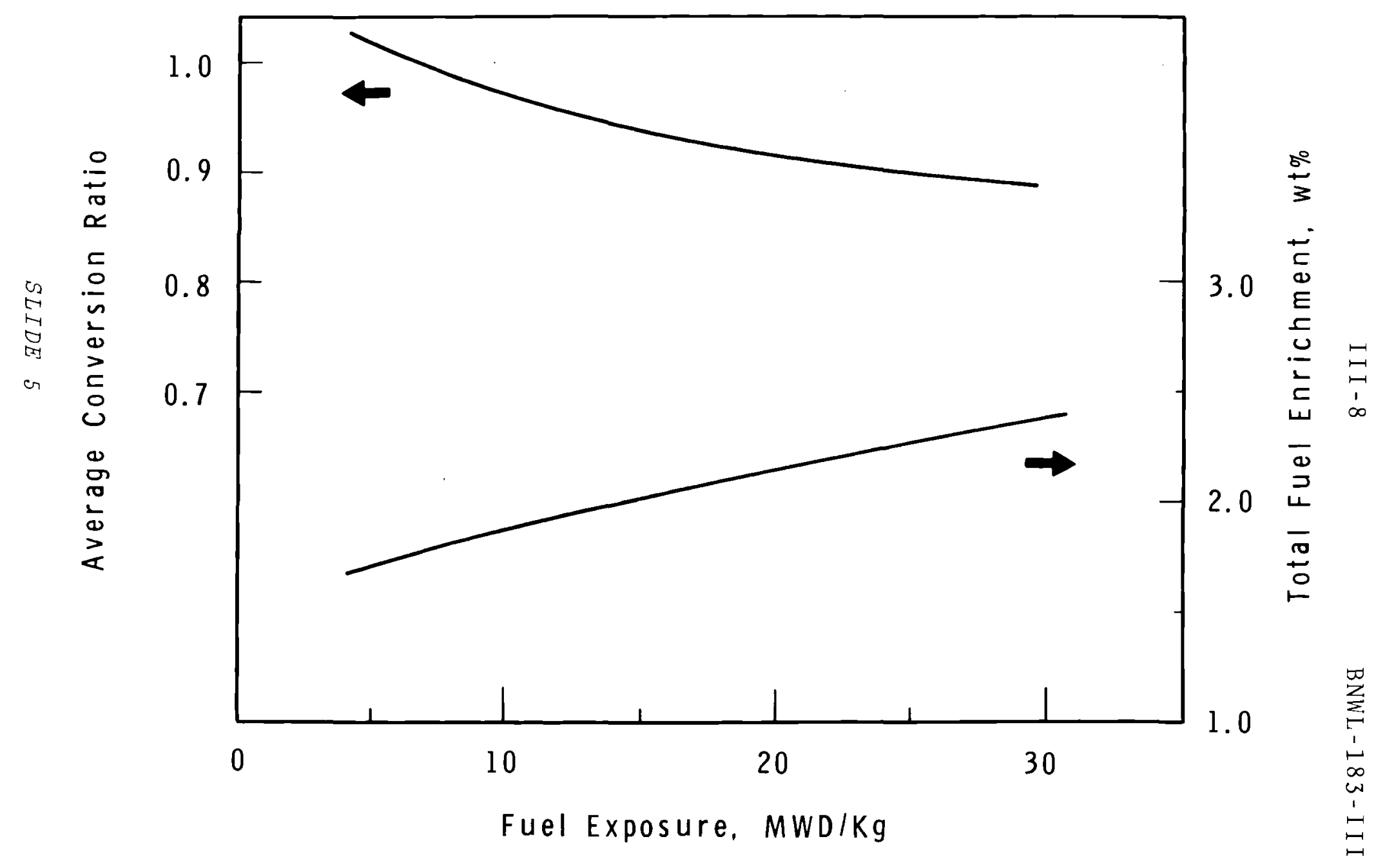




\section{NEUTRON BALANCE FOR U ${ }^{233}$ ENR ICHED NATURAL URANIUM FUEL IN PWR WITH MODERATOR VOLUME/FUEL VOLUME $=0.6$ \\ (Fuel Exposure 15,000 MWD/MT) \\ Based on 100 Neutrons Absorbed in Fissile Materials}

Fission Neutrons Formed

$$
\begin{aligned}
& U-233 \quad 99.8 \\
& U-235 \quad 35.7 \\
& P u-239 \quad 61.6
\end{aligned}
$$

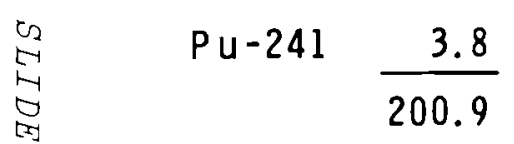

$$
\begin{aligned}
& \text { a From } \\
& \text { "Fast Effect" } \frac{23.1}{\overline{224.0}}
\end{aligned}
$$

\section{Neutrons Lost to Fertile Materials}

$$
\begin{array}{lr}
U-238 & 88.0 \\
\mathrm{Pu}-240 & 5.2 \\
\hline & 94.2
\end{array}
$$

Neutrons Lost to Non Fertile Materials

$$
\begin{array}{cc}
\text { U-236 } & 0.4 \\
\text { Pu-242 } & 0.1 \\
\text { Higher I sotopes } & \frac{0.2}{0.6}
\end{array}
$$

Non-Fuel Absorption and Leakage of Neutrons

Neutrons Absorbed in Fissile Isotopes

$$
\begin{array}{lr}
U-233 & 45.6 \\
U-235 & 19.3 \\
\text { Pu-239 } & 33.4 \\
\text { Pu-241 } & \frac{1.7}{100.0}
\end{array}
$$
$S M+X E$
4.0
other FP
7.8
Cladding and Moderator
4.7
Control and Leakage
$\frac{12.7}{29.2}$ 
$\mathrm{U}^{233}$ natural uranium fuel during burnup is very similar to that of slightly enriched uranium fuel. The reason is that plutonium is being formed during the burnup; and the fact that plutonium has a higher cross section than $U^{233}$ tends to reduce the change in reactivity.

Slide 7 shows the effect that changes in $\mathrm{U}^{233}$ or plutonium prices would have on the fuel cycle cost of $\mathrm{U}^{233}$-natural uranium fuel. So far we have assumed a price of $\$ 10 / \mathrm{g}$ fissile for plutonium and $\$ 14 / \mathrm{g}$ fissile for $\mathrm{U}^{233}$. As the slide indicates, a price increase for plutonium from $\$ 10 / \mathrm{g}$ fissile to $\$ 14 / \mathrm{g}$ fissile would reduce the fuel cycle cost about $0.04 \mathrm{mills} / \mathrm{kWh}_{\mathrm{e}}$. But a $\$ 4 / \mathrm{g}$ fissile increase in the $U^{233}$ price--namely from $\$ 14 / \mathrm{g}$ fissile to $\$ 18 / \mathrm{g}$ fissile-would raise the fuel cycle cost $0.32 \mathrm{mill} / \mathrm{kWh}$, or about 8 times more than an equivalent plutonium price increase. $U^{233}$ would have to be priced at $\$ 16 / \mathrm{g}$ fissile in order to make its fuel cycle cost equal to that of slightly enriched uranium, assuming that both fueling schemes each have their respective optimum $M / F$ ratios.

We have also assumed thus far that both $U^{233}$ and natural uranium are mixed to form a composite fuel. But we have not yet considered what the effect on fuel cycle cost would be when the $0.7 \% U^{235}$ in natural uranium is eventually depleted and the entire fuel enrichment must be supplied by the more expensive $\mathrm{U}^{233}$. According to our calculations, the depletion of $\mathrm{U}^{235}$ in this fuel would cause the fuel cycle cost to be $0.06 \mathrm{mills} / \mathrm{kWh} \mathrm{e}$ higher for $U^{233}$ priced at $\$ 14 / g$ fissile. To avoid mixing $U^{233}$ with natural uranium, we are investigating the possibility of physically separating the two components during fuel fabrication. In this type of fuel configuration, the $U^{233}$ might be placed in an annulus of its own near the outside of the fuel element.

So far we have only been concerned with a pressurized water reactor, where plutonium-thorium is not a particularly attractive fuel. We will now consider plutonium-thorium fue 1 in a $D_{2} O$ moderated reactor. Unlike a PWR, this reactor operates with low neutron temperatures and with a soft spectrum, both of which are more favorable to plutonium as regards capture to fission and to $\mathrm{Pu}^{233}$ as regards absorption.

SIide 8 lists the minimum fuel cycle costs of various fuels in a $D_{2} \mathrm{O}$ reactor. In this table we find that slightly enriched uranium, or $\mathrm{U}^{235}$ $\mathrm{U}^{238}$, fuel has the lowest fuel cost except for plutonium thorium in a tight pencil configuration. This novel fuel configuration has the same fuel cost as uniformly mixed $\mathrm{U}^{235}$. $\mathrm{u}^{238}$. Each minimum fuel cost shown represents the backed-up minimum cost explained in the first slide. These costs also include the price of $\mathrm{D}_{2} \mathrm{O}$ at $\$ 20 / 1 b .{ }^{*}$ At this price the cost of $\mathrm{D}_{2} \mathrm{O}$ amounts to $0.45 \mathrm{mills} / \mathrm{kwh}$ f for the moderator-to-fuel ratio of 23 used in these calculations. Conse-

* D,O is carried as a fuel cost here because the optimum moderator ratio is being selected. If fixel moderator situations were being analyzed, the price of $D_{2} O$ could be omitted from the comparison. 
FUEL CYCLE COST AS A FUNCTION OF PLUTONIUM PRICE AND THE PRICE OF U233 ENRICHMENT OF NATURAL URANIUM IN A PWR

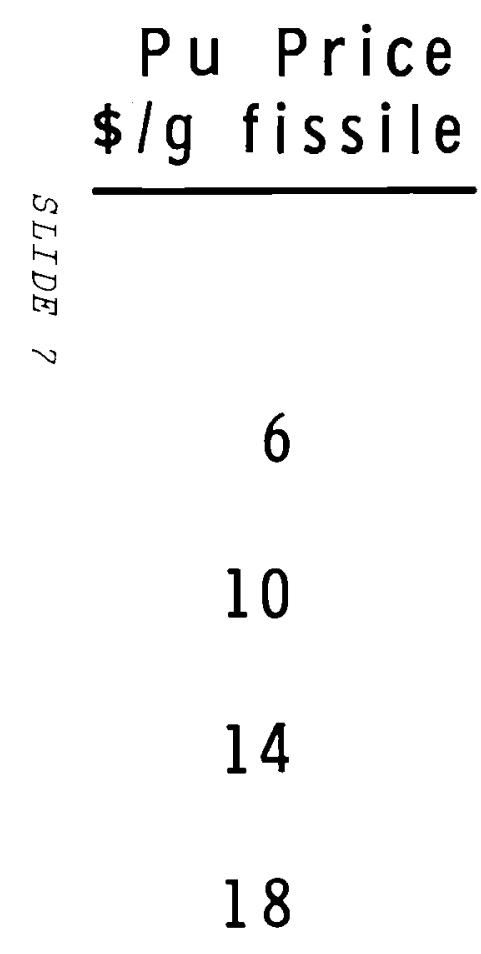

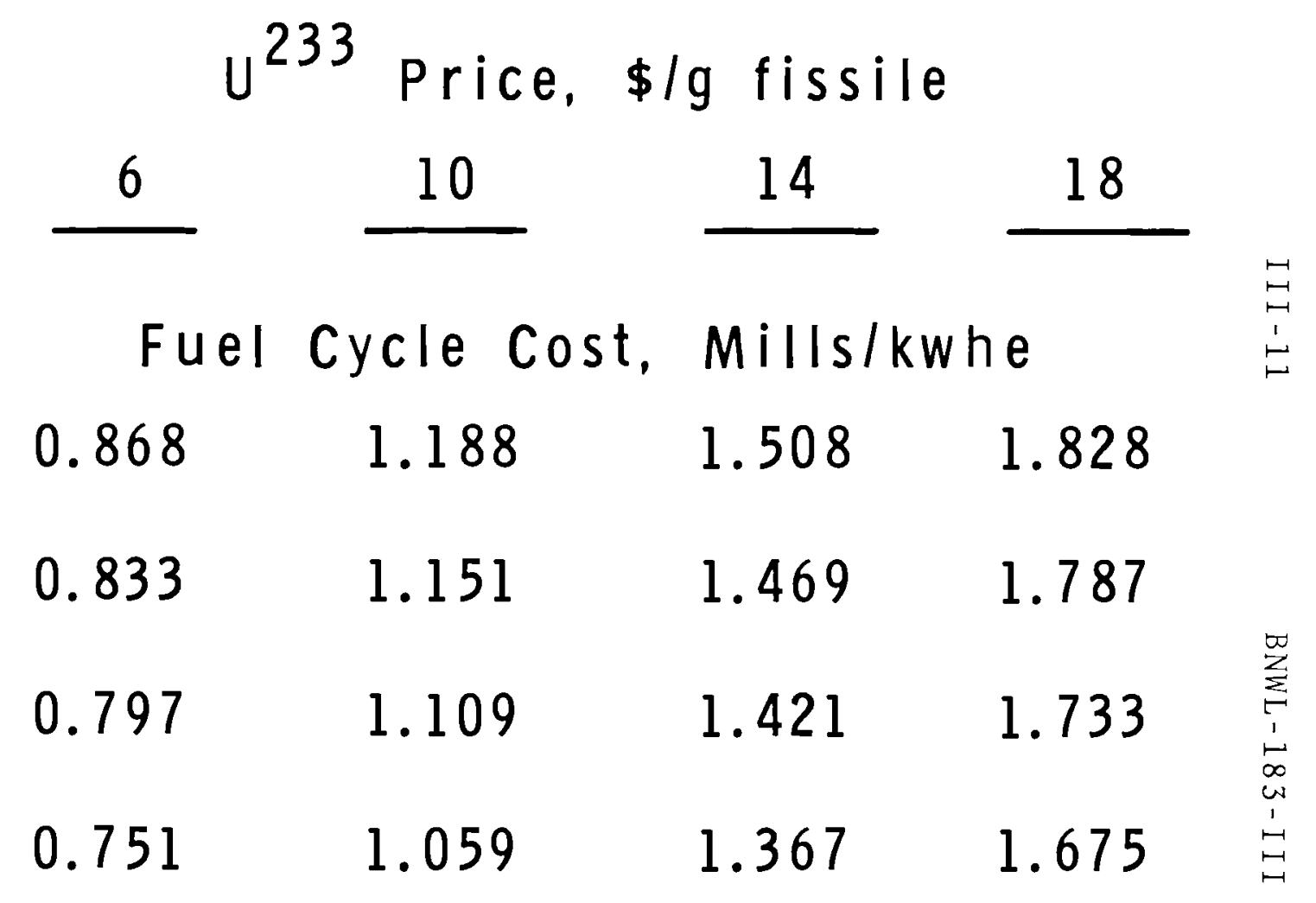


COMPARISON OF MINIMUM FUEL CYCLE COSTS IN A $D_{2} 0$ MODERATED REACTORS WITH VARIOUS FUELS

$\frac{\text { Fuel }}{235} u^{238}$
co Pu-Thorium
$\infty \quad$ Pu-Thorium
(Tight Pencil Configuration)

$u^{235}$-Thorium

$u^{233}$-Thorium

\begin{tabular}{|c|c|}
\hline $\begin{array}{l}\text { Minimum Fuel } \\
\text { Cycle Cost. Mills/kwhe }\end{array}$ & $\begin{array}{c}\text { Fuel } \\
\text { Enrichment, wt. }\end{array}$ \\
\hline 1.558 & 1.03 \\
\hline 1.739 & 1.79 \\
\hline 1.550 & 1.67 \\
\hline 1.968 & 2.22 \\
\hline 1.855 & 1.77 \\
\hline
\end{tabular}

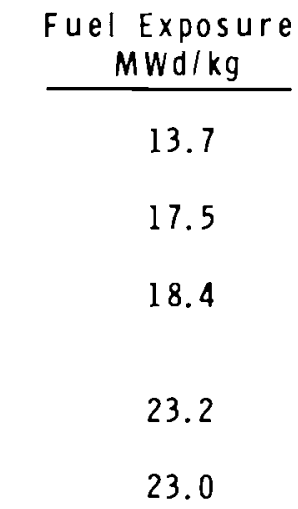

Average
Conversion Ratio
0.69
0.83
0.91


quently, both the tight pencil plutonium-thorium and the $U^{235}-U^{238}$ fuels are operating at a cost of about $1.0 \mathrm{mill} / \mathrm{kWh}_{\mathrm{e}}$. Notice, too, that the $U^{235}$-thorium and $U^{233}$ thorium fuels require at least as much enrichment as the other fuels. And since these two fuels are also more expensive per gram fissile, they will have higher burnup and inventory costs than the other fuels. And while operators using plutoniumthorium fuels are buying plutonium for $\$ 10 / \mathrm{g}$ and se11ing $\mathrm{U}^{233}$ for $\$ 14 / \mathrm{g}$, any increase in $U^{233}$ price would make the plutonium-thorium system look even better.

In the case of the plutoniumthorium tight pencil fuel, the initial alpha of $\mathrm{pu}^{239}$ is 0.39 , which was arrived at by adjusting the ALTHAEA computer code to agree with THERMOS and RBU calculations. It should be pointed out that the alpha experimentally measured in PRTR for plutonium-uranium mixed oxide fuels is 0.42 to 0.43 . Thus the tight pencil fuel has an improved alpha of only 0.03 . The low enrichment of the tight pencil fuel indicates that any loss of cross section is more than made up by the lower alpha. This is to be expected in a $\mathrm{D}_{2} \mathrm{O}$ reactor, where the cross section size of the fissile material has very 1 ittle effect on thermal utilization and where the resonance captures are reduced.

Let us now compare more in detail the $U^{235}$-thorium and plutoniumthorium fuels, both of which are of particular interest as starter fuels for any reactor fueled with $U^{233}$. thorium.

Notice first of all in Slide 9 that al1 three fuels have exposures of 21 $\mathrm{MWd} / \mathrm{kg}$. Moreover, the initial enrichment of each plutonium fuel is substantial1y lower than that of $\mathrm{U}^{235}$-thorium. Even in a tight pencil configuration, the plutonium-thorium fuel still has a cross section twice that of $\mathrm{U}^{235}$. thorium fuel. Here again, the alpha improvement for tight pencil fuel reduces inventory costs by reducing the required initial enrichment. The table shows that the conversion ratio of the tight pencil fuel is 91.8. It may be pointed out here that these three conversion ratios are not necessarily the maximum, that the spectrum could be made softer if one is willing to use more $\mathrm{D}_{2} \mathrm{O}$.

Improved conversion ratios could also be obtained by moving the fuel, by on-1ine charging, or by anything else that would eliminate neutron losses to the control system. For the three fuels shown here, the average reactivity loss to the control system is $25 \mathrm{milli-k}$. These calculations, like the previous ones for water reactors, are based on a plutonium price of $\$ 10 / \mathrm{g}$ fissile, with the plutonium composition being equal to that of a water reactor fuel discharge. The cost, or credit, for $\mathrm{U}^{233}$ is also the same, namely, $\$ 14 / \mathrm{g}$ fissile, with no cost penalty for $\mathrm{U}^{232}$. The price given to $U^{235}$ in these calculations is $\$ 12 / \mathrm{g}$ fissile, which is based on the present AEC price schedule for fully enriched uranium. Based on these prices, therefore, the table shows that the tight pencil fuel cycle cost 


\section{COMPARISON OF FUEL CYCLE CHARACTERISTICS OF A PLUTONIUM OR U ${ }^{235}$ ENRICHMENT IN THORIUM IN A D 20 \\ MODERATED REACTOR}

\begin{tabular}{|c|c|c|c|}
\hline & U-235 Thorium & $\begin{array}{c}\text { Piutonium-Thorium } \\
\text { (Tight Pencil Configuration) }\end{array}$ & $\begin{array}{l}\text { Plutonium-Thorium } \\
\text { (Homogeneous) } \\
\end{array}$ \\
\hline Fuel Exposure, MWd/kg & 21.0 & 21.0 & 21.0 \\
\hline Initial Enrichment, wt.\% & 2.18 & 1.73 & 1.88 \\
\hline Final Enrichment, wt. $\%$ & 1.62 & 1.38 & 1.33 \\
\hline Fissile Ratio $\left(\frac{\text { Final Enr }}{\text { Initial Enr }}\right)$ & 0.78 & 0.85 & 0.75 \\
\hline Average Conversion Ratio & 82.5 & 91.8 & 83.6 \\
\hline $\begin{array}{l}\text { Fuel Cycle Cost. Mills/Kwhe } \\
\left(\begin{array}{llll}P u @ \quad \$ 10 / g \text { Fissile, } U^{233} \\
@ \$ 14 / g, \quad U 235 @ \$ 12.05 / g\end{array}\right)\end{array}$ & 2.003 & 1.510 & 1.695 \\
\hline $\begin{array}{c}\text { Minimum ("Backed-Up") Fuel Cycle Cost. } \\
\text { Mills/kwhe }\end{array}$ & 1.968 & 1.550 & 1.739 \\
\hline $\begin{array}{l}\text { Fuel Exposure at Minimum Cost. } \\
\qquad \mathrm{MWd} / \mathrm{kg}\end{array}$ & 23.2 & 18.4 & 17.5 \\
\hline
\end{tabular}


is substantial1y less than that of the other fuels, particularly $U^{235}$-thorium. The point might also be made here that the use of plutonium instead of $U^{235}$ in thorium fuels is especially attractive because it avoids the contamination of newly formed $\mathrm{U}^{233}$ with $\mathrm{U}^{236}$, which greatly reduces the value of a $\mathrm{U}^{235}$-thorium discharge. It has a1ready been pointed out that natural uranium fueled $\mathrm{D}_{2} \mathrm{O}$ reactors can have fuel costs lower than those on this slide if processing costs are low enough not to require a high fuel exposure and if the interest rates on the $\mathrm{D}_{2} \mathrm{O}$ capital are low enough to permit large lattice spacings.

Slide 10 shows the neutron balance for the plutonium tight pencil enrichment of thorium. The neutron balance represents an average over a $15 \mathrm{MWd} / \mathrm{kg}$ exposure. Of the neutrons absorbed in fissile isotopes, $69 \%$ are absorbed by a combination of $\mathrm{Pu}^{239}$ and $\mathrm{Pu}^{241}$. And since the initial alpha of $\mathrm{Pu}^{239}$ is 0.39 , we have an average plutonium eta of 2.11. Now this eta plus the fast effect contribution give a total of 227 neutrons available after 100 neutrons have been absorbed in the fissile material. of these 227 neutrons, 79.7 are absorbed in thorium, 0.3 in $\mathrm{U}^{234}$, and 12.3 in $\mathrm{Pu}^{240}$, making a total of 92.3. However, since we lose 0.6 neutrons in $\mathrm{Pa}^{233}$, which does not become a fissile materia1, the net conversion ratio after subtracting 0.6 from 92.3 is 91.7 . The neutron losses to xenon and samarium, to other fission products, and to cladding and moderator add up to 22.5 neutrons, with the leakage and control losses accounting for the remaining 10.8 neutrons 1 ost. Here again, the leakage and control losses could be reduced if one were willing to incur the added expense of moving the fuel, using on-1ine charging, displacing the moderator, or using other techniques to reduce neutron losses.

Another interesting aspect of enriching thorium with plutonium is the reactivity swing during the burnup. Slide 11 shows that the plutoniumthorium fuel does have a significantly larger reactivity change during burnup. This is due to the plutonium cross section being larger than that of $\mathrm{U}^{233}$ formed during the burnup. In contrast, the $\mathrm{U}^{235}$-thorium fuel has a smaller reactivity change because the $\mathrm{U}^{235}$ itself has about the same cross section as $U^{233}$. As you can see, the tight pencil plutonium-thorium fuel falls between these extremes. The goal exposure for all three fuels is $20 \mathrm{MWd} / \mathrm{kg}$.

The foregoing remarks can be summarized as follows. First of all, it appears that under the pricing conditions assumed in this study, $\mathrm{U}^{233}$. natural uranium is an attractive fue 1 in a PWR because its fuel cycle cost is less than that of slightly enriched uranium and its conversion ratio is much greater.

Secondly, the other crossed-progeny fue1--name1y, plutonium in thorium-. does not seem an attractive fuel in a water reactor. However, this fuel in a tight pencil configuration does look attractive in a $D_{2} \mathrm{O}$ moderated reactor, where its fuel cost is equal to and its conversion ratio is greater than that of sightly enriched uranium.

A1so, if the $U^{233}$-natural uranium fueled $P W R$ and the $D_{2} O$ reactor using 


\section{NEUTRON BALANCE FOR PLUTONIUM ENRICHED THORIUM IN A D 20 MODERATED REACTOR (Fuel Exposure of $15 \mathrm{MWd} / \mathrm{kg}$ ) \\ Based on 100 Neutrons Absorbed in Fissile Materials}

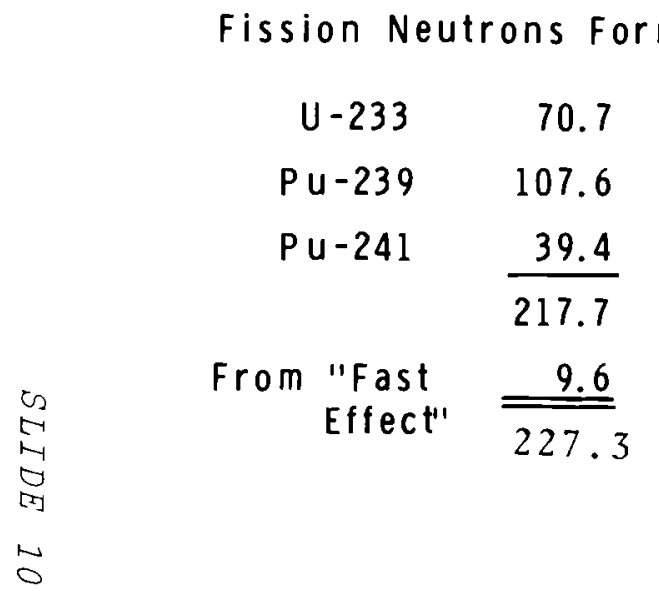

Neutrons Absorbed in Fissile Isotopes

\begin{tabular}{rr} 
U-233 & 31.3 \\
Pu-239 & 51.2 \\
Pu-24l & $\frac{17.5}{}$ \\
\hline 100.0
\end{tabular}

Neutrons Absorbed in Fertile Material

$$
\begin{array}{rr}
\text { Th-232 } & 79.7 \\
\mathrm{U}-234 & 0.3 \\
\mathrm{Pu}-240 & \frac{12.3}{92.3}
\end{array}
$$

Neutrons Absorbed in Non-Fertile Material

$$
\begin{array}{ll}
P u-233 & 0.6 \\
P u-242 & 0.4
\end{array}
$$$$
\text { Higher Isotopes } \frac{0.8}{1.8}
$$

Non-Fuel Absorption and Leakage of Neutrons

$$
\begin{aligned}
& S M+X E \\
& \text { Other FP } \\
& \text { Clad and Moderator } \\
& \text { Control and Leakage }
\end{aligned}
$$

$\begin{array}{r}6.3 \\ 7.0 \\ 9.2 \\ 10.8 \\ \hline 33.3\end{array}$

$$
\text { 皇 }
$$$$
\text { }
$$ 


\section{REACTIVITY AS A FUNCTION OF BURNUP FOR U 235 OR PLUTONIUM ENRICHMENT IN THORIUM}

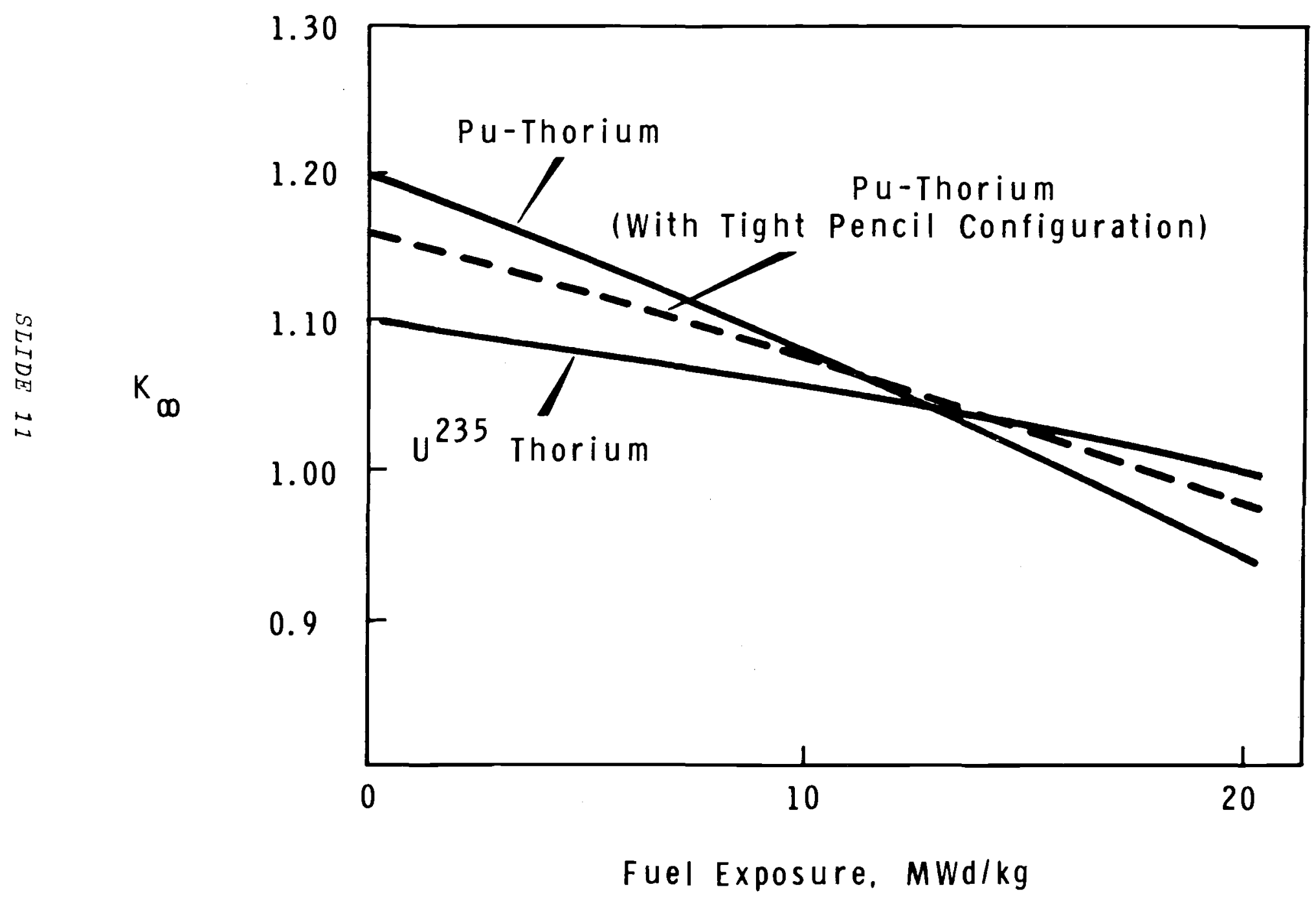


tight pencil plutonium-thorium fuel coexisted, the $U^{2.33}$ discharged from the $\mathrm{D}_{2} \mathrm{O}$ reactor could supply the $\mathrm{U}^{233}$ required by the PWR.

Last $1 y$, since these two reactors are close to being thermal breeders, only uranium would be required to sustain their working in combination. However, the plutonium-thorium cycle would then become a plutonium-U $U^{233}$ recycle-thorium cycle.

- 
BNWL - $183-I V$

\title{
SECTION IV
}

\section{THE CALIBRATION OF A HIGH SPEED BURNUP CODE FOR NUCLEAR FUEL SURVEYS}

\author{
W. W. Porath \\ D. E. Deonigi \\ E. T. Merrill \\ Battelle Memorial Institute \\ Pacific Northwest Laboratory \\ Richland, Washington
}

November, 1965

\footnotetext{
Paper for oral presentation at the American Nuclear Society 1965 Winter Meeting Washington, D.C., November 15-19, 1965
} 
THE CALIBRATION OF A High SPEED BURNup CODE FOR NUCLEAR FUEL SURVEYs*

\author{
W. W. Porath,** D. E. Deonigi, ${ }^{\dagger}$ and E. T. Merril1 $1^{\dagger}$
}

The high-speed burnup code whose calibration I am about to describe is named ALTHAEA. It is, in effect, a four group, one-dimensional code with a zero-dimensiona 1 option, and uses the Westcott formalism for cross sec$t$ ion representation. This code is capable of computing accurately a zero-dimensional burnup to $20,000 \mathrm{MWd} / \mathrm{T}$ in approximate $1 \mathrm{y} 15$ seconds. While doing this, the current compilation of the code handles 20 fue 1 isotopes and 15 fission products, accounts for all major forms of nuclear destruction, and prints out intermediate compositions at any desired interval. In addition, it accounts for self-shielding and cross shielding of all the isotope cross sections. When operating in the onedimensional mode, the code is capable of handing up to 24 burnable regions.

This code is a "workhorse" code and its makeup has, to a significant degree, been altered to allow better fitting of burnup data, with the strong restraint that computation

* This paper is based on work performed under the United States Atomic Energy Commission Contract AT $(45-2)-2830$. Permission to publish is gratefully acknowledged.

* Research Engineer

+ Senior Research Engineer, Physics and Instruments Department, Pacific Northwest Laboratory, operated by Battelle Memorial Institute for the United States Atomic Energy Commission, Richland, Washington. time should be less than 20 seconds of 7090 time for a $20,000 \mathrm{MWd} / \mathrm{T}$ burnup. In effect, by using some adjustable coefficients, ALTHAEA approximates the accuracy of more basic codes, without any decrease in its computational speed. A twogroup zero-dimensional version of the ALTHAEA code is known as MELEAGER. Burnups can be accurately computed by MELEAGLR when it is calibrated for a given reactor and range of enrichment levels. But MELEAGER requires recalibration if the lattice or fuel densities are altered significantly.

Codes using more groups than ALTHAEA can also handle a wide variety of problems, but calibrating them to burnup data and simple flux spectrum data is fraught with the difficulty of selecting the right group or group of groups to adjust. The specific four-group structure used by ALTHAEA was chosen mainly because one can visualize physically a fast, a slowing down, an epithermal-resonance, and a thermal flux breakdown, and one can reasonably es timate the adjustment required to fit burnup data. In addition, it was found that cross shielding of the lowlying transuranium isotope resonances, principally those of $\mathrm{Pu}^{239}, \mathrm{Pu}^{241}$, $\mathrm{Np}^{237}$, and $\mathrm{Am}^{241}$, was necessary to allow fitting of the data. The other major adjustable coefficients in the 
code are resonance self-shielding and moderator effectiveness; i.e., the relative probability of a neutron to undergo scattering in the moderator without being absorbed in the fuel. This latter coefficient could be eliminated by using a more sophisticated neutron-slowing-down-routine, which would require longer computational time.

The ALTHAEA code is calibrated to isotope concentrations which have been developed in slightly enriched uranium fuels at exposures up to $30,000 \mathrm{MWd} / \mathrm{T}$ and which have an atomic weight as high as that of $\mathrm{Cm}^{244}$. For fuel survey purposes, the calibration obtained appears valid over a wide range of lattice variables. With the above calibration, the code calculations agree well with published critical experiments in water, $\mathrm{D}_{2} \mathrm{O}$, and graphite lattices. Assemblages of more sophisticated burnup codes, such as appropriate combinations of GAM, THERMOS, and burnup routines can provide more precision, with more computer time. For example, one such assembly of codes for a single burnup requires 30 minutes of 7090 computer time, compared to 20 seconds with ALTHAEA.

S1ide 1 shows the four-group structure used by ALTHAEA. The fast group was arbitrarily set from $6 \mathrm{MeV}$ down to $0.2 \mathrm{MeV}$. The slowing down group extends from $0.2 \mathrm{MeV}$ to $0.083 \mathrm{eV}$, and the epithermal resonance group from $0.683 \mathrm{eV}$ to $\mu \mathrm{kT}$ in the westcott notation. The thermal group is based upon a Maxwellian flux. The slowing down group may be expanded to account for possible suc- cessive flux reductions due to the resonance absorption in the major fertile isotopes $\mathrm{Th}^{232}, \mathrm{U}^{238}, \mathrm{U}^{234}$, and $\mathrm{Pu}^{240}$.

The major calculational features include both Doppler broadening of al 1 resonances and thermal group cross sections reduced by flux depression calculations fitted against ce 11 blackness computed by a P- 3 ce 11 code. All resonances are self- and cross-shielded in the resonance group; in the slowing down group all resonances are selfshielded. The fluxes seen by lower groups and by successive resonances within a group are appropriately reduced by resonance absorption at higher neutron energies. Fast fissions in heavy atoms and significant $n-2 n$ reactions are accounted for in the fast group.

In Slide 2 we can see that calibration was accomplished in two ways - theoretically and experimentally. The theoretical calibration was performed against results of RBU and against data obtained by normalizing IIRG and THLRMOS results. The experimental calibration used critical data obtained from BNL work with $\mathrm{U}^{238}$ systems and from battelleNorthwest work with plutonium systems. Part of the burnup data was obtained by determining the isotopic compositions of $\mathrm{UO}_{2}$ fuels having exposures up to $30,000 \mathrm{MWd} / \mathrm{T}$ in Yankee and $B W R$ reactors. The rest of the burnup data was obtained by determining the isotopic compositions of spent PRTR mixed-oxide fuels.

In the calibration of a burnup code, one can never quite be satis- 


\section{ALTHAEA}

Features

In Effect, A Four Group Code with the Neutrun

Temperature and Neutron Spectrum Continually Recalculated

Group Structure:

6 Mev to 0.2 Mev Fast Group

0.2 Mev to 0.683 ev Slowing Down Group

0.683 ev to $\mu k T_{\text {neut }}$ Resonance Group

$\mu k T_{\text {neut }}$ to Thermal Thermal Group

\section{Major Calculation Features}

Doppler Broadening of all Resonances. Tneut Continually Recalculated

Thermal Group Cross Sections Reduced by $P_{3}$ Cell Calculation of Flux Depression vs Blackness

All Resonances Self-and Cross-Shielded in Resonance Group

All Resonances Self-Shielded in Slowing Down Group

Fast Fissions in Heavy Atoms and Significant $(n, 2 n)$ Reactions Accounted for in Fast Group

Resonance Absorptions in Upper Groups Reduce Fluxes Seen by Lower Groups 


\section{ALTHAEA}

\section{Calibration}

\section{Theoretical}

Against HRG-THERMOS and RBU

\section{Experimental}

BNL Data for U-238

Yankee Burnup to $30,000 \mathrm{Mwd} / \mathrm{T}\left(\mathrm{UO}_{2} \mathrm{Fuel}\right)$

Boiling Water (Vallecitos) to $30,000 \mathrm{Mwd} / \mathrm{T}\left(\mathrm{UO}_{2} \mathrm{Fuell}\right.$

PRTR Burnup to $3000 \mathrm{Mwd} / \mathrm{T}$ (Mixed 0xided Fuel) 
fied with the selection of standards. Basically, one should use experimental data--criticality for initial conditions--and spent fue 1 compositions for burnup data. The practical difficulty is that the significant burnup data is very 1 imited. Furthermore, the available critical data does not cover a wide range of conditions, particularly at the operating temperatures of fue 1 and moderator. To fill these lacks, one selects critical experiments and burnup data, and then by employing theoretical codes, one can extrapolate the 1 imited experimental data to a wide range of lattices, moerator temperatures, and so forth. The calibration can be made so that the burnup code will match the critical experiments. Then one does a burnup calculation and compares the results with the spent fuel analysis. If the check is not good, one can adjust the calibratable coefficients until the burnup calculation compares favorably with the spent fuel analysis. Often one then finds that further calculations based on the burnup calibration no longer match the critical experiments. Hence the goal of making the code agree with burnup data and crit: ical experiments is compromised. Thus, of necessity, the work I shal1 describe is just that kind of compromise, and, as more burnup data becomes available, the compromising will continue. However, the extent of compromise is apparently diminishing, and one hopes that this trend continues. Of course, a considerable degree of refinement beyond this is yet to be realized, in particular as regards spatial variations with burnup--variations that are treated here as averages.

Slide 3 shows the calibratable coefficients and where the various representations of the effective resonance integrals in the three upper groups occur during the iteration. As you can see at the top of the slide, the calculations begin by assuming a suitable value for the spectral index and neutron temperature. In the first box. a resonance self-shielding coefficient, or $z$, is calculated as a function of fuel temperature. In the second box, an effective g similar to the $g$ of Westcott is calculated as a function of the neutron temperature and the flux depression. Also calculated in the second box are the dilute resonance integrals in the three upper groups.

In the third box from the top, the self-shielding and cross shielding are calculated for the effective resonance integrals in Groups 2 and 3. As shown in the next box, the macroscopic absorption cross sections in the thermal, epithermal, and slowing down groups are calculated. These are functions of the neutron temperature $g_{\text {eff }}$ and the spectral index $r$. In the fifth box, explicit equations are used to calculate the neutron temperature and $r$. The neutron temperature is a function of the moderator temperature, the macroscopic cross section in the thermal group, and a calibratable coefficient we call RAYk 3. The spectral index is then calculated (by an iterative procedure) as a function of macroscopic absorption cross sections and 
ITERATIVE SCHEME USED TO DETERMINE NEUTRON SPECTRLM AND NEUTRON TEMPERATURE

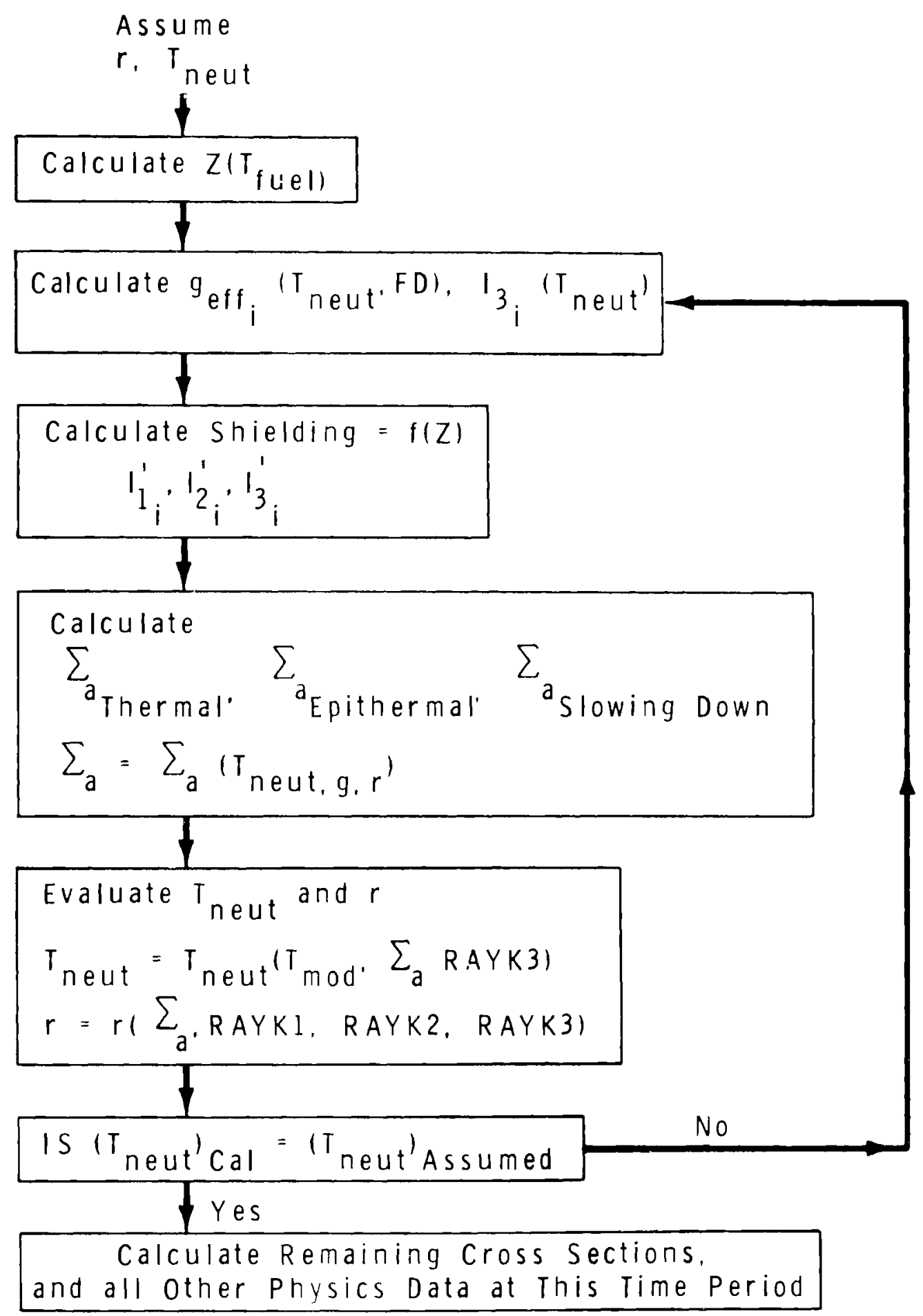


the three calibratable coefficients RAYK 1, 2, and 3. If the neutron temperature computed here is within $1^{\circ}$ of the assumed neutron temperature, we proceed to calculate the remaining cross sections and other physics data as shown in the last box. If not, we return to the second box from the top and repeat the calculations, using the new values of neutron temperature and spectral index.

The next two slides show the equations that are used in this calibration. Slide 4 contains the first three equations used for calculating the effective resonance integral in each group above thermal. Note the similarity of this formulation to that of the NRIA equation. The calibration coefficients in these three equations are the $C_{i j}$ 's and $z_{i}$. The $\mathrm{C}_{i j}{ }^{\prime} \mathrm{s}$ are the cross shielding coefficients, and they account for the shielding (by all other isotopes in the ce11) of the resonance of the isotope in question.

The initial selection of the $C_{i j}$ 's was made by measuring the overlapping areas in the low-lying resonances. For example, $\mathrm{Pu}^{239}, \mathrm{U}^{235}$, and $\mathrm{Am}^{241}$ al1 have resonances near $0.3 \mathrm{eV}$, while $\mathrm{Pu}^{241}$ has a resonance at $0.25 \mathrm{eV}$. These resonances all contribute to the same flux depression, and the overlap of each to the other is used as a measure of the total flux depression. To obtain the proper reaction rate of each isotope relative to the others, one must adjust the cross section of each isotope. Refinement to the $C_{i j}$ numbers has been made empirically to fit burnup data. A more elegant refinement to be tried will exploit that feature in THLRMOS which allows cross section calculation of one isotope on the basis of a flux determined by a given isotopic fue 1 mixture.

If no other information is available, the calibratable coefficient $Z$ represents the height of the lowest lying resonance. We have found that this number needs adjustment; for example, to simulate the reaction rates of $\mathrm{Pu}^{240}$, one must double the value of $Z$. Notice the term called SCA in the denominator of the second equation from the top. This te rm represents the potential scattering in the fuel plus a surface term reduced by the Bell correction (in lieu of the Dancoff correction on the fuel surface area). The term SCA takes into account the geometrical effects of the fue 1 configuration and the shadowing from fue 1 rod to fue 1 rod on the effective resonance integral. The SCA term and the Bell correction are calculated by a subroutine of the $\mathrm{P}_{3}$ cell code that is used for providing input to the ALTHAEA code. The leverage of SCA on the effective resonance integral is so great and the inter-rod shielding is so difficult to compute that SCA is considered to be a calibratable coefficient. Because of this leverage, one cannot overemphasize the importance of selecting a good model from which to calculate SCA.

In the calculation of the neutron temperature, the term RAYK 3 is used to perform the calibration. Looking first at the SDPV term, we see that 
PRINCIPAL EQUATIONS USED IN ALTHEA CALIBRATION

$$
I_{\text {eff }}=I_{1_{i}}^{\prime} \times R I D+I_{2_{i}}^{\prime}+I_{3_{i}}^{\prime} \times H
$$

$$
I_{3_{i}}^{\prime}=\frac{c_{i i}{ }^{I_{i}}}{\left(1+\frac{Y_{i} Z_{i}}{S C A}\right)^{1 / 2}}+\frac{1-c_{i i} I_{3}}{\left(1+\frac{\sum_{j}^{i} c_{i j} Y_{j} Z_{j}+\left(1-c_{i i}\right) Y_{i} Z_{i}}{S C A}\right)^{1 / 2}}
$$

$$
I_{2 i}^{\prime}=\frac{I_{2}}{\left(1+\frac{Y_{i} Z_{i}}{S C A}\right)^{1 / 2}}
$$

$c$
c
$a$
$a$
$x$

$$
i_{1}^{\prime}=l_{1}
$$

$\stackrel{\models}{\infty}$

$$
\begin{aligned}
S C A & =\frac{\left(\frac{S_{\text {Fuel }}}{4 V_{\text {Fuel }}}\right) \sum_{S}^{\text {Mod }}\left(\frac{V_{\text {Mod }}}{V_{\text {Fuel }}}\right)}{\left(\frac{S_{\text {Fuel }}}{4 V_{\text {Fuel }}}\right)+\sum_{S}^{\text {Mod }}\left(\frac{V_{\text {Mod }}}{V_{\text {Fuel }}}\right)} \\
H= & \frac{\nu \sum_{f} \sqrt{\frac{\pi T_{0}}{4 T}}\left(\frac{\epsilon-1}{Y}\right)}{\nu I_{l_{i}}^{\text {fission }}-1_{1}^{\text {absorption }}}
\end{aligned}
$$

RID $=1-\frac{\text { (Reaction Rate) Slowing Down }}{\text { (Reaction Rate) Total }}$

 
it is the slowing down power of the ce 11 per unit fue 1 volume. This term is also calculated by a subroutine in the $\mathrm{P}_{3}$ cell code that customarily precedes an ALTHAEA calculation. SPDV is a measure of the ability of a cell to thermalize the neutrons. $\Sigma_{a}$ is a measure of the flux distortion due to absorption. $\frac{\Sigma_{a} / g}{S D P V}$ is a measure of the tendency of the effective neutron temperature to be greater than the moderator temperature--a tendency due to the absorptions in the low energy portion of the Maxwellian, as described by Dawson and Steves, HW-75278. Then RAYK 3 is a calibratable coefficient that allows one to predict a portion of this shift in the effective neutron temperature.

On Slide 5 is the formulation of the spectral index, and all the components that go into calculating it. Since the spectral index, or $r$, is one of the most important variables to be determined, we used an iterative process that requires both the spectral index and the neutron temperature to be converged within specified limits before further computations are made. The calibratable coefficients in the spectral index equation include RAYK 1 and the flux depression term FD. RAYK 1 is a measure of the heterogeneity of the reactor; if cell calculations are done, RAYK 1 must have a value of unity to ensure that reasonable solutions are obtained. Then the spectral index equation takes on the form of a ratio of thermal absorptions in the fue 1 and nonfue 1 materials to the transfer cross section from epitherma 1 to thermal plus b multiplied by the thermal absorptions in the fue 1 and nonfue 1 materials, where $b$ is the normalization factor for the assumed flux shape as described by Westcott. When not doing cell calculations, the value of RAYK 1 is somewhat less than unity, and the spectral index becomes the ratio of the total thermal absorptions to the transfer cross section plus a fraction of the absorptions in the fuel and nonfuel materials minus the absorptions in the fuel in excess of the $1 / v$ absorptions, i.e., the excess resonance integral.

The flux depression correction to the cross sections is achieved by fitting data from the $\mathrm{P}_{3}$ cell code, where the magnitude of the flux depression as a function of thermal cell blackness is computed. This treatment provides more accurate cross section values as the cell blackness changes during burnup. It also provides another means of calibration; for it enables one to choose the form of the equation used in the fitting of the flux depression. RAYK 2 is a calibratable coefficient, and if it is equal to zero, there is no correction for the group three flux depletion; but if RAYK 2 is equal to 1.0 , the group three flux is reduced by the fractional amount of the absorptions in Group 2. Because of the probability of a large energy decrement per scattering collision in water moderator reactors, intermediate values of RAYK 2 are appropriate. Finally, we see at the bottom of the slide the equation for the formulation of the Westcott parameters and the cross section--namely, $\hat{o}$ equals o times $g_{\text {eff }}$ plus $r$ times $s_{\text {eff. At this }}$ point we have arrived at the final cross sections necessary to calculate 
PRINCIPAL EQUATIONS USED IN ALTHEA CALIBRATION

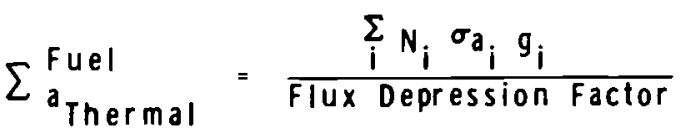

$$
\begin{aligned}
& \text { iNF }=\sum_{\text {thermal }}^{\text {Non Fuel }}=\sum_{\text {Tell }}^{\text {Con }} N_{i} \sigma_{a_{i}} V_{i} / V_{\text {Fuel }} \\
& R I D=1-\frac{r\left(\sum_{i} N_{i} I_{i}^{\prime}\right) \text { RAYK2 }}{\sum_{\text {a Thermal }}^{\text {Fuel }}+S N F+r\left(\sum_{i} N_{i} I_{2}^{\prime}+R I D\left(\sum_{i} N_{i} I_{3}^{\prime}\right)-b \sum_{a_{\text {Thermal }}}^{\text {Fuel }}\right)}
\end{aligned}
$$

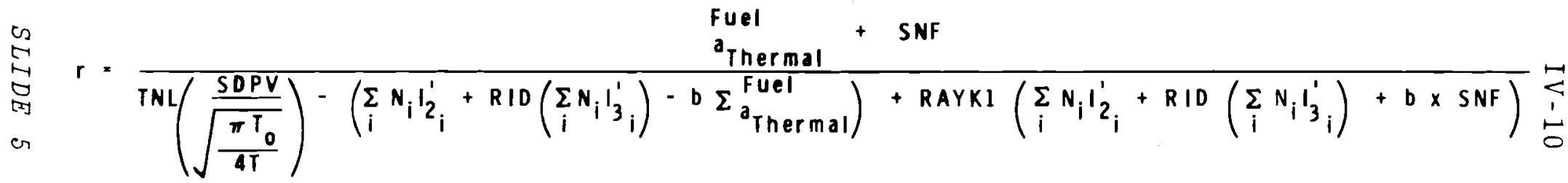

$$
\begin{aligned}
& s_{\text {eff }}=\frac{\text { 'eff }_{i}}{\sigma_{a_{i}}}-\text { bog eff }_{i} \\
& g_{\text {eff }}=g_{i} / \text { flux Depression Factor } \\
& \hat{\sigma}_{i}=\sigma_{i}\left(g_{\text {eff }}+r s_{\text {eff }}\right)
\end{aligned}
$$


the burnup. These cross sections are reevaluated during burnup when significant concentration changes occur.

The foregoing introduction, although lengthy, attempts to show that the calibratable coefficients employed have some physical basis; that they are not merely synthetic concepts.

Slide 6 shows how the form of the equation we used to calculate the effective resonance integral matches experimental data for $\mathrm{Pu}^{240}$. The experimental data are from work done by Nichols and reanalyzed by leeb, and the error $1 \mathrm{imits}$ on the points where the concentration of $\mathrm{Pu}^{240}$ is larger have been considerably reduced. Similar calibrations have been made for $\mathrm{U}^{238}$ and $\operatorname{Th}^{232}$ data.

In S1ide 7, we see a comparison between the result of the ALTHALA calibration and the BNL data. When the ALTHALA code is run, the usual method of operation is to use the $P_{3}$ cell code to calculate $f$, or the thermal utilization, $\varepsilon$, or the fast cffect, and several other ALTHAEA input parameters. Note the good agrecment betwecn the BNL data and the $f$ calculated by the $P_{3}$ code. The calculation of the resonance oscape probability is done entirely within the ALTHALA code. For these systems that are composed of slightly cnriched uranium metal, the curve of $p$ over the wide range of moderatorto-fuel ratios has the proper shape. slide 8 compares these experimental data with HRG-THERMOS calculations and the ALTILALA calibration. At the low end where the moderator-to-fuel ratio is approximately 1 , the values for the resonance escape probability are within the error limits obtained in the cxperiment. Since this is the region of major interest for 1 ight water moderated power reactors, we use this calibration. With this calibration we have tracked Yankee reactivity with burnup. For other moderator conditions a specific caljbration can be made.

S1ide 8 shows the actual numbers that we have obtained for $f, p$, and E. Again we see that the agreoment of the value of $f$ between the experiment and the $P_{3}$ code is excellent, while the values obtained from the HIRG-THERNOS combination are somewhat lower. The cause of the difference between the THERMOS calculated value of $f$ and the experimental value could be due to any, or a combination, of several things: systematic cxperimental error, the choice of the mesh spacing in the cell, the values used for the cross sections of the uranium isotopes, or the accuracy of the Nelhin kernel to represent the scattering model in light water.

Recently, Honeck reanalyzed these experiments, using the THLRMOS code, and he, too, obtained values of $f$ below those Iisted in the slide. The trend established in his calculations was that the value of $f$ was calculated hest for the cell with the lowest moderator-to-fuel ratio. In each case, his values for $f$ were somewhat closer to the experimental value than those shown in the side. He, too, postulated that part of the difference was due to errors made during the cxperiment and to the fact that the Nelkin hermel may have 
COMPARISON OF SHIELDING EQUATION WITH EXPERIMENTAL
DATA FOR PU240

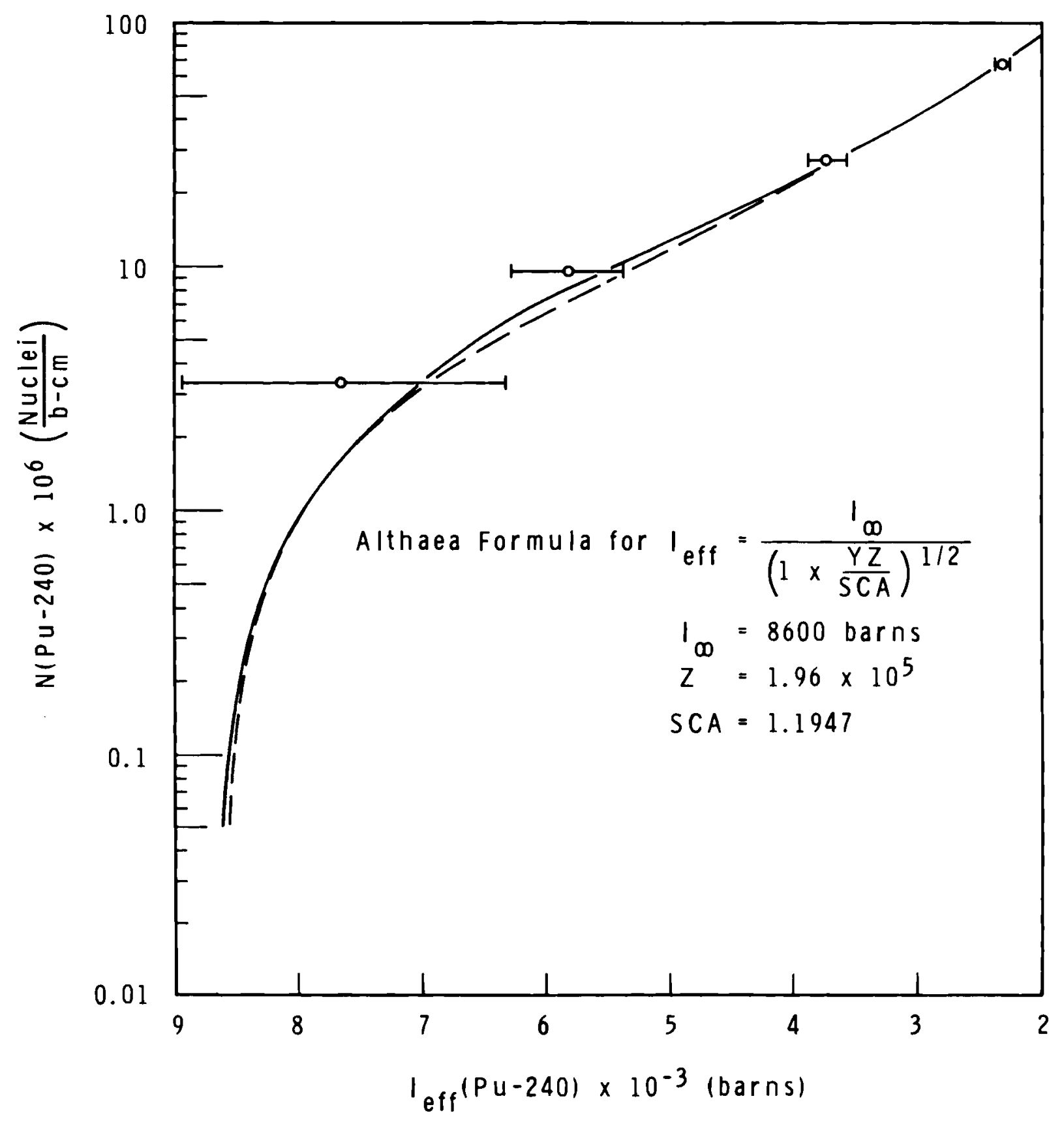


COMPARISON OF EXPERIMENTAL VALUES OF I AND $P$ WITH $P_{3}$-ALTHAEA VALUES

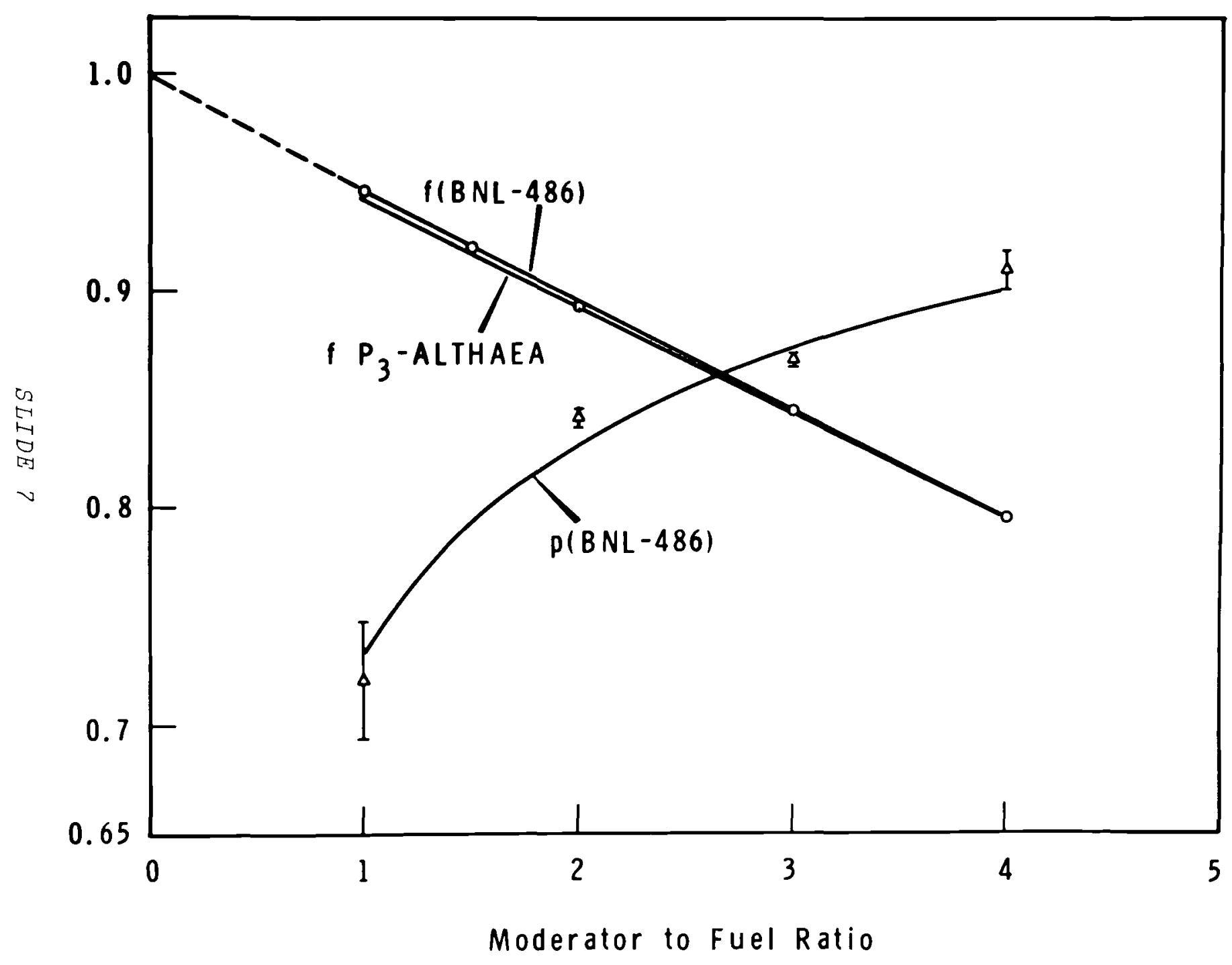


COMPARISON OF EXPERIMENTAL DATA AND COMPUTATIONS WITH P 3 -ALTHAEA, HRG-THERMOS. AND RBU CODES

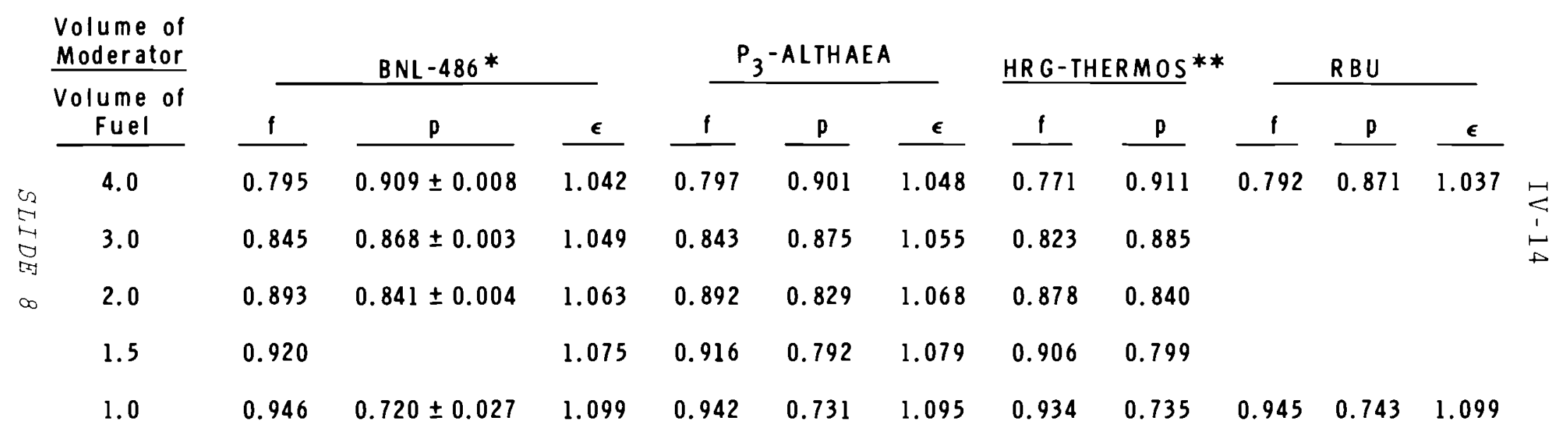

* These are Results of Extensive Experiments by BNL on Water Lattices at $20^{\circ} \mathrm{C}$.

** f from theRMOS is known to be Slightly Low. 
shortcomings for light water.

In examining the value of $p$ from the experiment and the values of $p$ obtained via HIRG-THLRMOS and ALTIIAEA, we can see that ALTILAEA agrees quite we 11 with HRG-THERMOS at three of the points, and disagrees about $2 \%$ at the other two points.

Slide 9 shows how well the ALTHALA code matched the burnup composition in the Yankee reactor. These data have just recently become available. Four different rods were analyzed at Battelle-Northwest, and the variation between the rods is due to the change of spectrum around the rods, each of which was located at a different position in the fuel bundle. Note that the values of the heat produced in megawatt days per ton for the experimental rods and the values obtained by ALTHALA are not the same. This difference is the result of arbitrarily running the code to an exposure that produced approximately the same number of grams of $U^{235}$ per ton at discharge as the experimentally determined value. Due to the difficulty of precisely computing the heat recovered by a reactor coolant, we felt that this was the best method of calibrating the code, since the most abundant isotope would be $\mathrm{U}^{235}$. As you can tell from this slide, the higher isotopes are usually in very good agreement.

let us now examine the agreement between the ALTHAEA calculations and the concentrations of the higher transuranium isotopes produced in Yankee fuel rods. In the case of the curium and americium concentrations, the agreement is excellent, except for $\mathrm{Am}^{241}$; this discrepancy is most likely due to not knowing the exact history of the fuel load from discharge to separation. Apparently, in the case of the $Y-5$ rod, some time elapsed between discharge and separation, and this time interval was not taken into account in back calculating the amount of $\mathrm{Am}^{241}$ present in the fuel at discharge. The same argument also applies to $\mathrm{Pu}^{238}$ in the Y-5 rod. The apparently large discrepancy in the $U^{236}$ concentration in the $Y-1$ and $Y-2$ rods is due to some errors in the analysis of the samples--errors that have just come to 1 ight.

Slide 10 shows how the ALTHALA code matches the plutonium concentrations that are a function of $U^{235}$ depletion. This is for a much shorter exposure, approximately 8000 $\mathrm{MWd} / \mathrm{T}$.

S1ide 11 shows data that has just become available from the PRTR facility. llere again, we are comparing plutonium compositions as a function of burnup; only in this case the fuel is a mixed-oxide fuel irradiated in the plutonium recycle reactor, which is $\mathrm{D}_{2} \mathrm{O}$ moderated. Again the compositions, as a function of burnup, match quite well.

So far, our calibration efforts have shown us that for a given lattice and moderator temperature it is possible to readily calibrate the code so that a wide variety of burnups and critical experiments can be accommodated. With the coefficients available, there are a large number of combinations that will fit 
COMPARISON OF CHEMICALLY DETERMINED ISOTOPIC CONCENTRATIONS IN YANKEE RODS WITH ALTHAEA BURNUP RESULTS

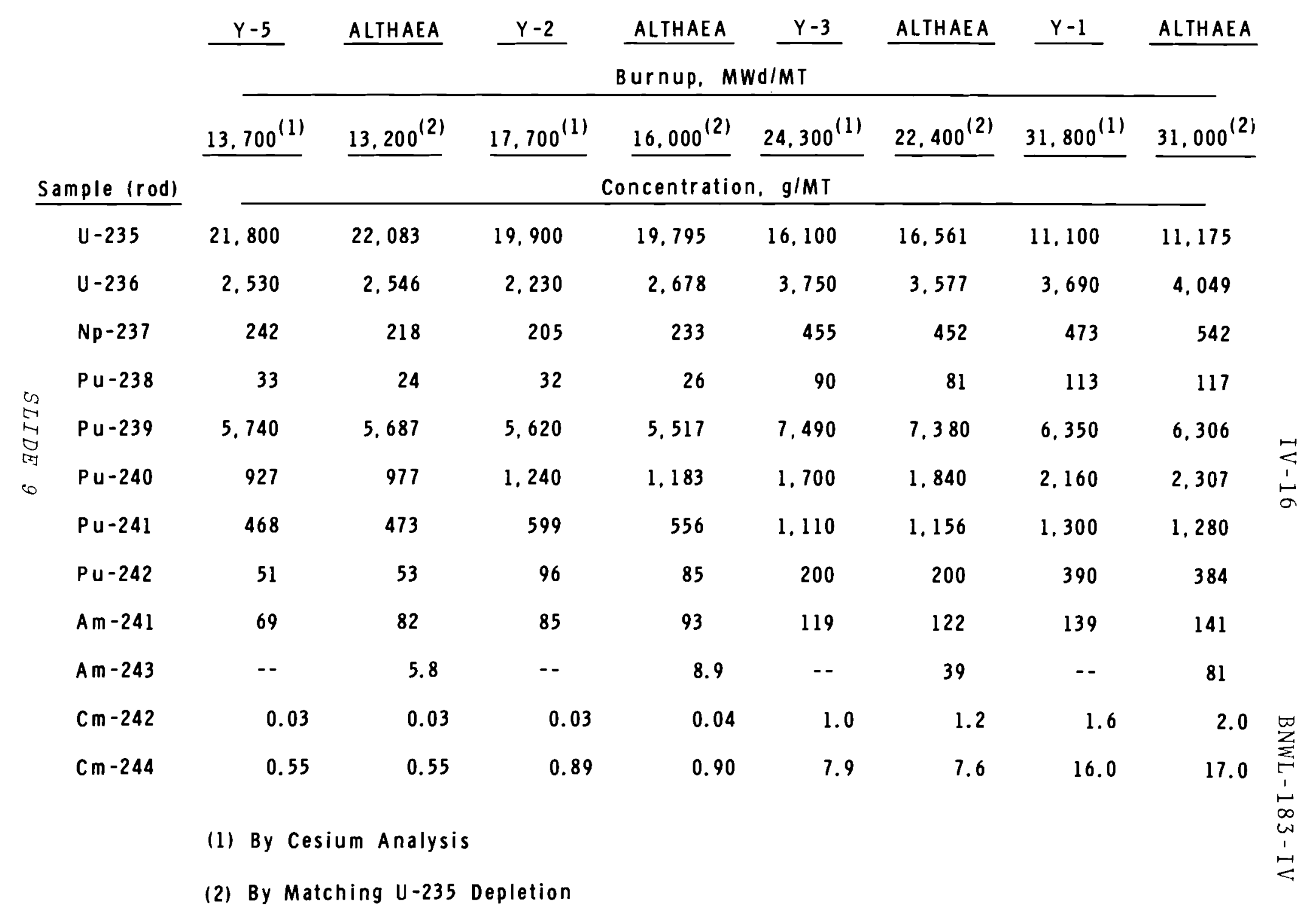


IV -17

BNWL-183-IV

YANKEE REACTOR

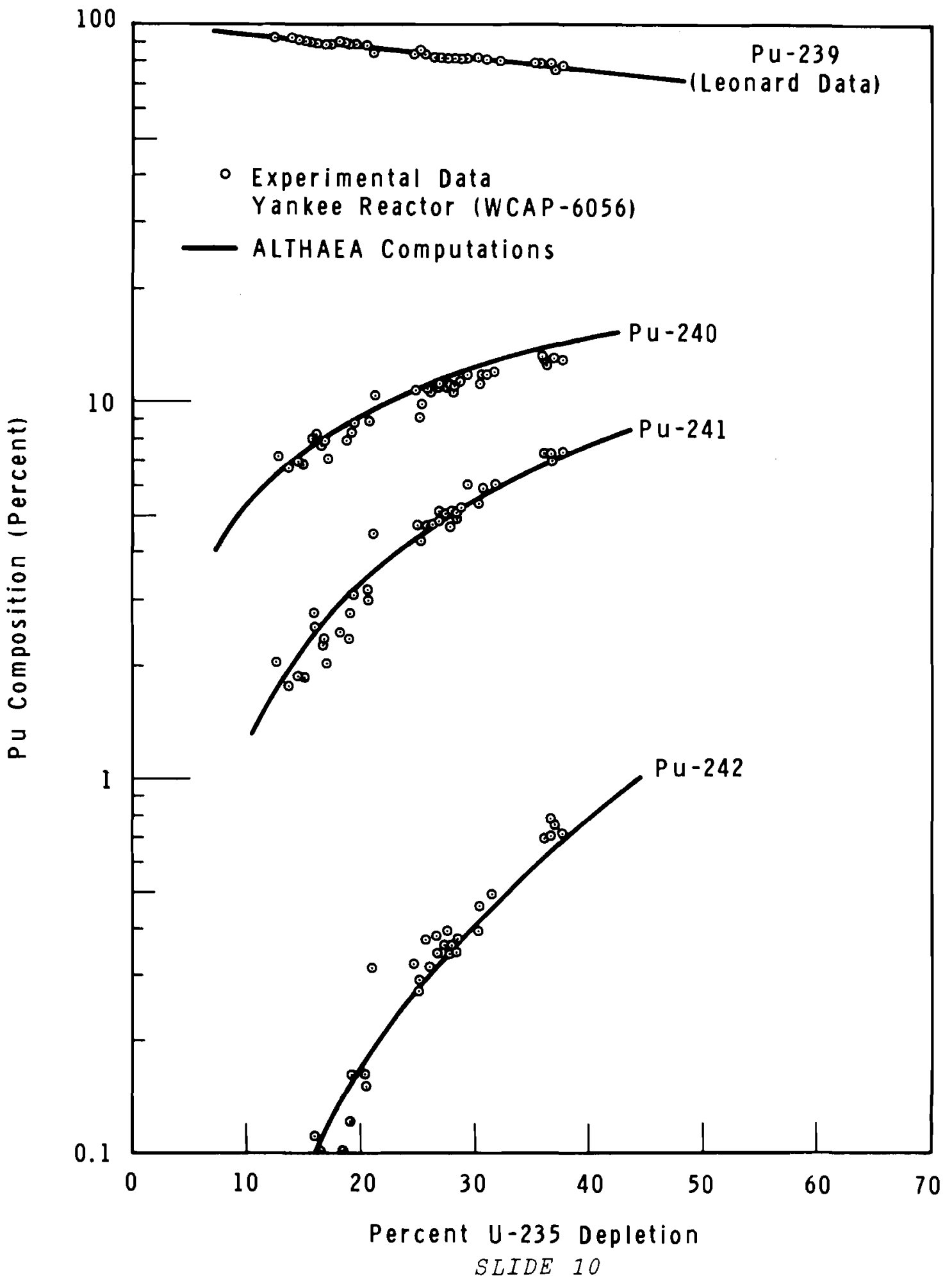


IV -18

BNWL-183-IV

$\mathrm{PUO}_{2}-\mathrm{UO}_{2}$ FUEL IRRADIATED IN PLUTONIUM RECYCLE

TEST REACTOR

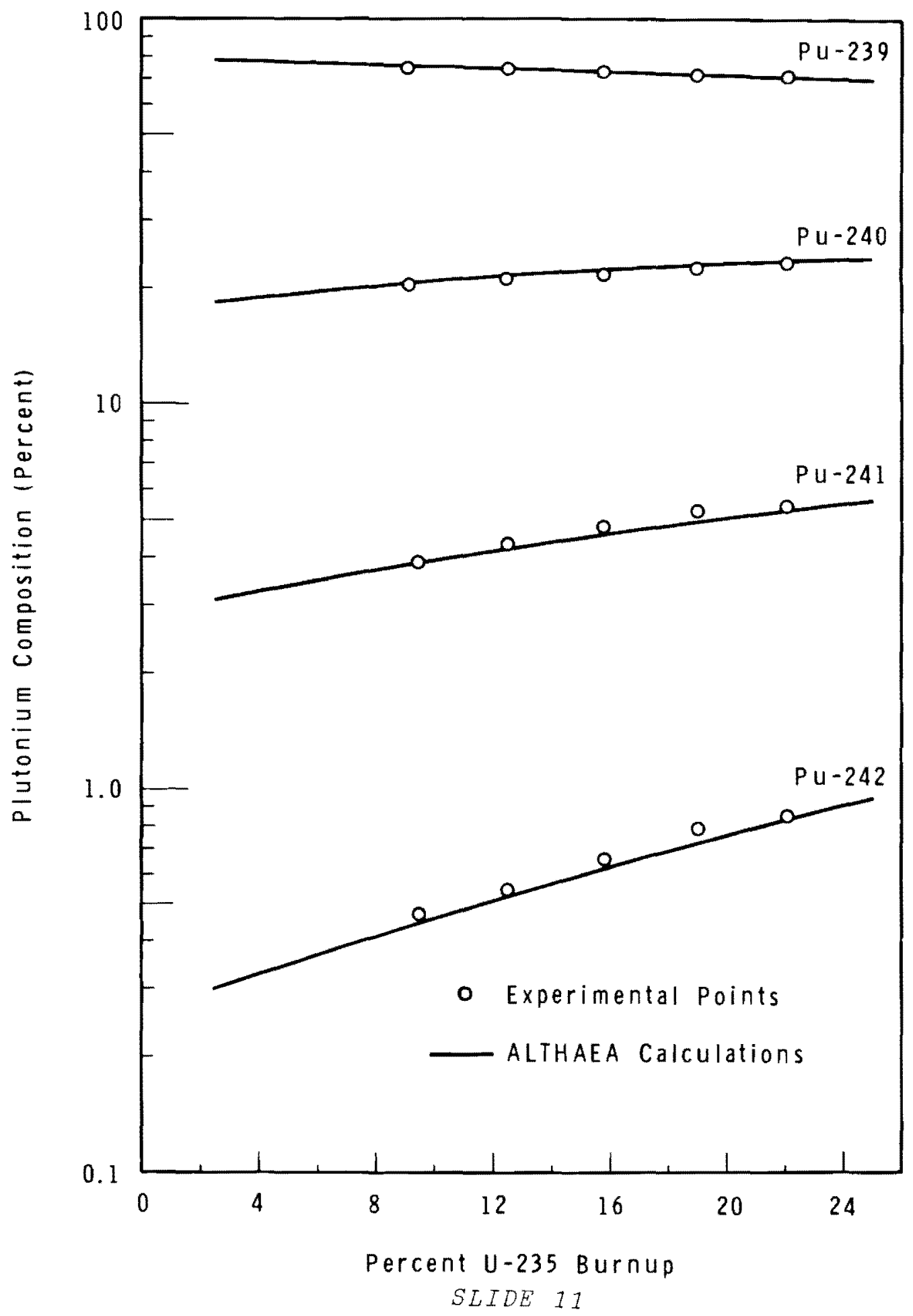


a single burnup case. However, as one applies a given calibration over a wider range, one must be willing either to accept a larger error or to provide a more general calibration by making a more adroit selection of the calibration coefficient adjustments. Further, one must know when to quit adjusting coefficients on ALTHAEA and when to secure the services of a more basic code. We are still calibrating the code, and we are just now developing enough "fee 1 " to be able to make an adjustment without throwing everything else out of kilter. As more burnup data become available, we may be able to use a formal statistical method to minimize all errors, rather than rely on intuition alone.

Slide 12 shows how we 11 the ALTHALA code can be calibrated when the number of variables affecting cross sections, flux, etc., is $1 \mathrm{im-}$ ited to one variable--namely, the moderator-to-fue 1 ratio. In this case, the fuel composition is like that found in a power reactor after an exposure of approximate $1 y$ $8000 \mathrm{MWd} / \mathrm{T}$. Note that for each isotope considered, the difference in cross section between the HRGTHERMOS codes and ALTHAEA is usually on the order of $1 \%$. Admittedly, only two moderator-to-fue 1 ratios were considered, but since these are characteristic of present-day power reactors, it was not necessary to consider others.

Slides 13 and 14 show the difficulties that arise in the determination of cross section when one tries to vary the enrichment in a given neutron spectrum. In Side 13 the fuel consisted of natural uranium oxide enriched with $1 / 2,1$, and $2 \%$ plutonium at $20^{\circ} \mathrm{C}$. Note that cross sections of the fissionable isotopes show variations with the changes in enrichment, but that the value of a associated with each isotope checks more close $1 y$.

Slide 14 presents the same fue 1 conditions; only this time the average cell temperature is $300{ }^{\circ} \mathrm{C}$. Note that the variation in cross section as the enrichment changes is not as drastic as in the $20^{\circ}$ casc. Again we see that the $\alpha$ for the fissionable isotopes checks well. Thus we arrive at the important question of whether cross section or a should be maintained. Of course, one would like to maintain both parameters. But when this is not possible, it can be shown that, from the viewpoint of fuel cycle analysis and reactivity, it is much better to maintain $\alpha$.

To summarize:

1. There is a definite need in fuel cycle economic surveys for a high speed burnup code that can be relied upon to produce accurate results for many types of reactor systems.

2. The ALTHAEA code satisfies this requirement; at the same time it is capable of being quickly and accurately calibrated to a particular reactor system.

3. Once calibrated, ALI'llAl:A can accurately determine at any time during the burnup the isotopic compositions of transuranium isotopes having atomic woights as high as that of $\mathrm{Cm}^{244}$

4. The calibration of ALIIIALA is 
COMPARISON OF HRG-THERMOS AND P 3 -ALTHAEA CROSS SECTION VALUES FOR PWR CELLS AT $20{ }^{\circ} \mathrm{C}$

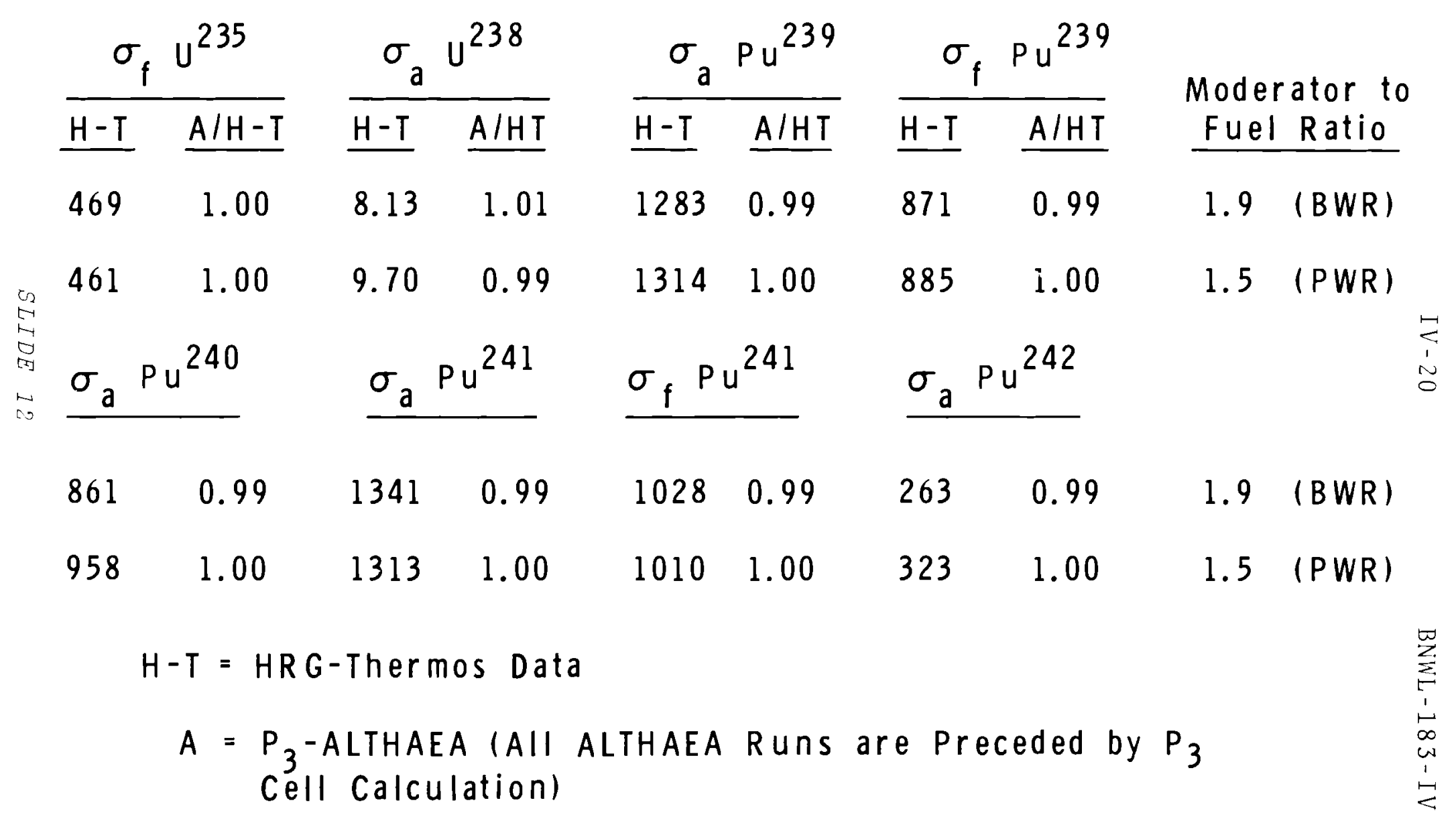


COMPARISON OF HRG-THERMOS AND P3-ALTHAEA CROSS SECTION VALUES
AT $20{ }^{\circ} \mathrm{C}$ ( $\frac{\text { Moderator }}{\text { Fuel }}=1.5$, Natural $\left.\mathrm{UO}_{2}-\mathrm{PuO}_{2}^{*} \mathrm{Fuel}\right)$

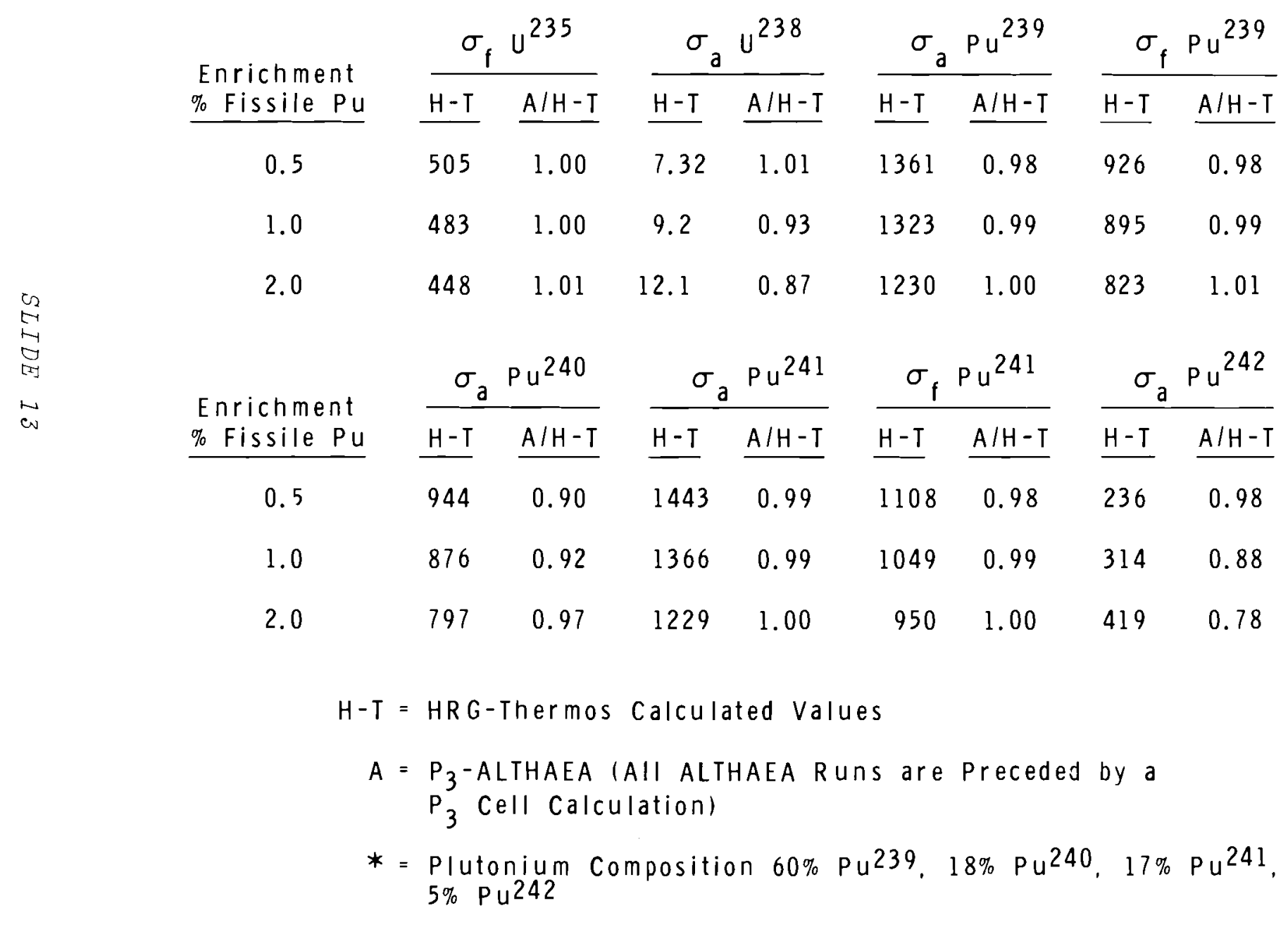


COMPARISON OF HRG-THERMOS AND P3-ALTHAEA CROSS SECTION VALUES AT $300^{\circ} \mathrm{C}$

( $\frac{\text { Moderator }}{\text { Fuel }}=1.5$, Natural $\left.\mathrm{UO}_{2}-\mathrm{PuO}_{2} * \mathrm{Fuel}\right)$

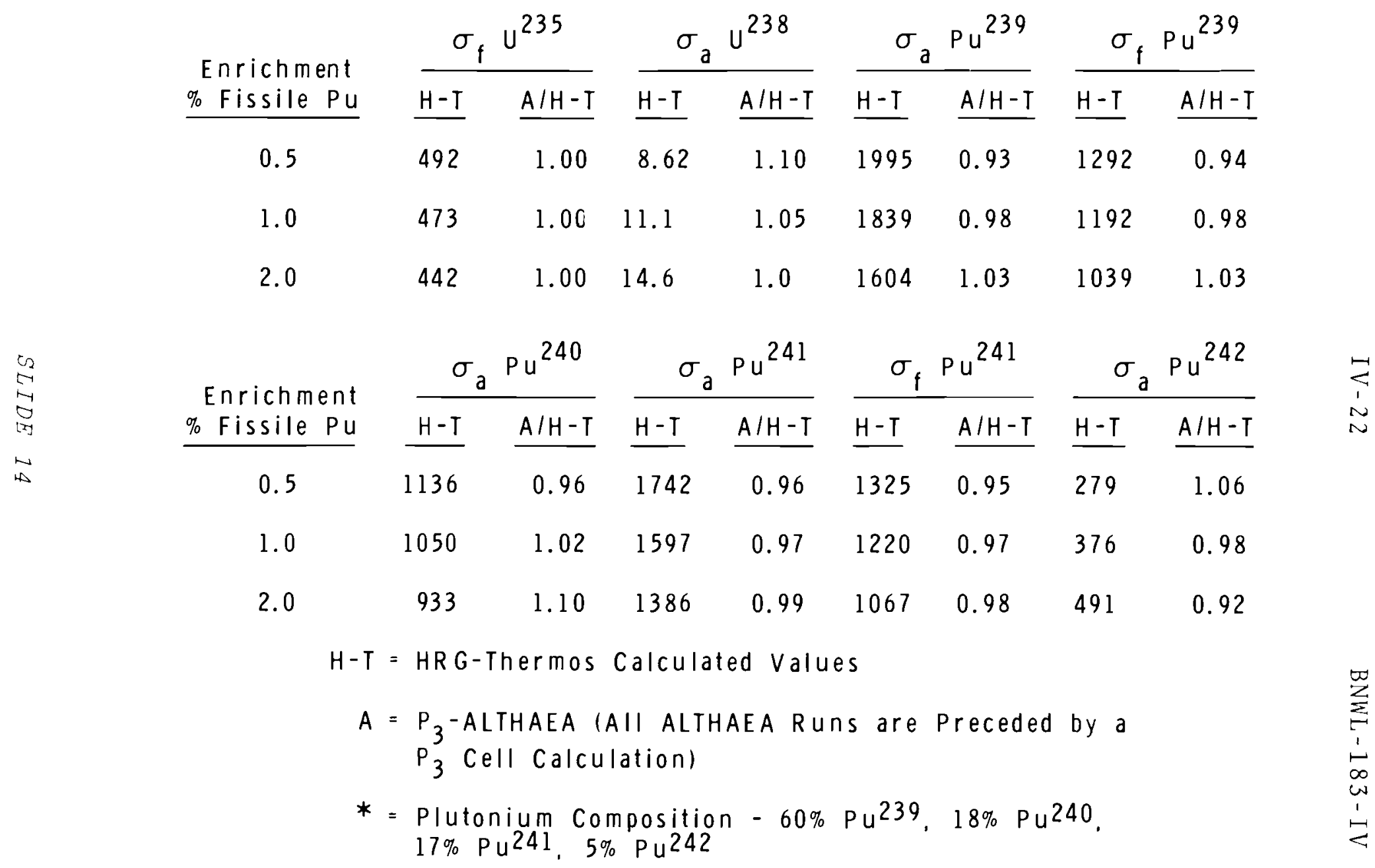


achieved by the adjustment of three primary calibration coefficients affecting neutron spectrum, resonance escape probability, and neutron temperature. Complete calibration is obtained when the self-shielding and cross shielding coefficients are adjusted to align computed isotopic compositions with experimental data available

for the reactor system under investigation.

5. Once calibrated for Iight water moderated reactors, ALTILALA will handle other moderators quite accurately. For this reason, the code is very useful for fuel survey purposes. 


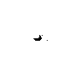

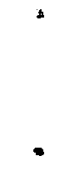

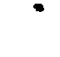


BNWL $-183-V$

SECTION V

\section{CONSERVATION ECONOMICS AND REACTOR TECHNOLOGY}

W. I. Neef

E. D. Jones

Battelle Memorial Institute Pacific Northwest Laboratory

Richland, Washington

November, 1965

Paper for oral presentation at the American Nuclear Society 1965 Winter Meeting Washington, D.C., November 15-19, 1965 


\title{
CONSERVATION ECONOMICS AND REACTOR TECHNOLOGY*
}

\author{
W. I. Neef*t and E. D. Jones, Jr. ${ }^{\dagger}$
}

There has been much concern recent1y about the problem of conserving our national uranium resources. There is universal agreement that breeder reactors will solve the problem after the year 2000 A.D. However, there is almost universal disagreement on the need for breeders during the rest of this century.

Some writers believe that we must begin a crash program to develop fast breeders so as not to deplete our fissile fuel resources to the point where we cannot exploit the energy potential in our fertile fuel resources. Other writers feel that, even with a crash program, breeders cannot be developed soon enough, and that high-conversinnratio advanced converter reactors must be developed in order to save fissile resources for use as breeder starters.

What further complicates this controversy is that there are variations in concept and detailed design within each of the main reactor types. The present work was undertaken in an at tempt to resolve this uranium conser-

* This paper is based on work performed under united states Atomic Energy Commission Contract AT $(45-2)-2830$. Permission so publish is gratefully acknowledged.

* Senior Research Engineer

+ Engineer, physics and Instruments Department, Pacific Northwest Laboratory, operated by Battezle Memorial Institute for the United States Atomic Energy Commission, Richland, Washington. vation question. In order to form an overall evaluation of uranium resource usage, we wrote a computer code, called VESTA, to combine nuclear power industry forecasts with reactor characteristics.

The forecast we used to obtain the results presented here is our modification of the forecast for this century published by the ABC in its 1962 "Report to the President," with our extrapolation into the next century added. We have deliberately used a forecast which is high in order to overstate the potential uranium requirements. The thermal reactors used in this work are simulated pres surized water reactors based on the $1000 \mathrm{MW}_{\mathrm{e}}$ PliR designed by Westinghouse. The advanced converter reactors we used are the sodium-graphite reactor (SGR), the heavy-water reactor (IHR), and the heavy water organic-cooled reactor (HWOCR). The two fast breeder reactors used in this study are based on designs by Allis-Chalmers and Combustion Engineering: the A11is Chalmers design was selected because it could be built in the very near future and has a long doubling time; the Combustion Engineering design because it has a short doubling time.

No matter what type of breeder reactor is developed or how soon it is developed, the economic use of uranium resources would seem to 
require the use of plutonium recycle in thermal reactors. The different roles played by thermal and breeder reactors in an expanding nuclear power industry could involve four dis tinct phases.

During the first phase, which will last for the next 10 to 20 years, thermal reactors will be constructed. These reactors will produce plutonium that can be either recycled or stockpiled for breeder inventories. To avoid delay in receiving payment for a valuable product, thermal reactor operators will probably sell or recycle plutonium rather than stockpile it until breeders become operationa1. (Plutonium recycle is now being adopted by the Production Group of the United Kingdom Atomic Energy Authority for just this reason.) However, by the time a reactor is ready to recycle its discharged plutonium, additional reactors will have been constructed. The available plutonium will be shared by all the reactors, leaving on $1 y$ part of the plutonium for the reactor that produces it. This first phase will be one of "fractional" recycle of plutonium in all reactors. The fraction will depend on the growth rate of the reactor indus try and the length of the holdup in the fuel cycle. The use of plutonium for enrichment will reduce the amount of uranium that would otherwise be required by thermal reactors during this phase.

During the second phase, which will probably begin during the 1980 's, breeder reactor construction will start. At the beginning of this phase, the nuclear power capacity will be doubling every 3 to 5 years. Most breeders are designed to produce a doubling of their total fissile fuel inventories every 7 to 20 years. To keep up with the expected demand for electrical encrgy, construction of thermal reactors must continue until the breeders become self-sustaining, which cannot occur until the doubling time of the nuclear power industry lengthens to greater than the fuel doubling time of the reactor. This second phase will extend to about the year 2010 or 2020 . It is interesting to note that during the first part of this phase, when the thermal reactors already constructed form a large share of the installed power generating capacity, the switchover of thermal reactors from plutonium recycle to operation on slight $1 y$ enriched uranium wi 11 require more total uranium than would have becn required had brecders not been introduced. It will on $1 y$ be during the latter part of the sccond phase that the inherent advantages of brecder reactors will begin to materialize. Throughout the second phase, the price of temporarily scarce plutonjum should rise, causing thermal reactor operators to reduce fuel exposures in order to export plutonium. And the resulting lower enrichments will tend to reduce the total uranium consumption.

The third phase, which may be the shortest, will occur when the breeders become almost self-sustaining and the growth in fuel inventory is kecping pace with the growth in nuclear power gencration. During this phase, all new reactor construction will be for breeder reactors, and after the plutonium inventory requirements of. 
breeder reactors have been satisfied, some plutonium will be available for recycle in thermal reactors. The thermal reactors will then return to operation with partial recycle, just as in the first phase, and plutonium will again be priced near its value as a thermal reactor fuel.

Finally, in the fourth phase, plutonium production will exceed demand. Thermal reactors will then recycle at least as much plutonium as they produce, and breeder reactors will, in all probability, be allowed to lose a few neutrons because the plutonium produced by these neutrons would not be salable. Plutonium will be available for other uses, such as burner cycles for portable reactors, and its price will not depend on its value as a thermal reactor fuel. It is worth noting that long-doublingtime reactors will then be able to siphon off plutonium without compromising the conservation of uranium resources.

Of course, we cannot say that the performance of reactors in the future will be the same as it is today. Nor can one accurately predict how improved reactors such as fast breeders will be introduced. For example, plutonium fast breeders could be introduced as fast converters using $U^{235}$ from the uranium cascade. And if fast reactors are designed with hard enough spectrums, a system of such reactors will use less natural uranium during the four phases described above than the system just analyzed.

The computer code VESTA calculated the effect that an expanding nuclear power industry would have on uranium utilization during each of the four phases described. As we have indicated in a previous report, the results show that the date when breeder reactors are introduced into the nuclear power economy is not nearly as important to the conservation of uranium resources as the type of breeder introduced, or developed to the point of being a competitive power producer. In this study we have extended the work to include both the impact of thermal reactor technology and the interaction of economic factors on uranium utilization. The first slide shows what hapnens to thermal and breeder power generating capacities if 7-year doubler and 20year doubler breeders using plutonium are introduced in 1975 and 1990. The top curve represents the total thermal and breeder nuclear generating capacity between now and the year 2020. This total will, of course, all be thermal reactor capacity if no breeders are developed.

The year 1975 was selected hecause this is the earliest date that a significant number of breeders could be in operation, even with a crash development program. The year 1990 , on the other hand, is the probable date when breeders will be in operation if the present rate of reactor development continues. If a 20-year doubler is the breeder ultimately developed, then the number of thermal reactors is about the same whether the breeder is introduced in 1975 or 1990. llowever, if the 7-year doubler is introduced even as late as 1990, the number of thermal reactors will be significantly fewer than when the 20 -year doubler 
INSTALLED CAPACITY FOR VARIOUS BREEDER

INTRODUCTION DATES--PWR-5 YEAR TIME STEP

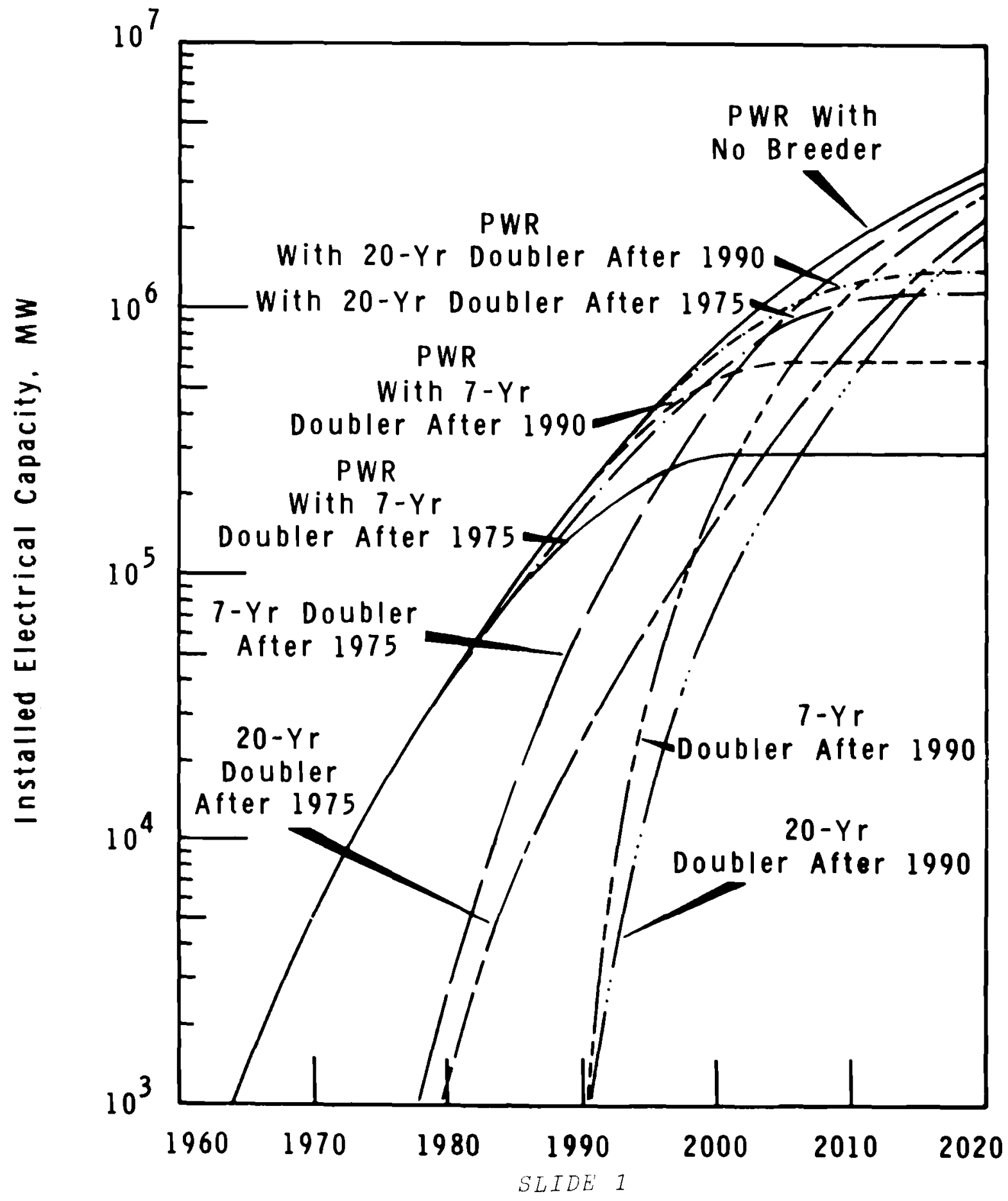


is introduced in 1975. The curve showing the lowest capacity, with a 7 -year doubler introduced after 1975 , is probably unattainable even on a crash program basis. The bottom curves show the breeder capacity for each of the four cases just mentioned. The figure also shows that the breeder capacity will be the dominant nuclear power source in the next century.

Slide 2 shows explicitly the uranium requirements for these four cases. The maximum amount of uranium will be required when there are no breeders in operation. Note that the date the 20 -year doubler is introduced makes 1 ittle difference in the amount of uranium consumed; also that if the 7 year loubler is introduced after 1990 , one-third less uranium will be required than if the 20 -year doubler is introduced after 1975. The lowest curve shows the uranium consumption if a 7 -year doubler is introduced after 1975. If we extrapolate the curves beyond the year 2020 , the difference between any two of them becomes even more dramatic. These data are for light water reactors. During the course of our calculations we performed similar studies on heavy water reactors and reached almost identical conclusions. S1ide 3 shows for several thermal reactor systems what happens to total thermal and breeder power generating capacity if 20 -year doublers are introduced in 1980 and if 7 -year doublers are introduced in 1990. Note that in the early 1990's, when sufficient plutonium is available to allow all of the increase in total nuclear capacity to be in breeders, the thermal capacity will be about the same, regardless of the type of thermal reactor in operation. Slide 4 shows the amount of uranium used by each of these four thermal reactor systems. The differences in the amount of uranium required for the various thermal reactors are on the order of $10 \%$ between reactor types. Slide 5 shows the important difference between reactor systems--namely, differences in separative duty requirements. Note that the $1 \mathrm{ight}$ water reactor separative duty requirement reaches a maximum around the year 1993. This maximum is about the same as our present capacity. The heavy water reactors also require a maximum separative duty requirement about the same time, but at a much lower level. Note that after about the year 2015 , the cascade plants will not be needed for the HwoCR system, because its optimum enrichment corresponds to that of natural uranium.

Another parameter of thermal reactor technology which is important to uranium conservation is the manner in which plutonjum is recycled. If placed in the proper position within the fuel elements of the reactor, plutonium can be uscd more efficiently to improve the conversion ratio of the reactor itself. Dotails of these recycle techniques were discussed carlicr by Mr. Merrill. How these techniques will affect uranium utili zation is shown in Slide 0 , which is based on the assumptions that 20 -year doublers are introduced after 1980 and that 7 -year doublers are int roduced after 1990. This figure shows the total amount of loranium consumed in a 
CONSERVATION EFFECT OF BREEDER INTRODUCTION

DATE--PWR-5 YEAR TIME STEP

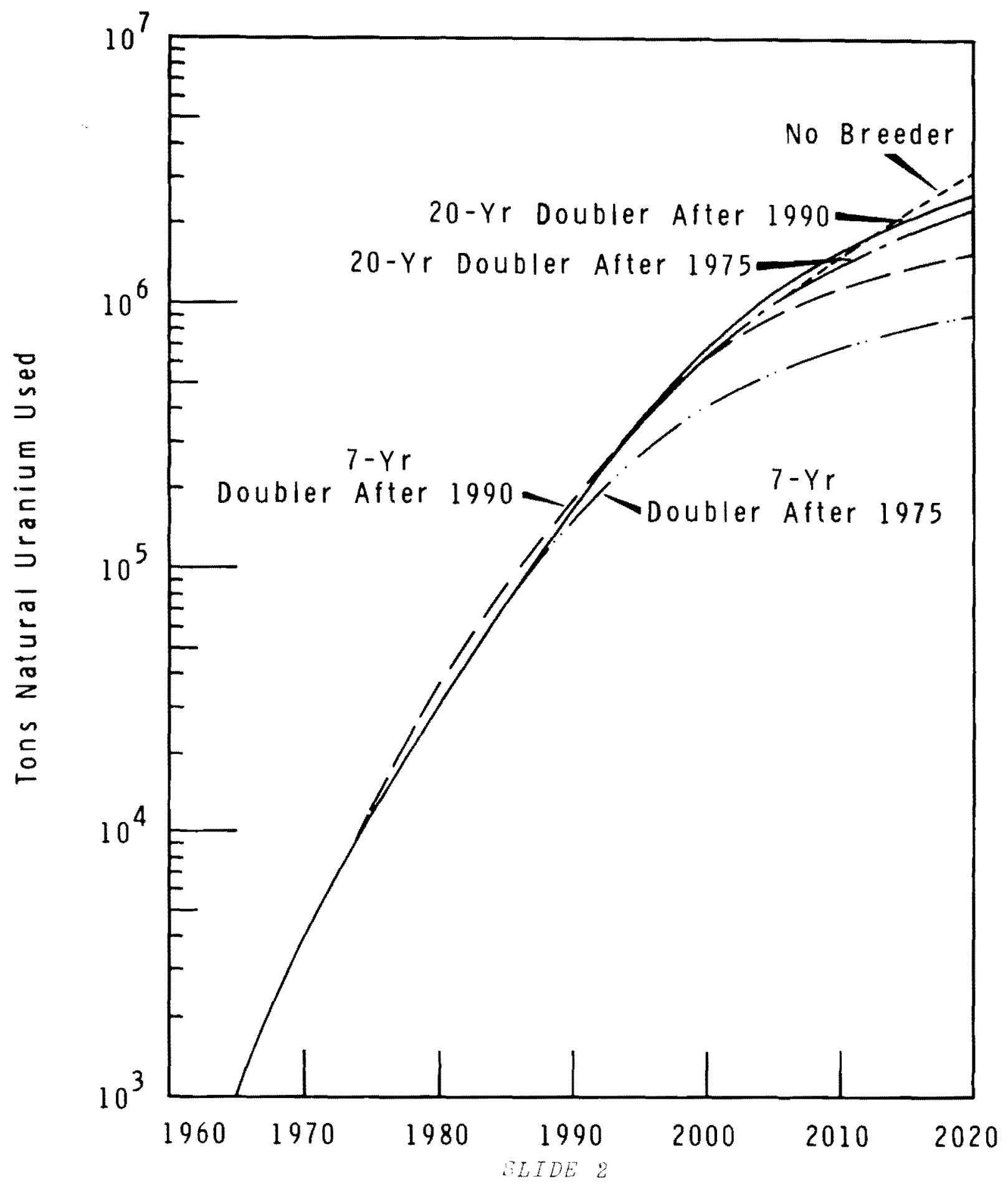


INSTALLED CAPACITY FOR PLUTONIUM LIMITED

BREEDER CONSTRUCTION--3-YEAR TIME STEP

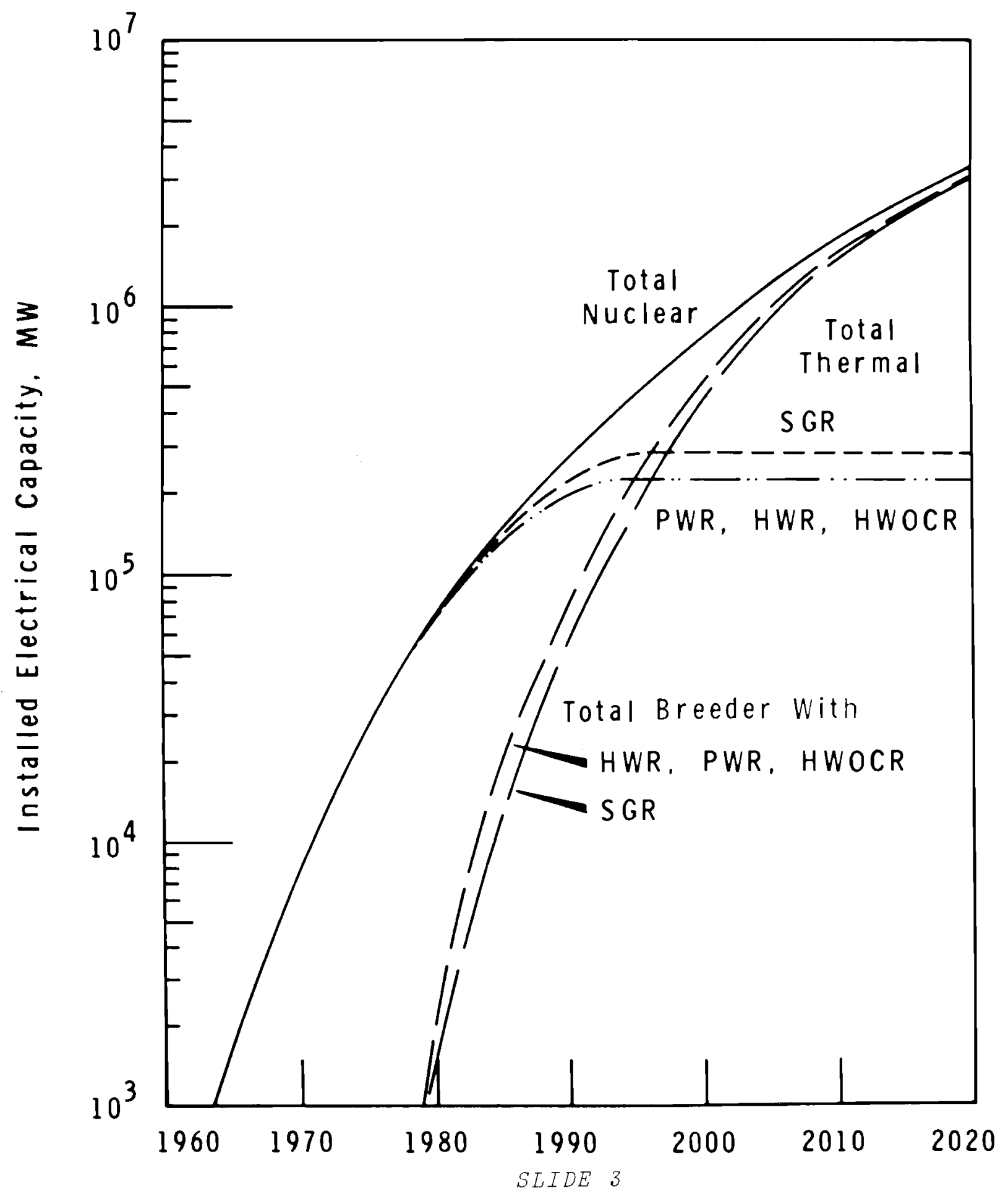


V -8

TONS OF NATURAL URANIUM USED FOR VARIOUS THERMAL REACTORS--3-YEAR TIME STEP

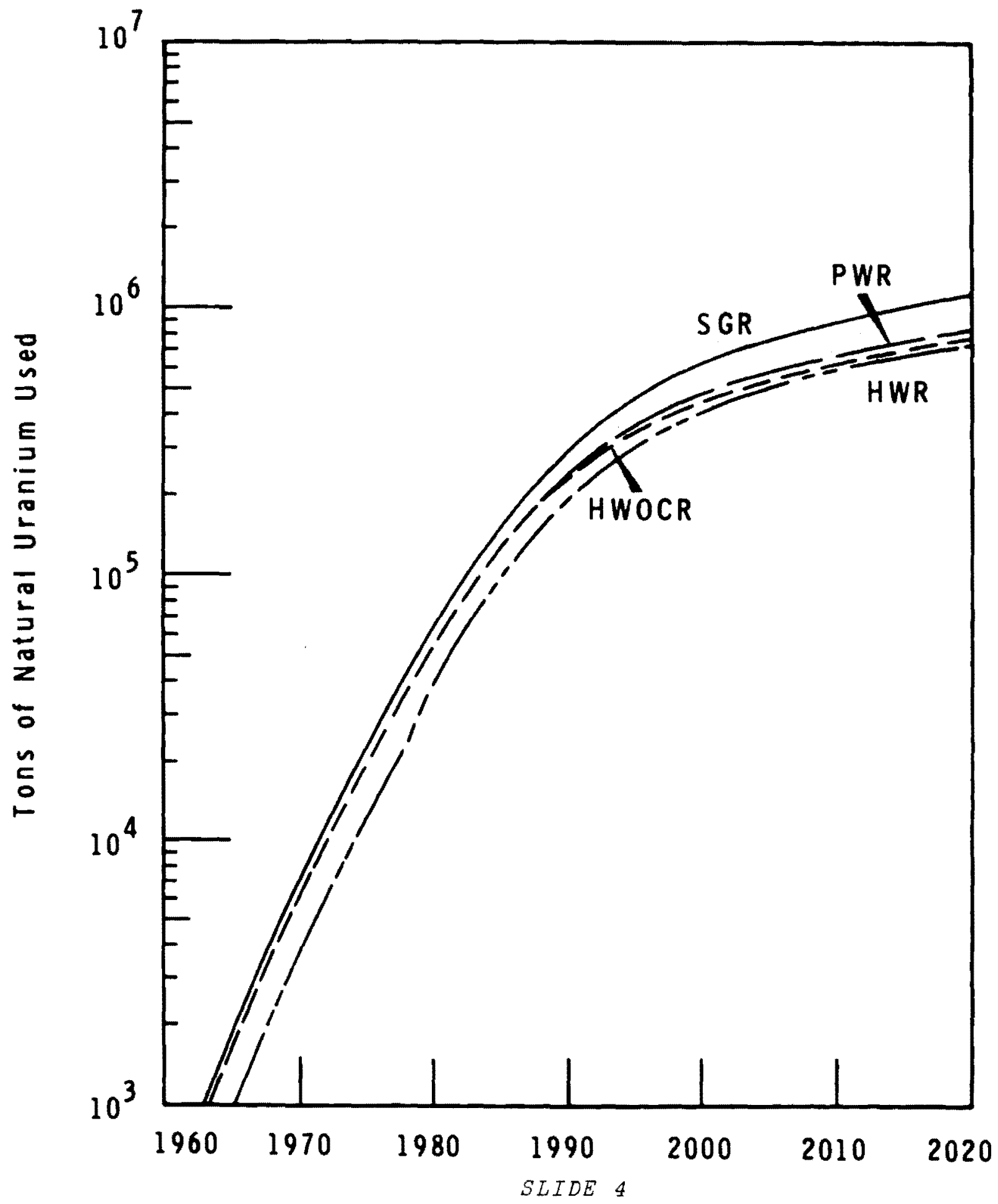


SEPARATIVE DUTY REQUIREMENTS FOR VARIOUS THERMAL REACTORS--3-YEAR TIME STEP

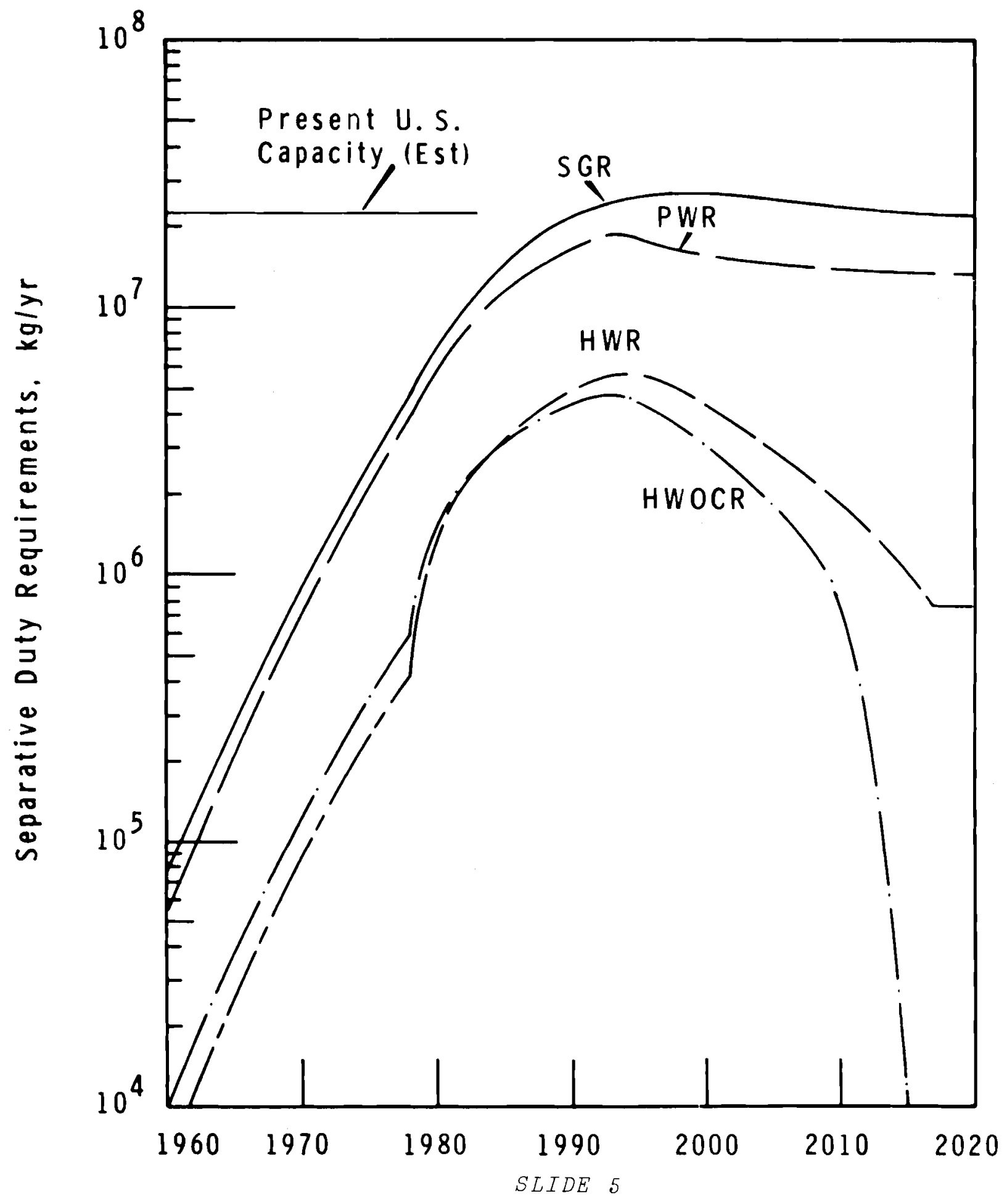


URANIUM REQUIRED FOR VARIOUS $\alpha^{49}$--PWR

3 YEAR TIME STEP

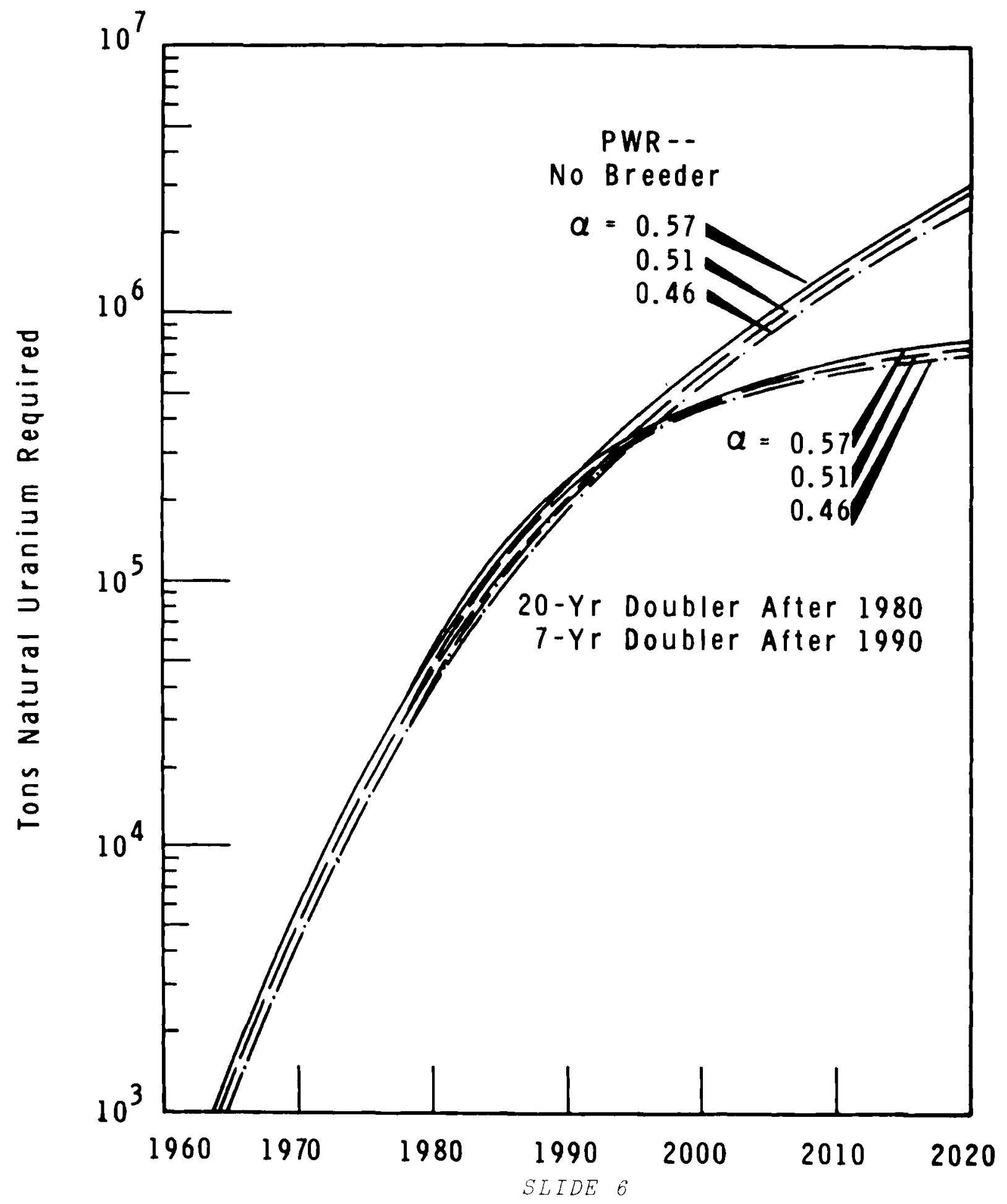


light water reactor system, with and without breeders, for three values of alpha (the capture-to-fission ratio) of $\mathrm{Pu}^{239}$ in recycled plutonium. In both sets of curves the lower the alpha is, the lower the amount of uranium consumed. One might expect the improvement in alpha to have a larger effect on uranium consumption. Howaver, the dynamics of an expanding economy override the effect of alpha variation. The lower alpha is only available in recycled plutonium, and a large fraction of the uranium is used when plutonium is not being recycled. (We at Pacific Northwest Laboratory are now performing calculations to determine the possible savings resulting from lowering the alpha of $\mathrm{U}^{235}$ by similar recycle techniques. Preliminary results from these calculations indicate that a one-fourth reduction in the alpha of $\mathrm{u}^{235} \mathrm{might}$ reduce the uranium requirements by more than $20 \%$ )

Slide 7 shows that the thermal reactor specific power also affects the total amount of uranium that will be consumed. The higher the specific power, the lower the amount of uranium required.

On page 577 of the Transactions, the first two rows in Table I of the summary of this paper show that the effect of the external processing costs on the total amount of uranium used is also important. Note that if the fuel fabrication and separation costs for a 1 ight water reactor can be reduced to about one-half the present values of $\$ 125 / \mathrm{kg}$ and $\$ 32 / \mathrm{kg}$ respectively, then the total amount of uranium required is reduced by almost
$10 \%$. This is primarily due to the fact that if the external processing cost is reduced, the optimum exposure is also reduced, giving a lower optimum enrichment.

Uranium resource conservation and nuclear fuel cost economy are somewhat conflicting optimization criteria. Suppose we calculate the enrichment which yields the minimum fuel cycle cost for a thermal reactor. Now let us reduce this enrichment by a slight amount such that we operate the reactor at a fuel cost which is a tenth of a mill per kilowatt-hour above the minimum. Slide 8 shows that this saves about $15 \%$ of the amount of uranium burned. liowever, reducing the enrichment further so that fuel cycle costs are 2 or 3 tenths of a mill per kilowatt-hour above the minimum does not save additional uranium because these decreases in enrichment are very slight. (It should be noted that a change in fuel cycle cost of a tenth of a mill per kilowatt-hour means $\$ 700,000$ per year to a 1000 megawatt reactor operator.)

It is reasonable to assume that during the next several years plutonium will be priced at its thermal reactor fuel value, and that thermal reactors will be built exclusively. During this period, thermal reactors will probably recycle the plutonium they produce. Later, while breeders are being introduced, thermal reactor operators may prefer to sell rather than recycle temporarily scarce plutonium, its value as a fast reactor fuel being perhaps two or three times its value as a thermal reactor fuel. Still later, when breeders become 
EFFECT OF SPECIFIC POWER ON URANIUM REQUIREMENTS--PWR-5 YEAR TIME STEP

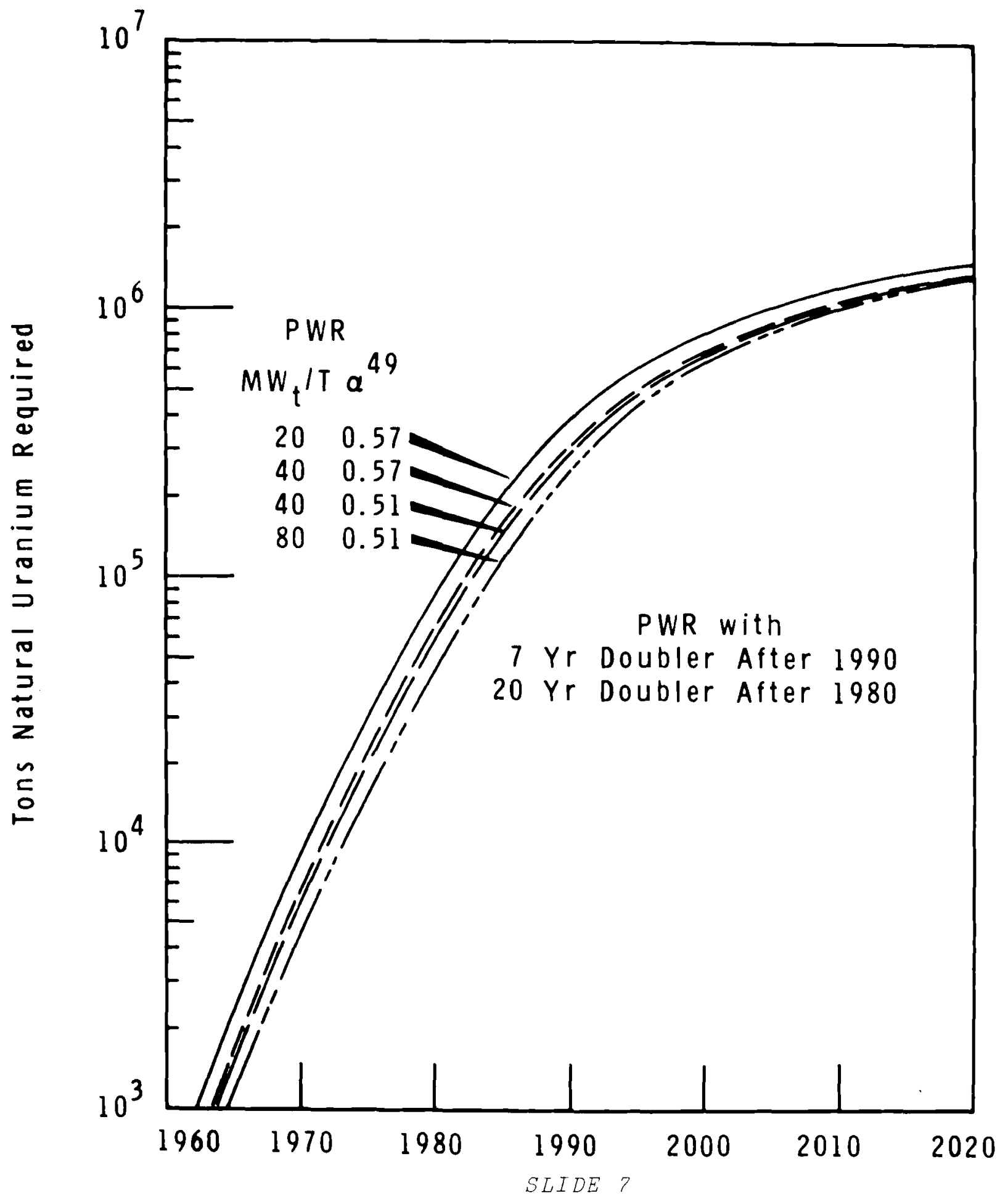




$$
\mathrm{V}-13
$$

BNWL- $183-V$

EFFECT OF FUEL COST MINIMIZATION ON URANIUM REQUIREMENTS--PWR-3 YEAR TIME STEP

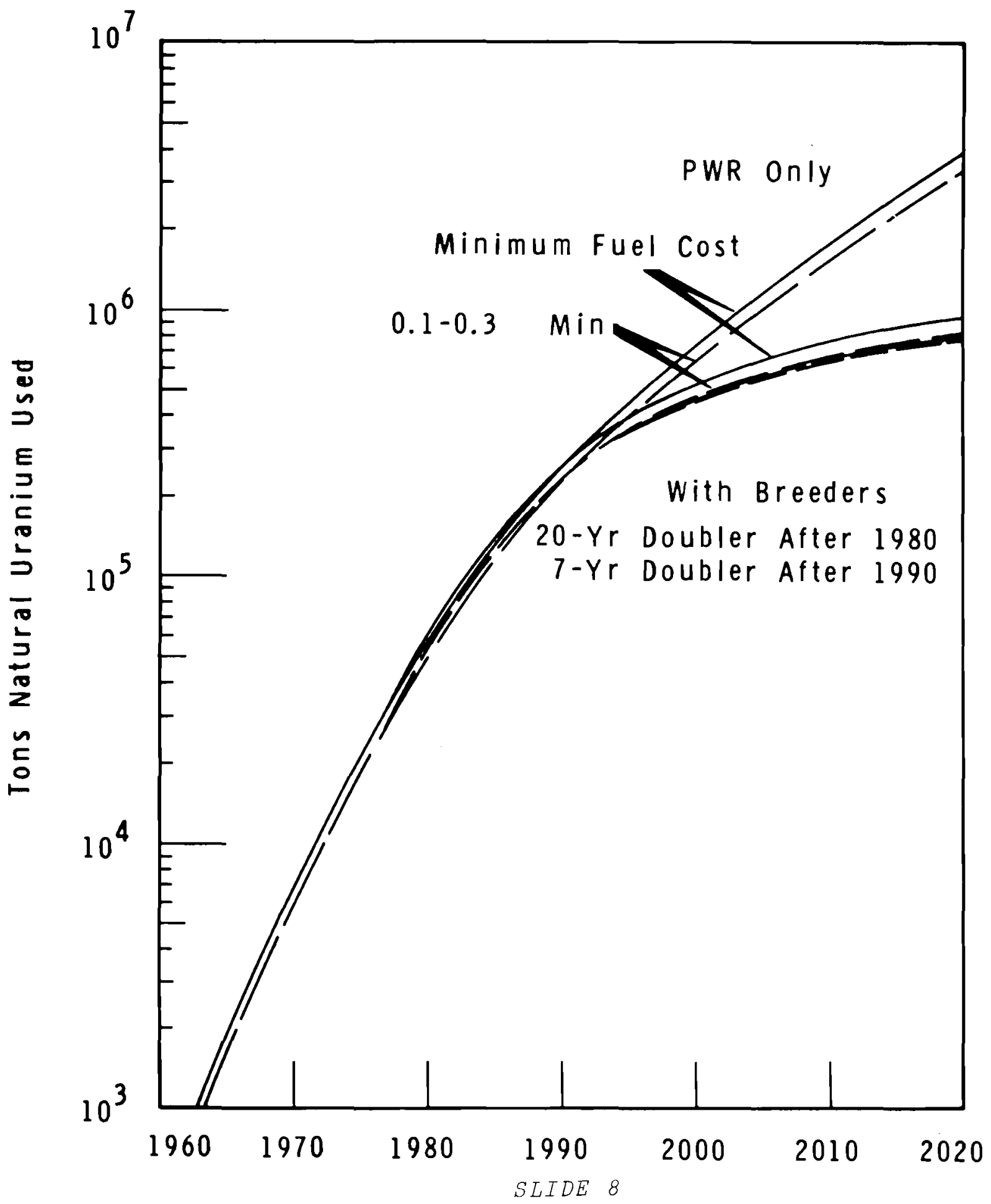


self-sustaining, plutonium will become a surplus commodity and the price of plutonium may then drop to half its value as a thermal reactor fuel. These differences in plutonium prices are shown in Table I of the Transactions of this meeting, page 577. The effect of these plutonium price variations on heavy water reactor uranium requirements is not great. However, for a 1 ight water reactor economy, these differences can be as much as 150,000 tons between now and the year 2020 .

The code written to perform these calculations divides the estimated growth of the nuclear power industry into successive time increments. During each of these increments the number of reactors in operation, the average plant factors, specific powers, conversion ratios, exposures, etc., remain constant and change on $1 y$ between time periods. The plutonium required to construct breeders for any one period must have been produced by the end of the previous period. This means there is a lag between the time that plutonium is produced and the time that it is needed, a lag equal to the length of the time step. We checked the importance of this lag by ruming parallel calculations which divided the growth curve between now and the year 2020 into time steps of $1,2,3$, 4 , and 5 years. The results of these calculations are shown in Slide 9. As expected, the shorter the time period, the more rapidly breeder reactors can be constructed. For example, in 1990, a total of 200,000 breeder megawats are installed if a one-year period length is assumed, but on $1 y 30,000$ megawatts are installed if a 5 -year period length is assumed. llowever, after the year 2020 , the total breeder megawatts are about the same, regardless of the time step assumed. As shown in Slide 10, variations in uranium requirements will be significant because of the additional thermal reactors required as a result of the plutonium limitation on breeder construction. A1so, more thermal reactors must be built if longer time period lengths are assumed. And if more thermal reactors are built, more uranium will be used. Slide 11 shows that the longer periods require a 1 arger separative duty. The cusp in the curve around 1980 represents the conversion of thermal reactors from plutonium recycle to uranium-only operation as breeders are introduced. The differences in these separative duty requirement curves result from differences in thermal reactor capacity. The curves flatten out when breeder reactors are supplying all the plutonium needed for the increasing breeder inventory requirements, and plutonium becomes an excess commodity. Breeders will also be exporting plutonium to thermal reactors, which will then be using as much of the excess plutonium as they can use conomically. The difference between the time plutonium is first produced and the time it can complete its residence in the reactor and then be separated and refabricated and made ready for charging back into a reactor is probably about three years. Of course, if close-coupled separations and fabrication plants are used, this time period might be reduced to about one 
INSTALLED BREEDER CAPACITY FOR VARIOUS TIME PER IOD LENGTHS--HWR

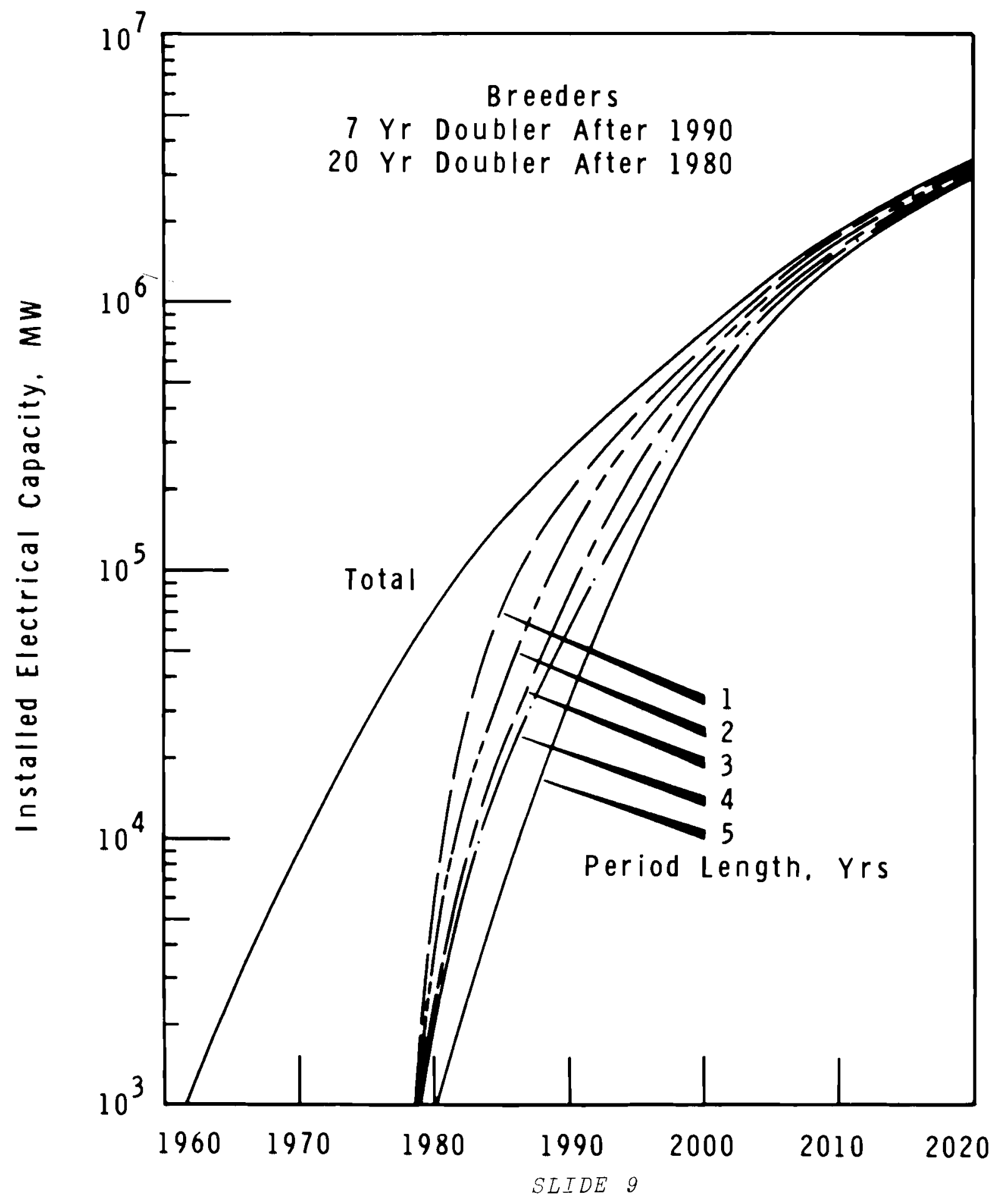


EFFECT OF TIME PERIOD LENGTH ON URANIUM REQUIREMENTS

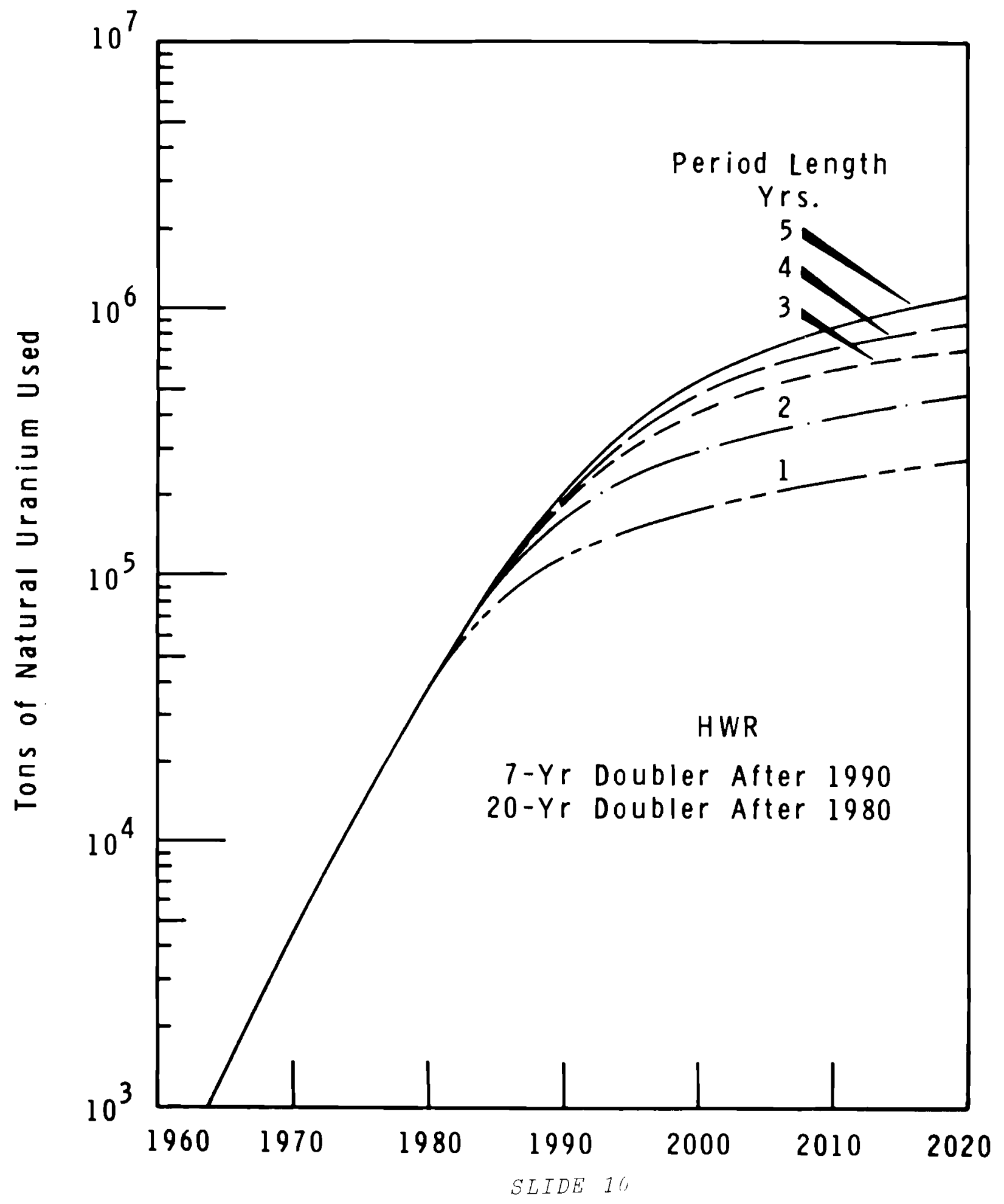




\section{EFFECT OF PERIOD LENGTH ON SEPARATIVE DUTY REQUIREMENTS - HWR}

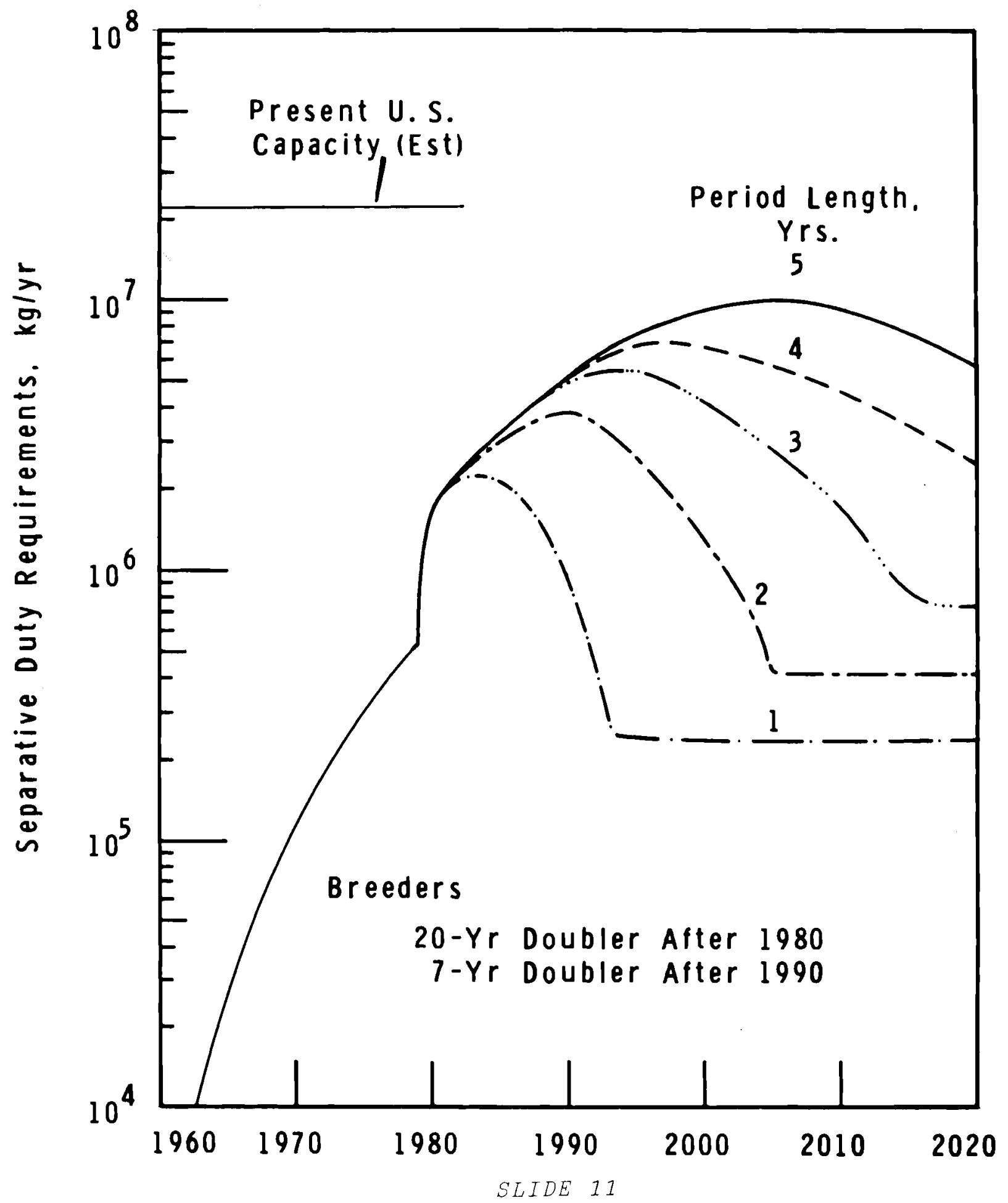


year; an increasing plutonium price might bring this about.

Although this study indicates that there is no real threat to our uranium resources, more investigation is needed to assess the effect of fast converters on uranium conservation and on the interaction of fast and thermal reactors. Our uranium resources could be stretched by using thorium systems, provided they do not unduly drain the plutonium or $\mathrm{U}^{235}$ needed by uranium systems. It would appear that some sort of hybrid system such as the crossed progeny system just described by $\mathrm{Mr}$. Deonigi might be best.

In this paper, we have presented a selection from several hundred cases. The complete study will be published as a BNWL report.

There are three primary conclusions to be drawn from all these calculations. First, the technological development of thermal reactors and the economic situation which may occur between now and the year 2020 wi 11 have as much effect on uranium resource conservation as will the breeder technology which is ultimately developed. Second, minimizing the cost of power will not necessarily minimize the amount of uranium consumed. However, maximum conservation in a reactor system can be essentially obtained from an investment of $0.1 \mathrm{mil} 1 / \mathrm{kWh}$ in fuel cycle costs. Third, the length of time that plutonium is "immobilized," as the French say, in the fuel cycle, is as important to the utilization of uranium as the type of fast reactor developed. The orderly development of high-specific-power short-doubling-time breeder reactors will do more toward preserving our resources and ensuring a long time energy supply than will a crash program to develop "interim" reactors which do not have these outstanding conservation characteristics. Lconomic considerations will affect the uranium utilization picture at least as much as technological considerations. 


\title{
ONSITE DISTRIBUTION
}

\section{Copy Number}

\author{
Pacific Northwest Laboratory \\ F. W. Albaugh \\ C. A. Bennett \\ F. G. Dawson, Jr. \\ D. E. Deonigi \\ R. F. Dickerson \\ E. A. Eschbach \\ $6-166$ \\ 167 \\ 168 \\ 169 \\ 170 \\ 171 \\ 172 \\ 173 \\ 174 \\ 175 \\ 176 \\ 177 \\ 178 \\ 179 \\ 180 \\ 181 \\ 182 \\ 183 \\ 184 \\ 185 \\ 186 \\ 187 \\ 188 \\ $189-190$ \\ S. L. Fawcett \\ H. Harty \\ P. A. Horton \\ E. D. Jones, Jr. \\ B. B. Lane \\ E. T. Merril1 \\ J. N. Morgan \\ J. H. Nail \\ W. I. Neef \\ R. S. Pau1 \\ J. G. Rake \\ W. A. Reardon \\ L. R. Reynolds \\ W. D. Richmond, Jr. \\ E. A. Schnaible \\ J. R. Sheff \\ R. E. Shippert \\ R. E. Thompson \\ C. R. Tipton, Jr. \\ M. T. Walling, Jr. \\ Technical Information Files \\ Technica1 Publications, 300 Area \\ Technical Publications, 700 Area \\ General Electric Company, Richland \\ $191-195$ \\ GETA File Copies \\ Richland Operations office \\ 196 \\ 197 \\ $198-200$ \\ R. K. Sharp \\ Technical Information Library \\ P. G. Holsted \\ OFFSITE DISTRIBUTION (SPECIAL) \\ No. of Copies \\ 59 \\ Division of Reactor Development \\ AEC, Washington, D.C.
}




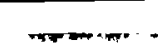

$\cdots$

,

$+$

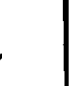

